University of Louisville

ThinkIR: The University of Louisville's Institutional Repository

Electronic Theses and Dissertations

$5-2013$

\title{
The social construction of ethnicity and masculinity of African American college men.
}

Jonathan Lee Johnson

University of Louisville

Follow this and additional works at: https://ir.library.louisville.edu/etd

\section{Recommended Citation}

Johnson, Jonathan Lee, "The social construction of ethnicity and masculinity of African American college men." (2013). Electronic Theses and Dissertations. Paper 702.

https://doi.org/10.18297/etd/702

This Doctoral Dissertation is brought to you for free and open access by ThinkIR: The University of Louisville's Institutional Repository. It has been accepted for inclusion in Electronic Theses and Dissertations by an authorized administrator of ThinkIR: The University of Louisville's Institutional Repository. This title appears here courtesy of the author, who has retained all other copyrights. For more information, please contact thinkir@louisville.edu. 
THE SOCIAL CONSTRUCTION OF ETHNICITY AND MASCULINITY OF AFRICAN AMERICAN COLLEGE MEN

\author{
By \\ Jonathan Lee Johnson \\ B.S., Berea College, 1999 \\ M.S., University of Kentucky, 2004

\begin{abstract}
A Dissertation
Submitted to the Faculty of the

College of Education and Human Development of the University of Louisville, in Partial Fulfillment of the Requirements

for the Degree of
\end{abstract} \\ Doctor of Philosophy \\ Department of Educational and Counseling Psychology \\ University of Louisville \\ Louisville, Kentucky
}

May 2013 
Copyright 2013 by Jonathan Lee Johnson

All rights reserved 

THE SOCIAL CONSTRUCTION OF ETHNICITY AND MASCULINITY OF AFRICAN AMERICAN COLLEGE MEN

\author{
By \\ Jonathan Lee Johnson \\ B.S., Berea College, 1999 \\ M.S., University of Kentucky, 2004
}

April 19, 2013

by the following Dissertation Committee:

Dissertation Director, Dr. Michael J. Cuyjet

Methodologist, Dr. Melissa Evans-Andris

Dr. Ricky L. Jones

Dr. Michael D. Anthony 


\section{DEDICATION}

I dedicate this book to the memory of my loving mother, Katherine Tony Johnson, and to my homegirl and colleague, Erica J. Holloman, who both courageously battled breast cancer with dignity, honor, and care for those closest to them. From them I learned selfassurance when confronted with doubt and resilience when gripped by pain.

Momma, you taught Delreo, Jimmy, and me to always to "keep our heads high" and "stand tall with pride," because we know you demanded no other way. You raised us to be "men, not boys," "leaders, not followers," and to "fight for what we want." We thank you for all the lessons you taught us, to be the men in faith we could become.

Erica, I have not forgotten about our $\$ 50$ bet!...About who would finish this

process first. For Josie, Bobby, Ebony, Kisha, McKenzie and for all who love and supported you during your life's journey, for ALWAYS challenging me, for secretly supporting me, I am collecting for the both of us! 


\section{ACKNOWLEDGMENTS}

I would like to thank my mentor, Dr. Michael J. Cuyjet, who hired me as a graduate assistant, trained me as a scholar, and supported me like a father. I would like to thank my methodologist, Dr. Melissa Evans-Andris, for taking the risk and supporting my ideas using critical race theory and methodology. To Dr. Ricky L. Jones, I appreciate you keeping it real with me, inside and outside of the classroom, your boldness in scholarship, and for being an example of how someone with my background has a place in the academy. To Dr. Michael D. Anthony, my fraternal Brother of Alpha Phi Alpha Fraternity, Inc., thank you for your friendship, brotherhood, support, and service on my committee. Special thanks for Dr. Natesha L. Smith for understanding my cry and providing friendship and guidance during this project.

It has been a long journey and I must acknowledge my friends who have been an inspiration and have encouraged each other since Berea College: Special thanks to Dwayne (my Ace, my Sandz, my Brother), my sisters, Antoinette and Aunneco, to Albert, Joe, Tony, Chuck, Juice, Cindy, Lakes, my Selma crew (Mae, Debbie, and Jose), my collection of professional mentors from Berea (Keith, Dr. Bullock, Virgil, Gus, Jessica, Gail W., Rev. Gloria, and President Shinn). Thanks to my Louisville Family (Erica, Terri, Gilandra, Kate, Fashaad, Kathy, John Mark, Kareem, Kia, and Glen), especially the Graduate School staff and friends. Pop, Delreo, Jimmy, Libby, Mrs. Mary, Mama Russell, Ma'Butler, Corey, Gail, and Jodi, thank you. Muchas gracias a mi suegra, Milagros, mi cuñados, Oscar, Ely, y Jessica. Los quiero mucho. 
Very special thanks to nine men involved in this study. Without your trust in sharing your stories with me this will not be possible. Most of all, I thank God for his grace during my journey and sending my partner, my wife, Suhail and my daughter Mia Katerina. I thank God each day for your strength, which encourages me to become a better man, a better partner, and a better husband. Te amo Mi Negra! 


\title{
ABSTRACT \\ THE SOCIAL CONSTRUCTION OF ETHNICITY AND MASCULINITY OF AFRICAN AMERICAN COLLEGE MEN
}

\author{
Jonathan Lee Johnson
}

April 19, 2013

The purpose of this study was to understand how African American college men construct masculine and ethnic notions of their identities, despite disproportionate social obstacles and hegemonic stereotypes. The primary research question of this study was, "how might African American undergraduate males understand and develop healthy concepts of their ethnic and masculine identities at a predominately White public institution?" The following research questions guided this study: (1) how do African American college men characterize their ethnic identity; (2) how do African American college men characterize their perception of their masculinity; (3) how do African American college men perceive their performance of masculinit(ies); (4) how do the ethnic and masculine identities of African American college men intersect?; and (5) how does being in college impact African American men's identities?

Critical race theory and methodology provided a conceptual framework for exploring and analyzing counterstories about the experiences of African American college men at a large research university in the Southeastern United States. 
In-depth, semi-structured interviewing served as the primary data collect source. Participants' in-depth interviews formed counterstories of how nine African American college men made meaning of perceptions of their ethnic and masculine identities. Interpretation of their stories structured the data into four major themed categories: (1) dimensions of race and ethnicity; (2) dimensions of masculinity and manhood; (3) intersection of ethnicity and masculinity; and (4) college networks and relationships.

The findings revealed that the African American college men involved in this study characterized ethnicity as the cultural expression of their identity and affirmed by the commonality of their African American heritage and culture. Race was characterized by the negative racial stereotypes ascribed to African American people, but particularly negative stereotypes attributed to African American men. Participants' dimensions of race and ethnicity were based upon cultural characteristics of their physical environment and varied by rural, suburban, and urban communities. Participants described using 'code switching' as a strategy to establish relationships as well as to gain access within a predominately White society.

Dimensions of masculinity and manhood were based upon traditional performances of masculinity and participants described their perception of manhood as a developmental process. The counterstories of participants' perception of masculinity included, "Handling your business" as responsible Black men, dismantling hegemonic stereotypes of unemotional men by being "emotionally strong." Faith, values, and respect emerged as cultural beliefs and characteristics of their African American background. For participants at the intersection of ethnicity and masculinity, findings reveal that negative racial stereotypes extend across physical environments and social 
class. Through a process of 'reframing,' the African American college men of this study describe establishing their own 'versions' of Black manhood and masculinity.

Lastly, African American college networks, especially those dedicated to the academic and social success of African American men, established an environment where they could thrive by establishing meaningful connections with Black faculty, staff, and other students. The African American affinity groups, along with participants' own determination to succeed, enabled the nine African American college men in this study to transcend all stereotypes.

Among recommendations for practice, this study suggests connecting Black college men to African American affinity groups, especially those dedicated to African American men. Implications for research and theory that promote further exploration of the intersectionality of African American college men are also recommended. 


\section{TABLE OF CONTENTS}

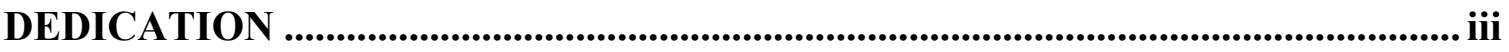

ACKNOWLEDGMENTS ...................................................................................... iv

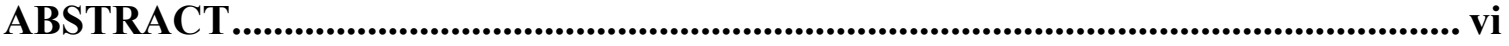

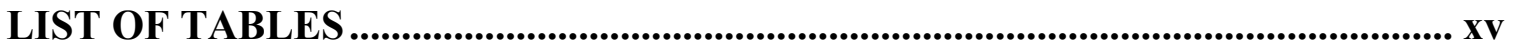

My Background, Role as a Researcher, and Positionality as an Advocate .............. 1

Student Leadership ....................................................................................................... 3

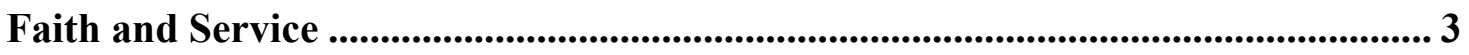

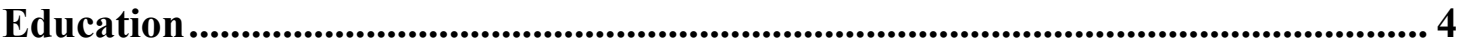

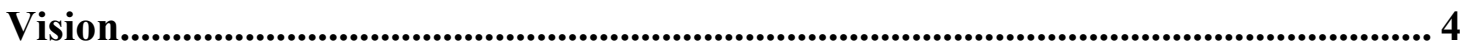

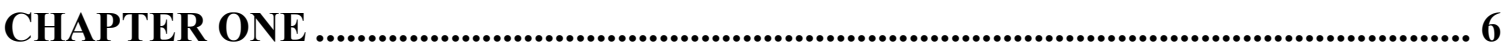

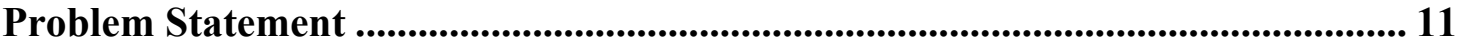

Purpose of the Study ................................................................................................. 11

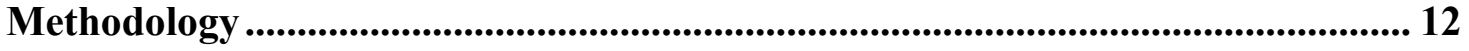

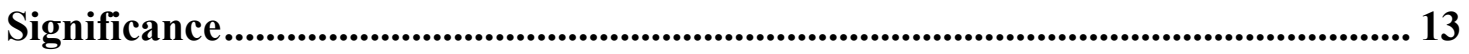

Definition of Key Terms ............................................................................................................ 14

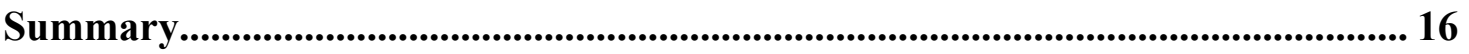

CHAPTER TWO ................................................................................................... 18

REVIEW OF LITERATURE .................................................................................... 18

Sociohistorical Context of African American Men.............................................. 18

Slavery's impact upon the African American family. .......................................... 20

Slavery's impact upon African American men............................................... 21 
Civil rights and Black power movement. .......................................................... 22

Intersection of Black consciousness and Black male identity............................ 25

Identity, Men and Masculinity .................................................................................. 28

Birth of men's studies from the feminist movement. .......................................... 28

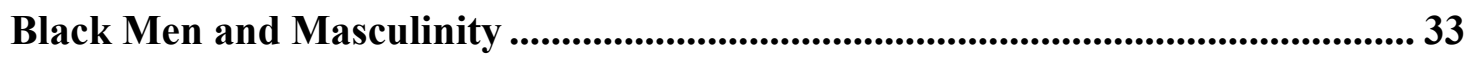

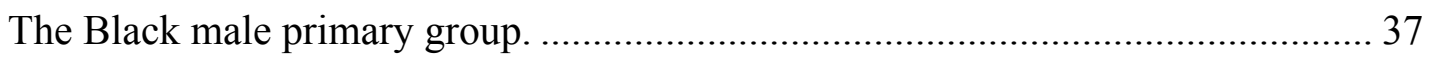

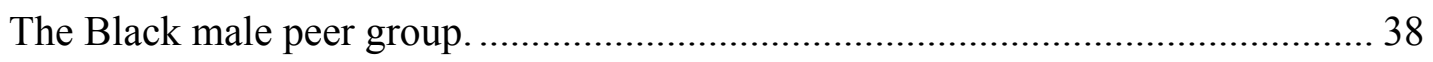

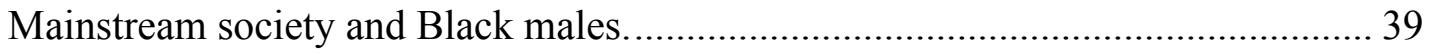

Progressive Black masculinities. .............................................................. 40

African American College Men and Masculinity .............................................. 46

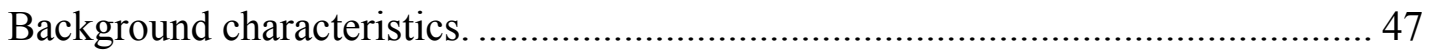

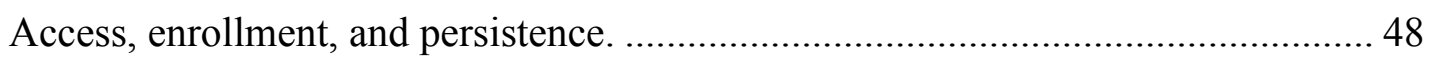

Development of Psychosocial, Racial and Ethnic Identities .............................. 50

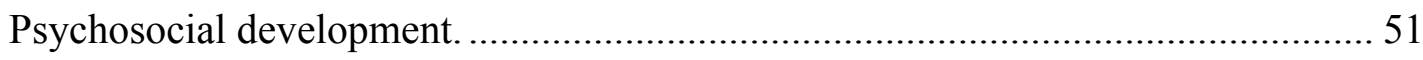

Racial and ethnic identity development ..................................................... 53

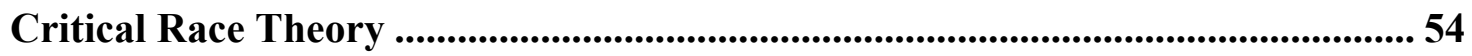

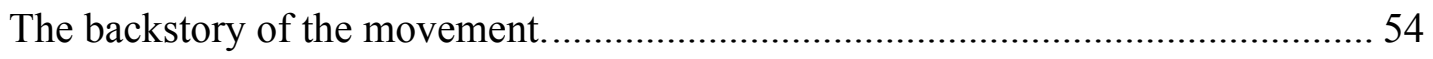

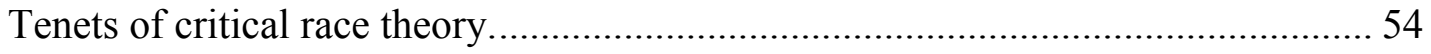

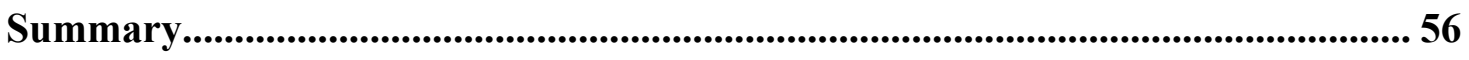

CHAPTER THREE ................................................................................................. 57

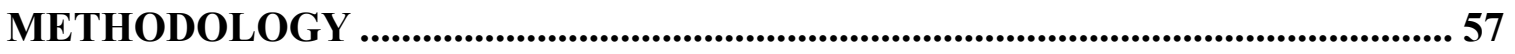

Rationale for Qualitative Inquiry ......................................................................... 58

A Critical Race Approach in Educational Research Design................................. 60 


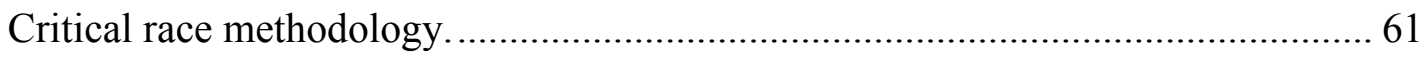

Research Setting and Recruitment of Participants ................................................. 63

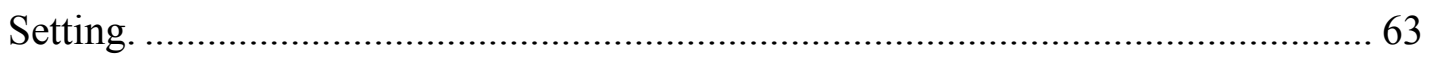

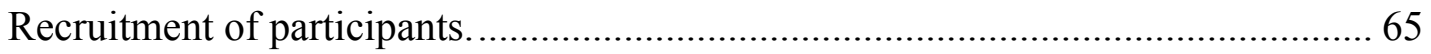

Data Collection Methods ............................................................................... 68

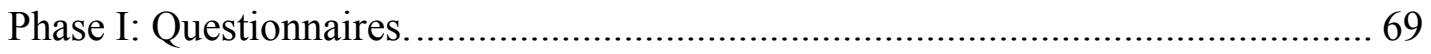

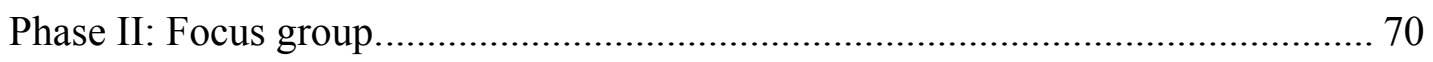

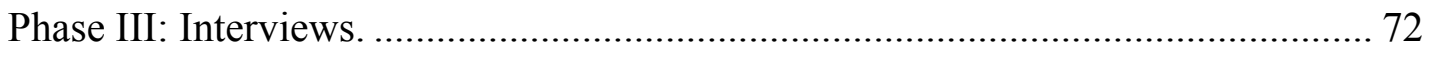

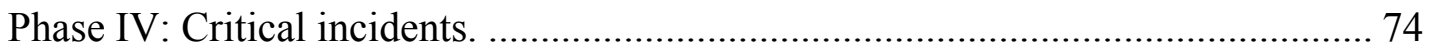

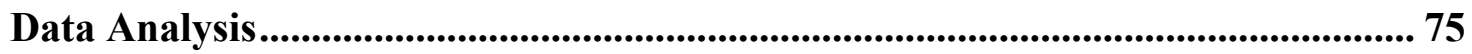

Ethical Considerations. ............................................................................................ 76

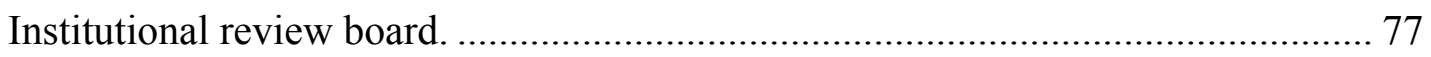

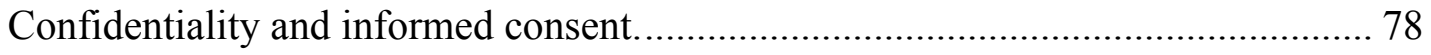

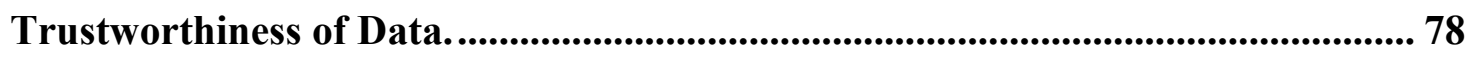

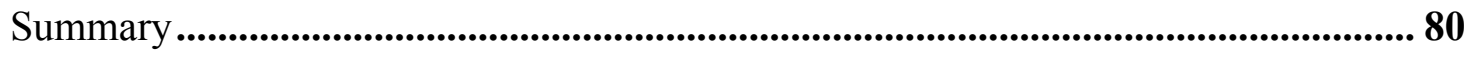

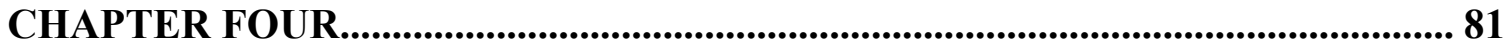

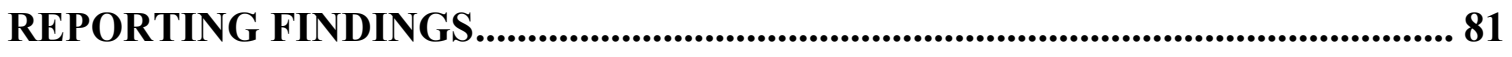

The Participants ............................................................................................................. 82

Participant Profiles ................................................................................................ 83

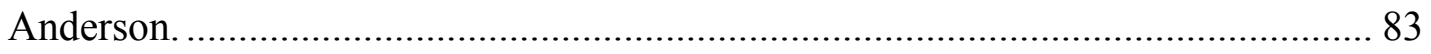

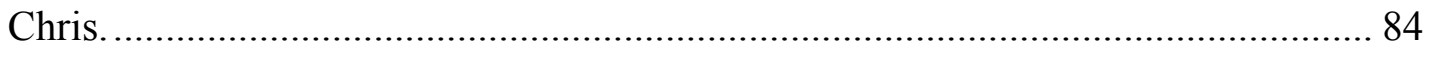

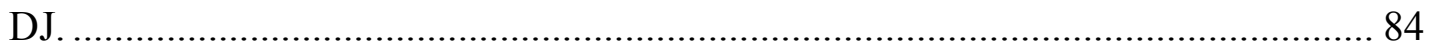

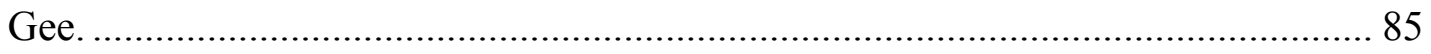




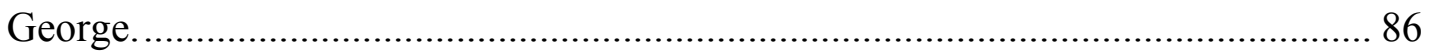

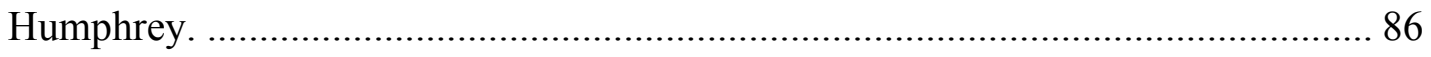

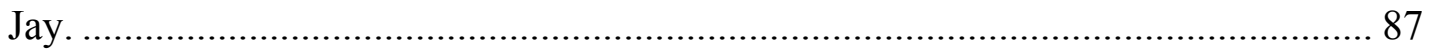

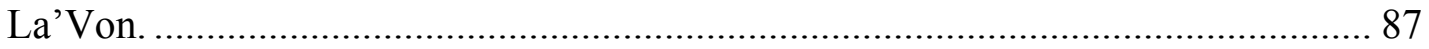

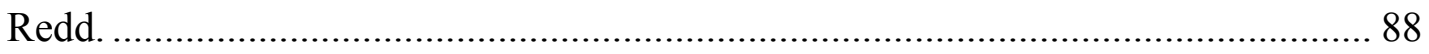

Presentation of Findings....................................................................................... 89

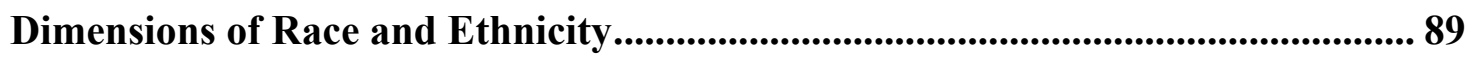

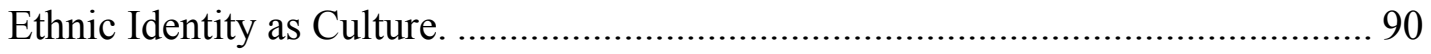

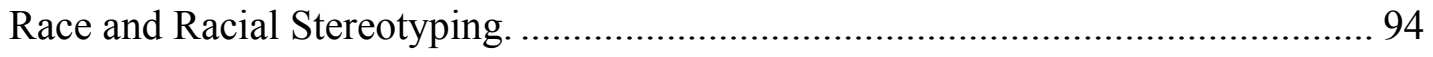

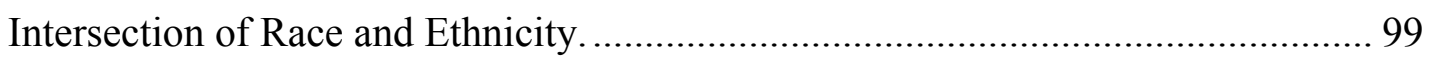

Dimensions of Masculinity and Manhood ............................................................. 114

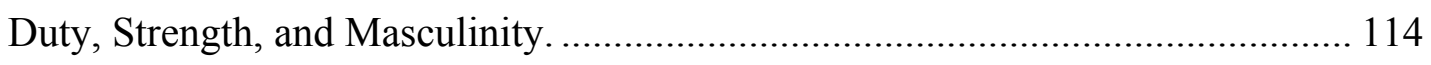

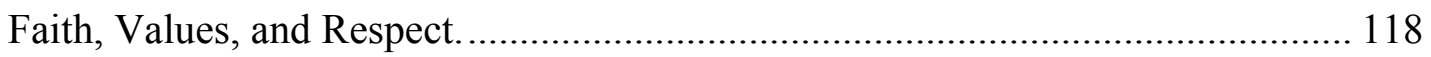

Traditional Roles of Manhood.................................................................. 120

Intersection of Ethnicity and Masculinity ............................................................... 123

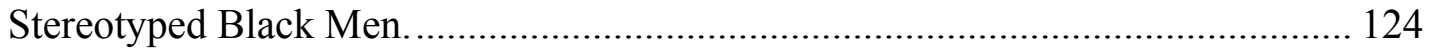

Reframing Black Manhood and Masculinities. .............................................. 126

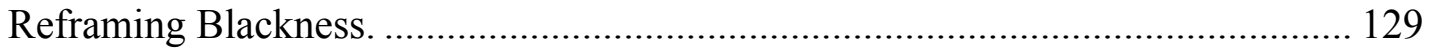

College Networks and Relationships.................................................................... 130

African American Networks and Relationships. ............................................ 131

Men and Masculinity Networks and Relationships. ..................................... 133

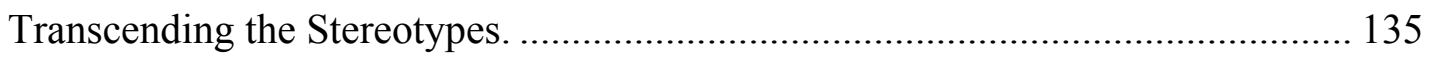

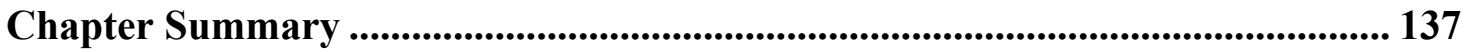


CHAPTER FIVE

DISCUSSION AND CONCLUSION

Overview of the Study ................................................................................... 140

Research Question 1 ....................................................................................... 141

Summary of Findings: Dimensions of Race and Ethnicity..................................... 141

Discussion of the Findings: Dimensions of Race and Ethnicity ............................ 143

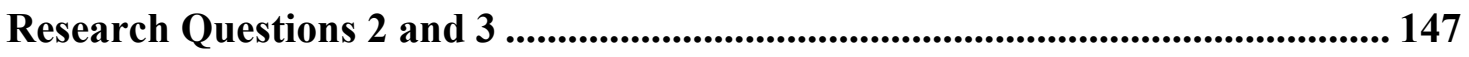

Summary of Findings: Dimensions of Masculinity and Manhood........................ 147

Discussion of the Findings: Dimensions of Masculinity and Manhood ................ 148

Research Question 4 ................................................................................... 150

Summary of Findings: Intersection of Ethnicity and Masculinity .......................... 150

Discussion of the Findings: Intersection of Ethnicity and Masculinity.................. 151

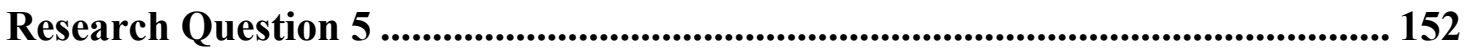

Summary of Findings: College Networks and Relationships ................................ 153

Discussion of the Findings: College Networks and Relationships........................... 154

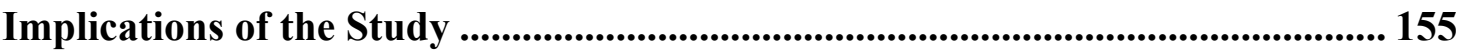

Implications for future research and theory development. .............................. 155

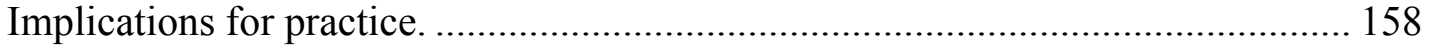

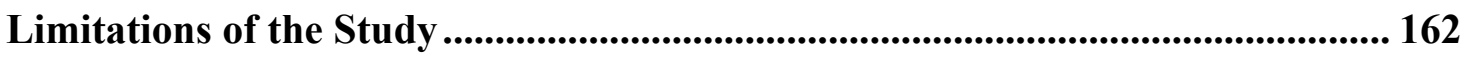

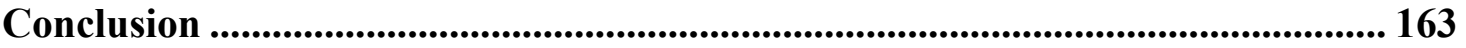

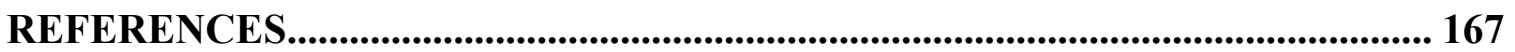

APPENDIX A.......................................................................................................................... 184

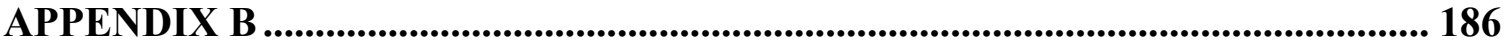


APPENDIX C.

APPENDIX D

APPENDIX E

APPENDIX F

APPENDIX G........................................................................................................................... 192

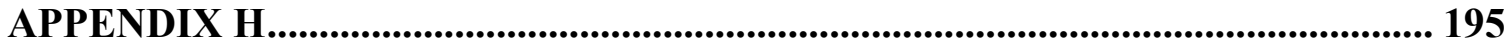

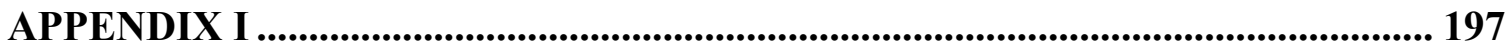

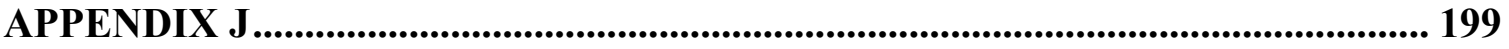

Demographic Profiles ..................................................................................... 201

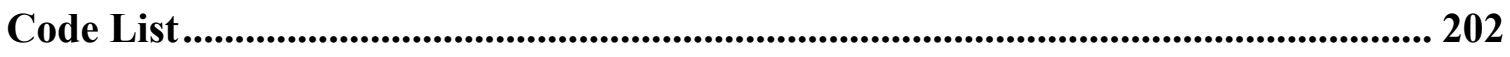

CURRICULUM VITAE............................................................................................. 203 


\section{LIST OF TABLES}

\section{TABLE}

1. Description of Predetermined Criteria .......................................61

2. Demographic Profiles.................................................. 195

3. Code List............................................................ 196

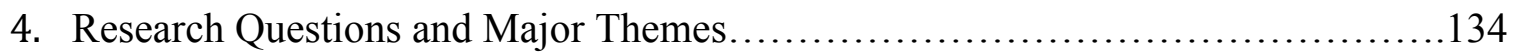

5. Major Theme: Dimensions of Race and Ethnicity............................ 135

6. Major Theme: Dimensions of Masculinity and Manhood........................141

7. Major Theme: Intersection of Ethnicity and Masculinity...................... 144

8. Major Theme: College Networks and Relationships...........................146 


\section{PROLOGUE}

\section{My Background, Role as a Researcher, and Positionality as an Advocate}

It is never possible to understand another perfectly, because to do so would mean that we had entered into the other's stream of consciousness and experienced what he or she had. If we could do that, we would be that other person. (Siedman, 1998. p. 3)

In qualitative inquiry, it was important for me to clearly establish my role as a researcher. My role extended beyond lengthy individual and group interviews, but also to campus wide events, student organizational activities, living-learning environments within residence halls, or any informal circumstance where I encountered participants who became involved in this study.

Equally important to my role as a researcher, was my role as a learner. I have always likened my role as a student development practitioner to that of a "teacherlearner," whereby I learn as much from students as they can learn from me. Glesne (1999) suggests that, "as a researcher, you are a curious student who comes to learn from and with research participants. You do not come as an expert or authority", therefore, "as a learner, you are expected to listen" (p. 41). In other words, I did not want participants looking to me for answers. Instead, my role was to ensure the African American men participating in this study were the authority of their experiences and my role was to learn more about them as well as the meaning they make of their experiences. 
Siedman (1998) offered a disclaimer for doctoral students and others who choose qualitative methodology and techniques in conducting research because it should be understood that, "[choosing] to do qualitative research is not the dominant one in the history of educational research" (p. 6). Indeed, as a doctoral candidate, it was important to understand that I might have a "stiffer battle" in establishing myself as a researcher, particularly while exploring critical race theoretical and methodological approaches.

One of the fundamental premises of qualitative methodologies and techniques is the researchers' genuine interests in peoples' stories. Siedman (1998) insists that researchers leave their egos at the door, understand the fact that, as an interviewer, you are not at the center of the world, and others' stories are important.

As a researcher and African American male in higher education, it was dually important to honor the voices of men who will be involved in this study, while understanding that my life experiences also came with assumptions about other African American men. It is important for me to underscore this significance as I articulate, not only my desire to do research, but also what strong contributions I hope to bring to the aims, legacy, leadership, and future of African American male undergraduates.

Their collective gifts of service, scholarship, integrity, and human compassion also stand as a reflection of my own life's purpose and progressive aims. Much like the ideals of Progressive Black Masculinities, it was my philosophy to strive to authentically give my talents to all of humanity, as I understand the personal responsibility in doing so, particularly within the African American community. Please allow me to share a little bit about my background as well as to voice my aspirations as a continuous learner and community servant. 
Despite growing up within a low income, single parent home, I was blessed with the opportunity to receive a full tuition scholarship from Berea College and became the first person in my family to graduate with a college degree. Berea College is not only committed to educating underrepresented students with great promise and limited economic resources, it also fosters an environment that promotes "interracial education."

I balance my leadership abilities and commitment as an educator with my personal compassion for people, which allows for my sense of humanity to be demonstrated in my life's service in the following ways:

\section{Student Leadership}

During my undergraduate experience I served as the Black Student Union's Historian, Vice President, and President. As President of the MLK Planning Committee, I collaborated with the local and campus community to organize a memorial march and successfully petitioned to have Martin Luther King, Jr. Day officially observed at Berea College. While pursuing my Master's part-time at the University of Kentucky, I also served as Vice President for the Black Graduate and Professional Student Association.

\section{Faith and Service}

My involvement with civic service, mentoring and tutoring high school students, and other volunteer civic activities during my early years as an undergraduate at Berea College, compelled me to seek leading roles in the campus and local community. In matters of faith, I led a Chapel Service entitled, Get up, Stand Up and Do Something!, that especially addressed the engagement of African American men. I also spoke with the Baptist Student Union, whereby I charged them to, Look to the Mission in ALL the Things You Do. In 2001, to give back to my community, I returned and chose to fulfill 
my professional vocation at Berea College in student affairs. I began my vocation in student affairs as a Residence Life Coordinator and later served as Interim Director for the Black Cultural Center. Returning enabled me to advance a better opportunity for those Black and African American students who would embark upon their own path of promise.

\section{Education}

As a professional, in an effort to provide positive and culturally affirming resources for the Black student population at Berea College, I founded and created the Ebony Explorations Book Club. Ebony Explorations was created out of the emergent need to holistically serve undergraduate Black men of African decent. Ebony Explorations created an opportunity for them to come together and critically dialogue about social, political, cultural, spiritual, and intellectual issues. The discussions that followed provided a forum for these young men to self-explore the motivations of success and the personal intricacies of being Black and male in America. At the University of Louisville, I dialogued with local high school juniors to enrich their understanding about the different types of colleges and universities, while sharing my ambition to complete my doctoral studies so that it may motivate others to fulfill their highest potential.

\section{Vision}

W. E. B. Du Bois and Carter G. Woodson (a Berea College alum) established a plateau of excellence for African American college men. Guided by such models of excellence, my vision is to secure the dreams of the African American community, serve to uplift humanity, and intellectually challenge oppressive ideologies. 
Given my background and contributions of service through my faith, education, leadership, and a progressive vision in education, I aspire to serve and lead along side scholars, educators, and practitioners in serving the needs of all students. 


\section{CHAPTER ONE}

Thus the black boy in growing up encounters some strange impediments. Schools discourage his ambitions, training for valued skills is not available to him, and when he does triumph in some youthful competition he receives compromised praise, not the glory he might expect. In time he comes to see society has locked arms against him; that rather than help, he can expect opposition to his development, and that he lives not in a benign community but in a society that views his growth with hostility. For the black man in this country, it is not so much a matter of acquiring manhood as it is a struggle to feel it his own... throughout his life, at each critical point of development, the black boy is told to hold back, to constrict, to subvert, and camouflage his normal masculinity. (Grier \& Cobbs, 1968, p. 59)

On the evening of November 4, 2008, the American people established a historical milestone that was once thought too difficult to realize in their lifetime-especially those of African descent — when Barack Obama, a bi-racial African American man, was elected President of the United States of America. Obama's presidential attainment is distinguished among other African American men who show determination, make outstanding contributions in their communities and families, and excel economically and educationally, while moving onward and upward despite political, social, and racial barriers 
There are many notable African American men in the United States, such as General Colin Powell (first Black secretary of state), Thurgood Marshall (first Black supreme court justice), Tony Dungy (first Black coach to win the Super Bowl), Martin Luther King, Jr. (civil rights leader and first Black Nobel Prize winner), and other celebrated men who have accomplished a great deal in their lifetime. Yet, a menacing dilemma persists for many African American males and their future status has been too often a discussion of perilous quandary.

It is with modest dispute that the experiences of African American males have been of significant debate concerning their academic achievement, social condition, employment opportunity, economic development, and their role in the Black family (Akbar, 1991; Cuyjet, 2006; Grier \& Cobbs, 1968; Hammond \& Mattis; 2005; Majors \& Gordon, 1994; Staples, 1971, 1982). Undergraduate enrollment, persistence, and graduation rates of African American men in higher education have some of the lowest rates and smallest gains in degree attainment over the last two decades. White male college enrollment rates increased from 31.2 percent in 1987 to 41.6 percent in 2007, yet African American men enrollment encountered disproportionate rates of improvement by ethnicity and gender, from 22.6 percent to 27.8 percent (ACE, 2006).

According to the American Council on Education (ACE) 2006 report on Minorities in Higher Education (2009), only 42.65 percent of college enrollments were men. Interestingly, of the 7,574,815 college male students, White men accounted for approximately 61 percent of the total male population. Further examination of these data revealed an overwhelming disparity within the subpopulation of the male gender among African American (9 percent), Latino/Hispanic American (9 percent), Asian American (6 
percent), American Indian (.87 percent), international male students (4 percent), and seven percent of the total subpopulation of college men were of "unknown" race/ethnicity.

African American men have been depicted as social pariahs, unintelligent, underachieving, dysfunctional, abusive, criminals, and absent fathers. Unfortunately, these less than endearing portrayals are not only overgeneralized misperceptions of the population, they have served as "blocked opportunity" models by a majority of empirical studies used to investigate the past, present, and projected plight of African American manhood (Hammond and Mathis, 2005). In other words, academic literature has too often oversimplified African American men as a "problem," thus failing to make meaning about the intricate nature of manhood for African American men.

Out of the feminist movement and scholarship from the 1960s, the study of men and masculinities was born. Although contemporary academic scholarship was "male oriented," scholars like, Farrell (1974), Fasteua (1975), Tolson (1977), Elizabeth and Joseph Pleck (1980), James A. Doyle (1983), Clyde W. Franklin, II (1984), and Harold Brod (1987) transformed a fledgling movement about men into an academic discipline aiming to deconstruct, and then redefine traditional conceptions of masculinity in a patriarchal society. In fact, Farrell (1974) was one of the first to loosen the constrained definition of masculinity towards a flexible gendered construct, urging men to "liberate" themselves from the rigidity of sex stereotypes. Fasteau (1975) described the perpetuated stereotypes of masculinity as a universal paradox that results in an unfulfilled journey for most men. As a strategy to deconstruct patriarchal ideology, Tolson (1977) urged men to use 'consciousness-raising' approaches to dismantle traditional constrictions of manhood. 
Brod (1987) further argued that the traditional role and scholarship about men are only "seemingly about men," as opposed to "the study of masculinities and male experiences as specific and varying social-historical-cultural formations” (Brod, 1987, p. 2).

Subsequently, other scholars further transformed the traditional perception of manhood into alternate paradigms of masculinity that account for the complexity and challenges associated with male norms (Levant, Hirsch, Celentano, \& Cozza, 1992; Thompson \& Pleck, 1986), masculine ideologies (Thompson, Pleck, \& Ferrera, 1992), male sex roles (Bem, 1974; Pleck, 1976), sex-role strain (Pleck, 1981), gender roles (Stroller, 1968), gender-role conflict (Good, Robertson, \& O’Neal, 1995; O’Neal, 1981, 1982), and masculine gender-role stress (Eisler \& Skidmore, 1987). In addition to the aforementioned studies, Hammond and Mattis (2005) noted how anthropological and ethnographic approaches (Brod \& Kaufman, 1994; Cornwell \& Lindisfarne, 1994; Di Stefano \& Kimmel, 1992; Gilmore, 1990) introduced cultural specific and rich descriptions of the social contexts of men.

Prior to the feminist movement and the deconstruction of hegemonic masculinity, the Civil Rights and Black Power Movements marked the beginning of grass roots social activism of the 1960s. These movements are considered a radical era of social unrest against racial and class injustices that has plagued the United States since the vile introduction of slavery over 350 years ago. Women and men, Black and White, and a nation of socially conscious citizens rebelled, challenging the monolith of racist and biased structures in American society. Audaciously, a revolution of Black consciousness emerged, transcending pathological images of Black masculinity counter to those imposed by White supremacist ideologies since slavery (Grier \& Cobbs, 1968; Staples, 
1971, 1982). Two prominent, but polarized, images of Black masculinity are of nonviolent—Martin Luther King, Jr.—to militant—Malcolm X—representations of Black leadership and masculinity. The Black Panther Party embodies an even more polarizing illustration of Black masculine characterizations as opposed to colonial images of the emasculated slave.

The study of Black men and masculinity emerged from the convergence of sociopolitical Black Power and Civil Rights activism of the 1960s and the sociohistoricalcultural investigations of Black psychologists and sociologists who critically examined the individual and collective consciousnesses of race and ethnicity (Cross, 1971; Helms, 1984; Jackson, 1976; and Thomas, 1971) and the reconstruction of Black masculinity (Grier \& Cobbs, 1968; Hare, 1971; and Staples, 1971, 1982). Black masculinity studies slowly entered into men's studies as academic discourse in the early 1980s. In a sociohistorical context, Robert Staples (1978b, 1982), a sociologist, was among the first researchers to establish an alternate empirical paradigm for the development of African American masculinity (Hammond \& Mattis, 2005; Majors \& Gordon, 1994). In an earlier analysis, Black psychologists, William H. Grier and Price M. Cobbs, published a critical examination of the plight of the African American family since slavery in a book entitled, Black Rage (1968). This work presents a clear account of the evolving lives of manhood, womanhood, education, employment, and the Black family in modern America. The chapter, Acquiring Manhood, especially draws attention to the "strange impediments" Black boys encounter as, "His personality and character structure, his emotional assets and liabilities, are being shaped as much by his blackness as by his personal environment" (Grier \& Cobbs, 1968, pp. 57-58). 
Equally important, Grier and Cobbs further articulate how African American men must feverously overcome barriers to seemingly assume a perception of masculinity as, "inner psychological obstacles to manhood are never so formidable as the impediments woven into American society" (1968, p. 59). The aforementioned pioneering studies shed light upon the emergence of Black men and masculinity studies in academic literature and the development of African American manhood, yet lost from contemporary literature are empirical studies that clearly ask young African American college men how they make meaning of masculinity, given social realities associated with their ethnicity.

\section{Problem Statement}

The traditional definition of masculinity is based upon hegemonic, patriarchal, and Eurocentric characterizations of men in America. Consequently, this socially constructed hegemonic understanding of masculinity not only constrains how men perceive themselves as men, but also does not account for the complex racial-cultural array of identities among African American men. Furthermore, such countestories are needed to add to the broader body empirical knowledge that informs the development of African American college men's authentic sense of masculinity and ethnicity.

\section{Purpose of the Study}

The purpose of this study was to understand how African American college men construct masculine and ethnic notions of their identities, despite disproportionate social obstacles. The primary research question of this study was, "how might African American undergraduate males understand and develop healthy concepts of their ethnic and masculine identities at a predominately White public institution?" The following 
research questions will further guide this study: (1) how do African American college men characterize their ethnic identity; (2) how do African American college men characterize their perception of their masculinity; (3) how do African American college men perceive their performance of masculinit(ies); (4) how do the ethnic and masculine identities of African American college men intersect?; and (5) how does being in college impact African American men's identities?

\section{Methodology}

There is limited empirical research that examines the intersection of both the ethnic and masculine constructs of identity development for African American college males. This study will use a qualitative research design to examine the authentic "voices" of African American male participants. Qualitative methodology is typically used to garner an in-depth understanding of individuals, phenomenon, or events when quantitative methods are not adequate or limited (Patterson, 2002). A critical race methodology and a constructivist paradigm approach will be used in this study to understand the process of African American college men's gender and masculine identity development. A constructivist epistemological perspective is used, as opposed to an objectivist paradigm, because its assumption is that reality and knowledge are socially constructed through the interactions between individuals and the world around them (Denzin \& Lincoln, 2003; Patton, 2002). Torres (2003) used an equivalent methodological paradigm in a qualitative theoretical exploration of Latino Ethnic Identity Development. As the researcher, it is my objective to offer a counter-narrative of the voices of African American collegiate men involved in this study, grounded in an 
inductive research strategy that explores the authentic experiences of participants (Glesne, 1999; Patton, 2002).

\section{Significance}

The narrative that results from this study is intended to provide broader insight about African American collegiate men, offer theoretical, action-oriented and strategic paradigms that contribute to the academic literature of African American college men and masculinity. While Harris (2008) called for the support of college men's gender identity development, this study will explore African American college men's perceptions about being men, while enhancing their consciousness as it relates to ethnic and masculine notions of Black identity. For some scholars, men's and masculinity studies have not adequately explored the "gendered" lives of African American men (Majors and Gordon, 1994; Hammond \& Mattis, 2005). Moreover, the majority of studies about African Americans have disproportionately focused on the gendered lives of women, the Black family, crime, while dismissing African American men as social enigmas (Cuyjet, 2006; Hall, 1981; Hammond \& Mattis, 2005; Majors \& Gordon, 1994). Majors and Gordon (1994) argued, "the fact that Black males face numerous obstructions in their efforts to assume visible masculine roles in American society is an issue that must be addressed if we are to understand the Black males' plight in America" (p. 18). This study will provide descriptive narratives and explicit empirical insight into the gendered identities of college men as well as new conceptualizations of African American college men's ethnic and masculine ideologies.

A radical departure from traditional scholarship in men's studies and practices in student affairs is demanded in order to understand and improve the quality of life of 
African American collegiate men. For this reason, a narrative framework informs this study in the development of innovative solutions, while examining the complexities within Black masculine ideologies. To this end, this study calls for a partnership between practitioners and researchers to propose and implement interventions and strategies designed to better integrate African American men within the college environment, and promote leadership and engagement among themselves and the rest of the campus community, while advancing access, persistence, and degree attainment.

\section{Definition of Key Terms}

The following are definitions of terms and concepts are used throughout this study. African, African American, \& Black - I use "African" to denote the historical context of Africans in America during slavery. Although I use "Black" and "African American" interchangeably throughout this study, African American is predominately used to respect the ethnic distinction and the rich cultural heritage of Africans and the descendants of African slaves in America. "Black" is used in the context of the literature and left unchanged. I use "Black" to reflect the socially constructed racial identity of African descendants and capitalize "Black" as a proper noun to denote this distinction as categorized by the 2010 US Census. In chapter two, I explain more about the shift from the historical and to contemporary identity of African Americans.

African American Male - "He is a husband and father, son and brother, lover and boyfriend, uncle and grandfather, construction worker and sharecropper, minister and ghetto hustler, doctor and mineworker, and auto mechanic and presidential candidate" (Marabel, 1984, p. 5). 
Black Masculinity—For the purpose of this study, I define Black masculinity as a socially constructed performance and expression of masculinity by people of African descent. Although I did not find an unambiguous definition in the literature, Staples (1982) shares that "I see the black male as being in conflict with the normative definition of masculinity. This is a status which few, if any, black males have been able to achieve" (p. 2).

Counterstorytelling - "Writing that aims to cast doubt on the validity of accepted premises or myths, especially ones held by the majority" (Delgado \& Stefancic, 2001, p. 153). Also known as counterstories or counternarratives.

Critical Race Methodology_ - A theoretical grounded approach to research that (a) foregrounds race and racism in all aspects of the research process. However, it also challenges the separate discourses on race, gender, and class by showing how these three elements intersect to affect the experiences of students of color; (b) challenges the traditional research paradigms, text, and theories used to explain the experiences of students of color; (c) offers a liberatory or transformative solution to racial, gender, and class subordination; and (d) focuses on the racialized, gendered, and classed experiences of students of color. Furthermore, it views these experiences as sources of strength and (e) uses the interdisciplinary knowledge base of ethnic studies, women's studies, sociology, history, humanities, and law to better understand the experiences of students of color" (Solórzano \& Yosso, 2002, p. 23).

Critical Race Theory - A theoretical perspective that seeks to transform relationships among race, racism, class, gender, and power (Delgado \& Stefancic, 2001). 
Ethnicity_- "Group characteristics often based on national origin, ancestry, language, or other cultural characteristics" (Delgado \& Stefancic, 2001, p. 146).

Predominantly White Institution (PWI) - A college or university in which the majority of the student population is White or of European origins.

Qualitative Research-“a qualitative approach is one in which the inquirer often makes knowledge claims based primarily on constructivist perspectives (i.e., the multiple meanings of individual experiences, meanings socially and historically constructed, with an intent of developing a theory or pattern) or advocacy/participatory perspectives (i.e., political, issue-oriented, collaborative, or change oriented) or both" (Creswell, 2003, p. 18).

Race - "notion of a distinct biological type of human being, usually based on skin color or other physical characteristics" (Delgado \& Stefancic, 2001, p. 153).

Racism - "any program or practice of discrimination, segregation, persecution, or mistreatment based on membership in a race or ethnic group" (Delgado \& Stefancic, 2001, p. 154).

\section{Summary}

The plight of African American college men has been, and persists as, an enigma in the media and academic literature in the United States (Cuyjet, 2006). Facing a considerable number of sociohistorical, cultural, economic, political, and educational obstacles, this study seeks to understand and demystify the ardent developmental experiences of how young African American men have come to make meaning of who they are in the college environment. The review of literature reflects how underlying social, historical, and interpersonal perceptions of race, ethnicity, and masculinity 
contribute to the development of African American men (Brod, 1987; Hammond \& Mattis, 2005; Majors \& Gordon, 1994; Staples, 1971, 1978b, 1982). 


\section{CHAPTER TWO}

\section{REVIEW OF LITERATURE}

In this dissertation, I will examine the intersection of masculinity and ethnicity of African American collegiate men, particularly how they understand and construct gendered and racialized notions of their identities, using counter-narratives to give voice to their perspectives. This chapter will review: (1) a sociohistorical context of African American men; (2) the underpinnings of the men's movement and men's studies; (3) the emergence of Black consciousness and Black masculinities; (4) African American collegiate men; and (5) psychosocial, racial and ethnic identity development.

\section{Sociohistorical Context of African American Men}

W. E. B. Du Bois (1903/2003) in his pioneering book, Souls of Black Folk, exposed the racial strife that shrouded the lives of men and women of African descent in America. Since the chattel of western slavery, African Americans have been challenged with a society where they have been historically burdened with limited political, economic, and cultural capital. Socially isolated, where could African American males locate their place in a modern "American world - a world which yields him no true selfconsciousness, but only lets him see himself through the revelation of the other world" (Du Bois, p. 5)? 
Throughout modern history, the significance of Africa - in relation to the rest of the world - has been devalued by Western and European worldviews due to the exploitive nature of the Atlantic slave trade (Gilroy, 1993). Consequently, it is of no surprise the ethnic significance of displaced Africans around the world and in the United States is racially segmented, ideologically assimilated, historically hollow, and seemingly undiscovered. The Atlantic slave trade shaped the ethnic demarcation and racial dehumanization of African descendants. As a result, their contemporary history is devoid of alternative authentic perceptions of who they are in the face of an adopted society where they find themselves as outsiders, unaccepted, and politically and socially challenged. Gilroy (1993) argued the gradual collapse of legal slavery as well as the acquisition of civil liberties and rights did not emancipate the enslaved from further cultural isolation, society, or from themselves. Instead, as a matter of survival and circumstance, racial prejudice remained and Africans essentially became ethnically "exiled."

The exile Gilroy (1993) spoke of first begins with the global enslavement of African peoples and then continues with their dislocation. Not of their own self-control, these Africans were separated from their geographic origin - Africa—and dispersed into a peculiar condition of location and identity—all over Europe, North America, South America, and the Caribbean. Slavery systematically endorsed the genocide of their knowledge and memory of African rootedness. Essentially, the enslaved Africans' relationship with Africa became broken. It is important to understand their arrival to these foreign lands was not akin to refugee flight, resettlement, or immigrant migration. Their transit was not endowed with the freedom to carry the whole of their identity and 
possessions with them, as they were themselves chattel of White supremacy. During that time, their identity was represented by their bondage. It was not until after slavery the Diaspora of African peoples would have the opportunity to develop autonomous and aesthetic expressions of modernity.

The Atlantic Slave Trade and its aftermath brought with it, as W.E.B. Du Bois (1903/2003) put, "the sum of all villainies, the cause of all sorrow, the root of all prejudice" (p. 7). What also came forward was the dilemma of confronting themselves as the estranged "problem" of society: being torn into at least two struggles of making meaning of their own identity and a "white humanity" (Du Bois, 1903/2003; Gilroy, 1993). Both Gilroy and Du Bois argued the modernity of Black people have been ignored and, essentially, lumped into the fabric of a dominant European worldview. Yet, historically, not all prominent African American intellectuals credited society with the underlying problems of African American men and African American family life.

Slavery's impact upon the African American family. E. Franklin Frazier, a notable African American sociologist, was responsible for some of the earlier distorted images of the African American family and African American men (Majors \& Gordon, 1994). Frazier (1927) believed there should be a comparable familial influence or exchange when two different cultures intersect with each other. In earlier writings, Frazier (1926) suggested the failure of Negroes in America to adapt socially and systematically assimilate into an European American culture was evidence enough to suggest the failure of the African American family. He argued the African American family's failure was due to a pathological "lack of traditions, knowledge, and ideas which 
all people acquire by living in the social and physical environment to which they have become adopted" (p. 210).

W. E. B. Du Bois (1908) also wrote extensively about the historical and contemporary barriers of the African American family and African American men. As a consequence of hundreds of years of legal slavery in America, Du Bois identified alternative triggers for the challenges of integration faced by African Americans. Differing from Frazier (1926, 1927, 1966), Du Bois (1908) expressed that it was not a matter of cultural competence, but identified inadequate economic and educational opportunities after the Civil War and during American industrialization, which were specific limitations to African American men, rather than African American women.

It is argued the institution of slavery delivered the ultimate and pervasive blow to African American families (Gary, 1981; Majors \& Gordon, 1994; Taylor, 1977). Severing kith and kin, the separation of children from parents, and husbands from wives were systematic tactics commonly exploited by slave owners to constrain liberties and subvert rebellion of their slaves - which further undermined African American parents, the institution of marriage, and particularly diminished the masculine societal role and authentic identity of African men.

Slavery's impact upon African American men. As fathers and husbands, it is believed slavery systematically denied African men the opportunity to serve in significant roles within the Black family. As slaves, the Black family could not assume the "ideal" family structure of stay-at-home moms and fathers who went off to work. African women were forced to assume responsibilities that were, by tradition, contradictory to feminine roles, thus performing otherwise masculine roles. Accordingly, African men 
were constrained to an "inferior" function within the Black family (Taylor, 1977). In an extreme illustration, Taylor (1977) argued the performance of masculine roles by women - therefore identifying women superior to men-were not only inconsistent with the mainstream male/female societal roles, but were regarded as "unnatural." Nonetheless, African men were left in a socializing paradox that made it nearly impossible for them to conform to traditional normative masculine roles within the Black family and within a patriarchal society. Du Bois rejects the hegemonic patriarchal structure of African American men in the African American family traditionally ascribed to the dominant culture (Majors \& Gordon, 1994).

Civil rights and Black power movement. The 1960s brought with it a pinnacle of social change for many Americans. Social activism was expressed in that era's revolutionary style of music, from rhythm and blues to rock and roll, as well as the liberation of sex and sexuality. Social activism was also illustrated both in the form of rebellion and militancy of numerous leaders epitomized by Malcolm X in dismantling what hooks (2004) refers to as the "imperialist White-supremacist capitalist" social structure and in nonviolent protests and marches such as those led by Dr. Martin Luther King, Jr. in Selma, Alabama and Washington, D.C. Though manifested differently, all expressions of civil rights were in the search for justice and equality. Each movement scripted its own complex counter-narrative of identity for African Americans, women, and other underrepresented people of color in American society.

Sociopolitically, the Civil Rights Act of 1964 provided constitutional accountability for equal rights and social integration, the Civil Rights Act of 1965 prohibited employment discrimination, and the Voting Rights Act of 1965 secured the 
right to vote for African Americans who once had those opportunities legally constrained (Gibbs, 1988; Solomon, 1988). According to Kimmel (1996), "the civil rights movement challenged the exclusion of black people from full citizenship and, thus, exclusion of black men from claiming their stake in American manhood" (p. 262).

However, not all scholars agree African American men accomplished what was necessary to assert themselves as men or provide a sound foundation for the African American family. In 1965, Daniel P. Moynihan's study, The Negro Family: The Case for National Action, stirred up controversy about the social condition of the African American family; it was at best oppositional and at worst divisive (White \& Cones, 1999). Like Frazier (1926), Moynihan (1965) believed much of the troubles of the African American family was a result of the absence of African American fathers and African American husbands in the lives of their children, wives, and loved ones. To Moynihan, African American men's failure to live up to the patriarchal structure in American society, particularly within the African American family, diminished their role as men and elevated the role of African American women, thus creating a "Black matriarchy" (Staples, (1978a). Feminist, activists, and scholars, such as hooks (1981, 2004) and Staples (1978a), criticized and rejected Moynihan's assertions that African American men were pathologically weak if they were raised in a single-parent, femaledominated household, moreover, if they did not conform to a mainstream American worldview of patriarchy (White \& Cones, 1999). White and Cones argued, " by using White family norms to assess the Black family, Moynihan repeated a familiar strategy used by White social scientists to judge Black institutions and behavior" (p. 197). 
Conversely, the Moynihan report was not totally off base because there were underlying disparities recognized in his analysis of 1960s census data comparing African American and White unemployment and families with welfare benefits. However, Staples (1978a) criticized Moynihan for being hypocritical in his incomplete analysis and further characterization of the African American family as a disorganized and ill-judged view of African American men. Furthermore, Staples (1978a) also argued Moynihan failed to acknowledge the prevailing barriers of racism and discrimination White men did not have to reconcile in American society.

Withstanding such social barriers, African Americans began to re-identify themselves, and by a growing public, as an emerging social, political, economic, passionate, and intellectual population in the United States (Akbar, 1991; Jackson, 2001; Johnson \& Cuyjet, 2010; Newton, 2005). The Student Nonviolent Coordinating Committee (SNCC), whose membership was largely African American men, is an early illustration of student resilience and social activism.

The Student Nonviolent Coordinating Committee began as a collegiate student organization of African Americans, Whites, and allies of the Civil Rights movement. College students who organized sit-ins at North Carolina lunch-counters in protest for political, economic, and racial justice formed SNCC. As a student-led, grassroots organization, SNCC soundly established itself as a social activist group in the South and then grew in national recognition. Newton (2005) acknowledges the role SNCC had in the general impact upon Black masculine ideology.

Although neither SNCC nor the civil rights movement as a whole explicitly focused on male gender transformation, both struggled to extend the rights of 
citizenship to black men and women, thereby breaking with the ideal of "national manhood" that identified citizens with white, property-owning males. (p. 56) As the Black Power movement evolved from the social activism of community organizers to a national and international awakening of Black consciousness, African American men predominately stood-out in leading roles, which began to evoke traditional definitions of national manhood. A "Black national manhood" emerged out of the push to adopt the more hegemonic role of head of household in the African American family (Newton, 2005).

Intersection of Black consciousness and Black male identity. The most striking portrait of African American men during the Civil Rights and Black Power movements were their expressed performances of Blackness and masculinities, as opposed to stereotypically emasculated images and monolithic caricaturizations of all men of African descent. For African American men and women, the social transformation of the 1960s and 1970s erupted with profound developments of Black consciousness (Johnson \& Cuyjet, 2010).

The Black Panther Party for Self Defense and the Black Liberation Army of the 1960s symbolized one of the most visible illustrations of the intersection of Black consciousness and Black male identity. The social, political, cultural, and revolutionary movements of that era of social activism provoked African Americans to reflect critically about their identities and collective purpose in an American society. African American men and women became the catalysts of their own awakening to reclaim their history, redefine their values and beliefs, and rename who they are and who they will become. 
In 1967, Kwame Ture (formerly known as Stokely Carmichael) and Charles V. Hamilton wrote of the synthesis uniting political power and Black consciousness during the Civil Rights Movement in their book, Black Power (1967/1992). These men insisted African Americans must not only seek the dismantling of systematic forms of racism, but understood lasting Black liberation comes from self-discovery. Their argument is clearly articulated here:

Black people must redefine themselves, and only they can do that. Throughout this country, vast segments of the black communities are beginning to recognize the need to assert their own definitions, to reclaim their history, their culture; to create their own sense of community and togetherness. There is a growing resentment of the word "Negro," for example, because this term is the invention of our oppressor; it is his image of us that he describes. Many blacks are now claiming themselves African-Americans, Afro-Americans or black people because that is our image of ourselves. When we begin to define our own image, the stereotypes - that is, lies - that our oppressor has developed will begin in the white community and end there. The black community would have a positive image of itself that it has created. This means we will no longer call ourselves lazy, apathetic, dumb, good-timers, shiftless, etc. Those are words used by white America to define us. If we accept these adjectives, as some of us have in the past, then we see ourselves only in a negative way, precisely the way white America wants us to see ourselves... From now on we shall view ourselves as African-Americans and as black people who are in fact energetic, determined, intelligent, beautiful and peace-loving. (pp. 37-38) [emphasis in original] 
African Americans celebrated the ethnic distinctions of their African heritage and organized as a community redefining their own cultural norms; thereby countering individualism, pejorative stereotypes, some gender expectations, and other institutionalized systems of subjugation that prevailed in a predominate White American society. In the spirit of the movement, African American men found role models in the diverse representation of leadership and manhood in Martin Luther King, Jr., Malcolm X, and Kwame Ture, while promoting Black liberation, self-exploration, and selfdetermination, a Black ideology—Black Power.

The movements of Black liberation, Civil Rights, and Black conceptualizations of identity and ideology commanded the attention of scholars such as, Thomas (1971), Cross (1971), Jackson (1976), Hardiman (1982), and Helms (1995), who began to explore the racial transformation from "Negroes" to "Blacks" towards an affirming ethnic distinction as "African Americans," an African identity (Johnson \& Cuyjet, 2010; also see, Yin, 2013, for discussion on the continued use of Negro in the 2010 Census). These sociologists, psychologists, behavioral scientists, and researchers were witness to the spirit of the movement and documented diverse theoretical patterns of reconstructing Blackness in America. During the same time, Black psychologists such as, William H. Grier \& Price M. Cobbs (1968) and sociologists Nathan Hare (1971) and Robert Staples (1978b; 1982), recognized overwhelmingly that African American men not only were major contributors to the Black Power Movement, but also identified a paradigm shift in how African American men began to define their own performances of masculinities. I will offer a review of literature on African American men and masculinities later in this chapter. 


\section{Identity, Men and Masculinity}

Birth of men's studies from the feminist movement. Profeminist scholarship, leaders and allies of the women's movement of the 1960s and 1970s provided the contributing framework toward a critical examination of men and masculinities (Clatterbaugh, 1990; Franklin, 1994). Much like the spirit of feminist intellectuals' critique of "traditional" scholarship (early scholarship overwhelmingly dominated by the voices of men or otherwise devoid of the voices of women), men's studies is born out of the need of men to explore and offer their own critique of men (Brod, 1987). In "The Case for Men's Studies," Brod (1987) explains the emerging field of men's studies is not a recapitulation of "traditionally male-biased scholarship," but "like women's studies, men's studies aims at the emasculation of patriarchal ideology's masquerade as knowledge" (p. 40). He goes on to clarify,

While seemingly about men, traditional scholarship's treatment of generic man as the human norm in fact systematically excludes from consideration what is unique to men qua men. The overgeneralization from male to generic human experience not only distorts our understanding of what, if anything, is truly generic humanity but also precludes the study of masculinity as a specific male experience, rather than a universal paradigm for human experience. The most general definition of men's studies is that it is the study of masculinities and male experiences as specific and varying social-historical-cultural formations. Such studies situate masculinities as objects of study on a par with femininities, instead of elevating them to universal norms. (p. 40) [emphasis in original] 
Though Brod (1987) does not speak directly about African American men’s masculine identities, he does "make the case for men's studies" to include its specific and varying social-historical-cultural formations (p. 2). Brod borrowed a theme from bell hook's (1984) Feminist Theory: From Margin to Center and ultimately argued to bring forward the study of women (from the margins) and men (from the foreground) to the center of discourse, collectively offering a revisionist view of knowledge as well as dismantling hegemonic masculinity.

Men's studies to men's movement. The critical examination of men and masculinities began in the 1980s. Men's studies began with an academic introduction in college textbooks, scholarly literature, and papers, such as The American Man (Pleck \& Pleck, 1980); Men, Masculinity, and the Process of Sociological Enquiry (Morgan, 1981); The Myth of Masculinity (Pleck, 1981); Men's Studies Modified: The Impact of Feminism on the Academic Discipline (Spender, 1981); Modern Man, or Men's Studies in the '80s (August, 1982); The Male Experience (Doyle, 1983); The Changing Definition of Masculinity (Franklin, 1984); Men's Studies: Defining Its Contents and Boundaries (Davis, 1985); The Making of Masculinities: The New Men's Studies (Brod, 1987); and Men and Society (Franklin, 1988).

Brod (1987) offered early context on men and masculinity and the emergence of men's studies. He essentially addressed the question and criticism, in a patriarchal society, is there a need for the study of men? He confronted any suspicion about the study of men as another attempt by men to "undermine rather than contribute to feminist scholarship" or by those who believed that men's studies "threaten the fundamental premise of women's studies" (p. 39). 
As a movement, men began to come together in solidarity with other men involved in the women's movement and these men were compelled to no longer conform to rigid expectations of traditional male sex roles (Clatterbaugh, 1990; Franklin, 1994). These men were more than allies of feminists and advocates of the women's movement, they were activists of a fledgling men's movement that sought to provide an alternative perspective of masculinity. Here is an excerpt from a manifesto by men at the Berkeley Men's Center in 1970:

We, as men, want to take back our full humanity. We no longer want to strain and compete to live up to an impossible oppressive masculine imagestrong, silent, cool, handsome, unemotional, successful, master of women, leader of men, wealthy, brilliant, athletic, and "heavy." We no longer want to feel the need to perform sexually, socially, or in any way to live up to an imposed male role, from a traditional American society...

We want to relate to both women and men in more human ways-with warmth, sensitivity, emotion, and honesty. We want to share our feelings with one another to break down the walls and grow closer. We want to be equal with women and end destructive competitive relationships between men...

As we put ideas into practice, we will work to form a more concrete analysis of our oppression as men, and clarify what needs to be done in a socially and personally political way to free ourselves. We want men to share their lives and experiences with each other in order to understand who we are, how we got this way, and what we must do to be free. (Franklin, 1994, pp. 7-8) 
As the focus of men's development grew out of academia and as a social movement, activists and professionals established national, regional, and local organizations and conferences to focus their initiatives. In 1975, the National Men and Masculinity Conference was the first conference about men. The National Men and Masculinity Conference was held annually in Nashville, Tennessee for the next seventeen years (Franklin, 1994). Spiritual organizations, such as Promise Keepers as well as politically oriented organizations, namely the National Organization of Men Against Sexism (NOMAS) — formerly the National Organization for Changing Men — were among the initial organizations about men. Men's Rights, Inc. as well as the National Congress for Men provided a space for men, and some women, in the development of men's studies and the Men's Movement (Clatterbaugh, 1990; Franklin, 1994). However, not all men found these organizations sufficient or reflective of their particular interests, particularly African American men.

Black men and the men's movement. Although the organizations that sprang out of the men's movement were open to and encouraged the involvement of African American men, their overall eagerness and participation were minimal. Franklin (1994) offers a cognitive schema as a rationale to explain African American men's perceptions and limited participation in the men's movement:

- The men's movement is a White middle-class "luxury"

- Men's movement issues are not relevant for Black men because Black men enjoyed little power in the social structure

- Dysfunctions associated with masculinity are not Black male problems because of societal barriers to Black males "masculine" role assumptions 
- The men's movement does not address issues of great importance to Black males

- The problems White males have are not recognized as important by Black males

- Black males have not held the oppressive power that White males have held

- Black male's interests are better served if Black men devote their energies to fighting for racial equality (p. 10).

Whether or not all of Franklin's (1994) themes are a direct reflection or justification that explains African American men's limited involvement in the men's movement of the 1980s, it is not due to a lack of motivation. African American men were inspired to advance their causes and explore their own development, particularly reflecting upon their social activism demonstrated during the previous decades. Therefore, instead of the speculation behind why they were not present, White and Cones (1999) identified specific organizations and social movements to which African American men were motivated to commit their interests.

It was important for African American men to identify with organizations and causes they equally believed in and affirmed their identities (White \& Cones, 1999). According to White and Cones, it was unnecessary for African American men to expose themselves or otherwise subject themselves to constraining vulnerabilities. For example, the National Council of African American Men (NCAAM) was founded in 1990 by Jacob U. Gordon (2002), author of The Black Male in White America, and psychologist Richard Majors and Janet Mancini Billson (1992), authors of Cool Pose: The Dilemmas of Black Manhood in America. The NCAAM advocates for national, state, and local 
policy on behalf of African American men's issues, such as education, employment, and economic development as well as sponsors manhood training and family workshops. The Journal of African American Male Studies, the first journal exclusively dedicated to African American men, as well as The Status of Black Men in America, was established by the NCAAM.

Furthermore, other organizations predate the contemporary study and movement of African American men. Fraternal organizations, such as The Knights of Pythias, Oddfellows, Elks, and Prince Hall Masonic orders as well as Black collegiate fraternities have aided as a network of service and development of African American men since the 1800s (Gordon, 2002; White \& Cones, 1999). 100 Black Men of America, Inc., a Black male civic organization, was founded in 1967 during the Black Studies movement on college and university campuses in the 1960s. The 100 Black Men of America, Inc. was among a number of educational and civic organizations that sprang out of the movements of the 1960s and 1970s. Not only did these organizations contribute towards the collective advancement and development of African American people but, though limited in scope, they also contributed to the study and movement of African American men and masculinities.

\section{Black Men and Masculinity}

In the case of black men, their subordination as a racial minority has more than canceled out their advantages as males in the larger society. Any understanding of their experiences will have to come from an analysis of complex problems they face as blacks and as men...As a result, we have to examine the sociocultural 
forces which have combined to create the increasing plight of black men in the United States. (Staples, 1978b, pp. 169-170)

In the above excerpt, what Robert Staples advocates for is similar to what Jewell Taylor Gibbs (1988) outlines as contributing factors that have impacted generations of African American men in the United States. For Gibbs, the barriers experienced by young African American men are a diminishing result of 250 years of slavery, 100 years of state and federally supported segregation, and decades of social dismantling of opportunities created in the 1960s and 1970s due to the urbanization, economic downturn, and political divestment of civil service programs. A Black middle class emerged from the movements of the 1960s after taking full advantage of newfound opportunities, then many integrated into urban and suburban areas. What was unforeseen was the gap created between the poor and middle class African Americans, which progressively widened with the middle class' exodus. Gibbs further explains, [the] increased isolation from the black middle class and alienation from the white community, black inner-city ghettos have gradually become "welfare reservations" where black youth have few, if any, positive role models; where they lack access to high-quality educational, recreational, and cultural facilities; where they do not have job opportunities or adequate transportation to locate jobs. (p. 18)

Competition over jobs and limited resources swelled and without the type of stability and social networks often privileged to White communities, the challenges of the poor, discriminated, underemployed, and those educated in mediocre schools persisted for African Americans. 
In Visions for Black Men, Na'im Akbar (1991), an African American

psychologist, suggested African American men should not try to ascribe to Eurocentric ideals of masculinity, which has historically emphasized individualism, competitiveness, dominance, power, and control. This Eurocentric worldview of masculinity is not an authentic representation of the full range of experiences and perspectives of all men in American society, particularly African American men.

Akbar further asserted it is counterintuitive for African American men to adopt characteristics of a masculine ideal that has enslaved them, denied them the respect of manhood, and historically oppressed them as African American men. The fundamentals of manhood are defined by one's discipline and knowledge. Lastly, but most importantly, Akbar affirmed, "[African American] men must define themselves. They think from their own perspectives. They are able to access their power by defining who they are. It is their definitions that give them power" (p. 32). The movement from boyhood to manhood is much greater than the biological development of maleness, it is psychologically "transformative," inexplicably woven into their personal knowledge of Black consciousness, and bound by shared kinship of the Black experience. Akbar maintains Black "consciousness is a natural possibility or potential, but it must be tended and guided in order for it to develop properly" (p. 12). Akbar declares "we want children who are Black, intelligent, prepared to cope with the European way, understand the African way, and are capable of bringing both ways together...Our major problem is that we've started imitating them (Euro-Americans) too much" (p. 33).

Like Akbar (1991), White and Cones (1999) affirmed it is psychologically unhealthy for African American men to try to assume a Eurocentric American ideology 
of masculinity. They argue African American men are veiled in a socially constructed paradox of masculinity and ethnicity where they do not have the freedom to be powerful, control their environment, assert themselves as risk takers, or proudly pronounce their manliness, with acceptance, as their White male counterparts do in America. As a similar conundrum, this Eurocentric American ideology of masculinity is not congruent with the community-oriented, emotionally expressive, and cultural collective ideology affirmed within the African American community. For this reason, in order for African American men to overcome the paradoxical limitations of a Eurocentric masculinity and for their manhood to be affirmed by the African American community, they must reconcile a masculine ideology that is their own.

Furthermore, Eurocentric ideology about sex roles juxtapose men as strong and women as weak; however, African Americans are stigmatized by a false notion of women who are the stronger and men who are weak (Collins, 2006). Collins (2006) further noted, "African American men have been harmed by this conflict, presumably because it skewed the fact that black men have never been allowed to achieve the ideal of the real man of white middle-class masculinity yet have been evaluated using these criteria. The strong black woman-weak black man thesis has taken an especially pernicious form in the post-civil rights era" (p. 74).

Franklin (1994) discussed the development of the men's movement of the 1980s as well as the development of Black masculinities in America. Franklin asserted African American men experience a "lethal socialization triangle," postulating that the self is a reflection of society, thus "Black men can be typed according to the extent that the socialization reflects predominantly the influence of one of three worlds": (1) Black 
male's primary group — a type of primary group socialization providing mixed messages regarding the meaning of Black masculinity; (2) Black male's peer group — a peer group socialization source that teaches innovative Black masculine traits; and (3) Mainstream society — a mainstream societal socialization source that sends Black men mixed messages regarding competitiveness, aggressiveness, passivity, inferiority, and invisibility. His characterization of African American men's development as "lethal" is confounding; however, Franklin's description of African American men's complex development of Black masculinities is compelling (p. 12).

Though paradoxical, African American men's performances of Black masculinities and their "triangle" of experiences serve as diverse socialization groups. These experiences also form controlled groups that "type" African American men with distinct "versions" of masculinities. The three sources of African American men's socialization as well as three corresponding types of Black masculinities are elucidated in the next three sections.

The Black male primary group. The Black male primary group mirrors mainstream society with its version of American values and beliefs in name only (Franklin, 1994). The American ideals of freedom, democracy, individualism, equal opportunity, competitiveness, the value of work, and humanitarianism are socializing influences for the Black male's primary group, however, Franklin further emphasized these are "ideals" that are often distant realities for African American men due to the lasting limitations from slavery, poverty, de facto segregation, and discrimination. Because these mainstream messages are integrated from a perspective of the Black community, a set of alternative how-to's about what can be achieved out of the grand 
scheme of American ideals are resourcefully supplemented for African American men, which then have sweeping influences on their socialization process.

These contributing influences on the Black male primary group socially construct and reinforce a type of Black masculinity Franklin (1994) described as Black male primary group controlled masculinity. The version of masculinity provided by this group comes from diverse sources influenced by single and two-parent households, and siblings and extended family. These consist of a range of socioeconomic statuses and social barriers. Because of the diversity of interactions within each group, there are also conflicting expectations regarding how African American men are able to achieve the American dream. The primary group for African American men provides them with necessary skills in negotiating their role in fitting into an American society. In order for African American men to conform to mainstream societal roles, they are ultimately left vulnerable, inevitably subject to the barriers and realities of their social status.

The Black male peer group. In adolescence and early adulthood, a Black male peer group is particularly influential in the lives of these individuals. This is a transformative time for young African American men, especially as they begin to shift away from the influences of their primary group. During this stage of development of their lives, Black male peer groups open the door of opportunity for African American men to deeply explore, alter, and define their own identities based on collective or individual experiences. Within this peer group, African American men develop a sense of comfort and security because they create their own space to fit in, with shared experiences of adversity and adaptation, challenger and supporter, each serving as both protégé and mentor. 
According to Franklin (1994), the Black male peer group is essentially expressed as a version of Black masculinity. In this "Black male peer group-controlled masculinity," African American men rely on other African American men who attempt to live up to the ideals of an American dream, while establishing their ethnic and masculine identities along the way. Because of the realities faced by African American men, they do not have the same access and opportunity as their White male counterparts. As a result, Franklin further argued their "construction of Black masculinities may bear little resemblance to mainstream masculinity or at very least, dramatically altered forms of mainstream masculinities" (p. 15 i.e., their versions or performances of Black masculinity).

Mainstream society and Black males. Mainstream society and Black males complete the third side of the triangle socialization process. Franklin (1994) regarded African American men's socialization by mainstream society as the most "lethal" because of how African American men are negatively depicted in America. Franklin strongly asserted that mainstream society has been disproportionately proscriptive regarding social expectations and behaviors of, particularly young, African American men. Given excessive profiles of African American men in juvenile and adult detention institutions, Franklin was not surprised by how popular media communicate messages to society and African American males about what Black men are not supposed to do. In essence, Franklin underscored that it is the failure of mainstream society to accept African American men on the same level as the majority of American men that cripples their socialization process. Perhaps, mainstream America is not adequately prepared to offer prescriptive interventions or serve as socializing agents for African American men 
as men. To do so, by comparison, Franklin suggested the mainstream would have to fully recognize "the various masculinities of Black men and some alterations in the hegemonic definitions of masculinity" (p. 14).

As illustrated above, the mainstream society proscribes rigid socializing characteristics of masculine identity to all African American men. Franklin (1994) contended this kind of socialization establishes as a mainstream society controlled version of Black masculinity. Often described pejoratively as a group, mainstream society is defined little by African American men, only rendering them as pathological "outsiders" in an American society. This type of Black masculinity is contradictory to the socializing lessons learned from their Black male peers and the Black community. Unfortunately, African American men are only supported by mainstream society, and may otherwise find themselves vulnerable and constrained by misguided beliefs that they could be accepted, if they assumed traditional or hegemonic definitions of masculinity along with the majority of society.

Franklin (1994) urged further study of Black male masculinities in America. He declared, "How Black males construct their various masculinities in the face of such obstructions must be subjected to analysis in any viable study of Black masculinities in America" (p. 18).

Progressive Black masculinities. In a contemporary and comprehensive collection of essays about African American men and masculinity, Athena D. Mutua's (2006) book, Progressive Black Masculinities, examined the intersectionality and multidimensionality of Black masculinities. In the first chapter, she contended that 
African American men are particularly constrained by the pervasive blight of racism and deceived by invalidated privileges of a White male patriarchy.

Mutua (2006) posited that part of African American men's identity is bound between ideological performances of "progressive blackness" and "progressive masculinities." Together, these "twin concepts" construct the foundation of Progressive Black Masculinities. Mutua defines Progressive Black Masculinities as,

Men who take an active and ethical stance against all social systems of domination and will act personally and in concert with others in the activities against racism, sexism, homophobia and heterosexuals and, class and economic exploitation, imperialism, and other systems of oppression that limited human potential of the Black masculine self and others. This is challenging given normative-ideal and hegemonic_-masculinity (p. 7).

Mutua celebrated the diversity Blackness and masculinities shared by a progressive culture of African American men that affirm and advocate for women, who are profeminist and antisexist, and reject all racial, gendered, and homophobic structures of domination and oppression of other men as progressives. Holistically, Mutua offered an understanding of Progressive Black Masculinities that advocates for African American men to embrace their full humanity, accepting the multidimensionality of ethnicity and Blackness, gender and masculinity.

Mutua (2006) offered an examination of a collection of theoretical concepts that explored the ways in which hegemonic masculinity impact the positionality and meaning making of African American men. Furthermore, Mutua postulated through the lens of gendered racism, intersectional theory, and multidimensionality theory, what is the 
positionality of Black men? How do Black men engage in the performance of Progressive Black Masculinities?

Gendered racism. The social system of patriarchy demands men hold the power and influence above women, children, and other subordinated groups in American society. The question is do these privileges extend to African American men? Due to the history of racism in America, it is argued that African American men are blocked from sharing the inherent privileges of masculinity. Mutua (2006) acknowledged the social limitations of racism, but asserted patriarchy also served as barrier for African American men. To explain this dubious dilemma, Mutua posited the following:

Whereas Afrocentrics and others analyze these problems as resulting primarily from the racist structure of the society, their focus on black men belies their emphasis. That is, the focus illustrates that black men are not only oppressed by racism but also may be harmed by the gender oppression implicit in the notion of gendered racism. Further, these conditions do not mean that black men are not in many ways privileged by the patriarchal sex-gender system through the operation of sexism and gender oppression nor does it mean there are no representations of black man as masculine. Rather, as Franklin suggested, multiple forms of Black masculinities exist. These have adapted in, varying degrees, to the realization that Black men's opportunities to attain ideal masculinity had been blocked (p. 20). Intersectional theory. Intersectional theory was first developed by Kimberlé Crenshaw $(1989,1991)$, who also contributed to the earlier formation of Critical Race Theory (Crenshaw, Gotanda, Peller, \& Thomas, 1995). Intersectionality was developed to fill the gap in literature about the lived experiences of women of color as well as to 
critique traditional approaches in social sciences that has historically examined race, class, and gender independently from each other. Intersectional theory challenges the notion that women of color are either oppressed by race or oppressed by gender. Instead, it centers the experiences of African American women, accounts for those experiences that have marginalized them by racism and sexism, and further insists for the inclusion of various system, positions, and intra group dynamics to serve as an ever evolving composite of one's intersecting identities.

With regard to the application of intersectionality to African American men, Mutua (2006) acknowledged intellectual assumptions that has placed the privilege of patriarchal masculinity on African American men, ascribing that they were oppressed by race, but privileged by gender. It is not a surprising assumption to make when examining median income levels as an example of socioeconomic disparity; African American men make much less than White American men, but much more than African American women. However, Mutua noted that male privilege could not explain instances of African American male profiling, which is a consequence of their race and gender. Although all of these analyses are valid, Mutua further noted:

The idea that black men were privileged by gender and subordinated by race undermined the potential of intersectional theory to further delineate differences among black men. Black men are not just some undifferentiated group; they are not just raced and gendered but also are distinguished by class, age, and region. Potentially the intersections were many and varied. (p. 22) In a like manner, Michael Kimmel (2006) argued that the phenomenon of patriarchal privilege is not reproduced in the same fashion for all men, particularly for African 
American men. To explain, he declared that "racism tends to problematize masculinity of the 'other' by declaring him —Black, gay, ethnic minority — to be simultaneously too masculine and not masculine enough" in American society (p. 71). In this case, Kimmel offers additional understanding of how privilege fits in with intersectionality and Progressive Black Masculinities:

In examining privilege, we should consider using an intersectional approach to explore the ways in which race, class, gender, and sexuality intersect and interact. This method was first developed by women of color, who argued the variables of race, class, gender, and sexuality could not be separated in understanding their experiences. This was a response to the traditional studies of race, which focus on race alone and usually ended up focused narrowly on men of color, and to women's studies, which often focus only on the experiences of White women. But some of these theorists asked different questions: Where does the Black person stop and the woman begin? How can one analyze the totality of one's experience without examining the ways in which all of these categories coincide, collide, contradict?

An intersectional analysis in this instance would explore the ways in which race, gender, class, and sexuality interact in the lives of those who are privileged by one or more of these identities. (p. 70)

Indeed, an intersectional approach can be used in attempts to demystify the patriarchal paradox between hegemonic ideals of Black masculinity and Progressive Black Masculinities. Notwithstanding some challenges, Kimmel (2006) also described the "trappings of patriarchy," whereby African American men regress to traditional 
performances of an "ideal masculinity." He contended that their manhood becomes undermined by oppressive structures of racism, heterosexism, and classism as a way to "restore and to revive a damaged sense of masculinity" (p. 72). In spite of such trappings, Kimmel also asserted other African American men used such challenging incidents to frame strategies of resistance as well as find allies in African American women that dismantled stereotypes, and thus became a unified force toward a shared vision to reclaim Progressive Black Masculinities.

Multidimensionality theory. Prior to its application in understanding Black masculinity, Black feminist, LatCrit (Delgado-Bernal, 2001, 2002) and QueerCrit (Delgado \& Stefancic, 2001) theorists were subsequent spin-off's of the progressive methodology and research of Critical Race Theory. Also, they were major contributors in the development of Multidimensionality Theory, which sprang out of Intersectionality Theory. Mutua (2006) posited that Multidimensionality has three insights and recognizes that (1) individuals have multidimensional traits, (2) society structures dichotomous systems of domination, juxtaposing privilege and disadvantage, and lastly (3) dichotomous systems of domination interact and are mutually reinforced.

First, human traits are varied. Some are visible characteristics, such as eye, hair, or skin color, while others are invisible or expressive and can be as varied as belonging to a religious denomination or being vegan or vegetarian. Second, Mutua (2006) suggested that over time society assigns meaning to these traits and, in effect, chooses what traits are privileged and what traits are disadvantaged. In this instance, skin color developed a privileged meaning, whereas a vegan lifestyle had not. In the third instance of multidimensionality, if society privileges those groups who are rich, white, heterosexual, 
and male, then this intersection privileges rich, White, heterosexual men as an "idealized norm." On the other hand, in the case of Black men, Mutua conversely noted:

The intersection of two or more systems of disadvantage may produce unique categories and experiences. For example, although intersectional theory might suggest that black men are privileged by gender and oppressed by race, multidimensionality might capture the experience and phenomenon of racial profiling by suggesting that black men are sometimes oppressed because they are Blackmen-one socially and multidimensionally constructed positionality [emphasis added]. Thus, to the extent the various systems of disadvantage are mutually reinforcing, the elimination of only one system, such as race, while weakening the overall structure of domination, is unlikely to change to oppressed conditions of Black people. (pp. 23-24)

In essence, the privileged remain privileged and in the case of African American men, their masculinities make them no more or less advantaged because of the disadvantage of their race. Herein lies the paradox of African American men, constrained by their gender or by their race; mutidimensionally disadvantaged by gendered racism.

\section{African American College Men and Masculinity}

Public American colleges and universities are tasked with the responsibility of providing access and quality of education to all students, particularly as enrollment of students become more diversified by culture, race, ethnicity, and gender. In consequence of this growing diversity, the needs of all students must be considered to broaden the definition of student success. 
African American men have become less visible on campuses that have been traditionally or predominantly white institutions (Cuyjet, 1997, 2006). Given the stereotypical assumptions that come with being racialized as Black, gendered by a narrow patriarchal paradox of manhood, along with other characteristics contributing to the backgrounds of African American men in higher education, it is increasingly important to give context to the unique sociopolitical, historical, economic, cultural (i.e., race and gender) and current status of this underrepresented, yet distinct, population.

Background characteristics. Longstanding socioeconomic barriers of poverty and low-income families certainly impact African American men's ability to negotiate a discernible path from high school to college (Rumberger, 1983). In an examination of data from a college student engagement survey, the College Student Experiences Questionnaire (CSEQ), Cuyjet (1997) noted $44.4 \%$ of African American men had limited or no financial support due to their families' lack of ability to adequately contribute toward their overall cost of education.

Poverty has an early impact on the lives of African American men. Parham, White, and Ajamu (2000) presented that:

Recent data now available indicate that nearly one in four children $(23 \%)$ under the age of 6 lived in poverty during 1996. Research also indicates that poverty rates disproportionately impact African Americans with 44\% of children under 6 affected. This figure is more than three times the rate for White children (13\%) nationwide. When accounting for children up to the age of $18,34 \%$ of African American youth were classified as poor. (p. 58) 
Like other college students, African American males come from diverse socioeconomic backgrounds upon entering college. The literature shows how the socioeconomic status of college students impacts their academic experience, particularly those family backgrounds with lower income levels. In examining the achievement gap between African American students and other populations of students, Ogbu (2002) finds that students from Black middle-class backgrounds, meaning those who are more socially and economically privileged, are not shielded from negative stereotypes often projected upon African American males. In other words, such prevailing attitudes prohibit African American males from directly benefiting from the resources and social status of their families and otherwise grants them no more advantage than other African American students with more or less financial resources.

The challenges of the family become the challenges African American men bring to college, further leaving them burdened and vulnerable to financial "distractions," as described by Cuyjet (1997), teetering between access and academic success. In 1985, as illustrated by Reed (1988), family financial challenges had persisted for decades, which further impacted test scores, grades, and enrollment.

Access, enrollment, and persistence. According to Cuyjet (1997, 2006), the retention rate and academic achievement of African American students have been a great concern among American colleges and universities over recent decades. Tinto (1987, 1993) emphasized how institutional "fit" is an important factor when considering how to bridge the gap between the old traditional campus and a new diverse campus. Tinto (1987) suggested that if the values, goals, and attitudes of students are congruent with the institution, student enrollment and persistence rates increase. Tinto (1993) argued that 
student persistence and attrition are directly influenced by the institution's commitment and motivation for students to graduate as well as students' goals and motivations to earn a college degree. In other words, academic and social integration are essential.

As reported by Seidman (1989), students' experiences before, during, and after the college admissions process are significant influences towards developing attainable and prosperous expectations of the institution. For example, when students were equipped with adequate and appropriate information about college and its environment, students made better decisions about college choice; which is all-important in African American men's determination of institutional fit (Tinto \& Wallace, 1986; Seidman, 1989). For Seidman, retention begins with the admissions process. As a resulting outcome, Seidman contended that the more informed students were about personal choices made throughout the admissions process, the more students persisted.

However, Seidman (1989) and Tinto and Wallace (1986) did not account for issues of privilege and discrimination. Although African American men from lower to middle-class families are equally subjugated by race (Ogbu, 2002), Reed's (1988) analysis of census data suggest students from higher income families are more likely to enroll in college. In spite of the review of these data, what is interesting is more than half of African American students enrolled in college came from families with lower income levels. Reed insisted that "the college enrollment of Black students from lower- to middle-class family income brackets attests not only to their desire and motivation to attain higher education, but also to a greater willingness of their parents to sacrifice financially for them to do so" (p. 69). 
In How College Affects Students: A Third Decade of Research, Pascarella and Terenzini (2005) offer a synthesis of research of post-secondary institutions of the past few decades. Pascarella and Terenzizni credited a study by Cabrera, Nora, Terenzini, Pascarella, and Hagedorn (1999) that examines how 410 African American and 1300 White students perceived the racial climate at 18 predominately White institutions. Pascarella et al. found racial prejudice and discrimination were significantly and negatively related to both groups of students' persistence into their second year. Pascarella and Terenzini also note that the perception of racial and ethnic prejudice negatively affected college transition and adjustment as well as a sense of belonging and institutional commitment for African American and other ethnically marginalized students.

\section{Development of Psychosocial, Racial and Ethnic Identities}

Erik Erikson $(1950,1968,1980)$, a clinical psychologist, developed an identity model covering the lifespan of human development from birth to death. Erikson postulated that development is determined by the interaction of biological (genetic), psychological (mind), and cultural (ethos) influences. Erikson identified factors of a psychosocial development of identity that consists of a eight critical stages: Stage 1Basic Trust versus Mistrusts, Stage 2-Autonomy versus Shame and Doubt, Stage 3 Initiative versus Guilt, Stage 4-Industry versus Inferiority, Stage 5-Identity versus Identity Diffusion, Stage 6-Intimacy versus Isolation, Stage 7-Generativity versus Stagnation, and Stage 8-Integrity versus Despair. The most relevant stages to this study are the fifth and sixth stages of identity development. Identity versus Identity Diffusion (confusion) accounts for adolescence (12 to 18 years). Here, life is more complex as 
students negotiate social interactions, develop their core values and beliefs, and attempt to make meaning of their identity. If unsuccessful in navigating through this stage of the process, students will experience identity confusion. Intimacy versus Isolation accounts for young adulthood (18 to 35 years). As young adults, this stage is about finding mutually satisfying relationships with friends and family as well as lasting intimacy with a partner. Without meaningful relationships and a healthy sense of identity, social and emotional isolation is inevitable.

Erikson (1968) believed the lifecycle of human development is always changing, but they must accomplish a series of developmental tasks or crisis at each stage of development. In the case of African American men, Staples (1982) contended that cultural, social, and economic barriers have limited their ability to conform to traditional roles of masculine identity. Therefore, African American men are left at a social disadvantage in fulfilling developmental crises fundamental in their transition from childhood to manhood. For African American collegiate men, it is vitally important they have a clear understanding about who they are to avoid identity diffusion and social isolation, while at the same time mitigating threats toward their academic success.

Psychosocial development. Arthur Chickering (1969) conducted studies that primarily examined how the college environment influenced the development of undergraduate students in his original work, Education and Identity. The underpinnings of Education and Identity were influenced by stages five and six (Adolescence and Young Adult) of Erikson's (1968) human identity development theory.

Although Chickering's (1969) initial work aimed to offer better insight to faculty in improving students' development, student affairs professionals soon realized how his 
studies could inform student service practices as well as foster student identity development (Evans, Forney, DiBrito, Patton, and Renn, 2010). Chickering, along with Linda Reisser (1993), revised his original work to include an updated theoretical context for student psychosocial development of identity. Chickering's psychosocial theory is described as unsequenced "vectors" or tasks, illustrated in the following seven vectors of identity development (Chickering \& Reisser, 1993; Evans, et al., 2010): (1) Developing Competence, (2) Managing Emotions, (3) Moving Through Autonomy Towards Interdependence, (4) Developing Mature Interpersonal Relationships, (5) Establishing Identity, (6) Developing Purpose, and (7) Developing Integrity. Although there is not a rigid linear progression, the seven vectors build upon each other and are linked to the psychosocial development of college-aged students. Though the 1993 revisions of the model included a reordering of tasks, there are critics and others who have debated how Chickering and Reisser's theory may be applicable to underrepresented student populations.

For instance, while students who might identify as Lesbian, Gay, Bisexual, Transgendered, or Queer (LGBTQ) share many of the experiences and qualities of the majority of college students, there are distinct experiences of alienation, harassment, and victimization (Evans \& D'Augelli, 1996) that take precedence over developmental tasks, as described by Chickering and Reisser (1993). Researchers who have addressed issues of gender (Blackhurst, 1995; Foubert, Nixon, Sissons, \& Barnes, 1995; Taub \& McEwen, 1991) women (Straub, 1987; Taub, 1995), and racial and ethnic identity development (Branch-Simpson, 1984; Durham, Hays, \& Martinez, 1994; Pope, 1998, 2000; Taub \& McEwen, 1992; Wright, 1987) in student affairs "questioned the applicability of 
Chickering's theory for students who are not from white, middle-class backgrounds" (Evans et al., 2010, p. 74).

Racial and ethnic identity development. Regarding underrepresented racial and ethnic student populations, Wright (1987) discusses the historical limitation of student development models in adequately accounting for the developmental needs of students of color, specifically at predominantly White institutions. Wright claimed:

a. The various models and theories of college student development did not take into account the culture specific aspects of development, but assume that all students (regardless of race or culture) experienced developmental phenomena in a similar fashion;

b. Most theories of college development were based on the assumption that growth occurs within a monolingual or monocultural environment when, in fact, many students of color live and learn in bilingual or bicultural environments;

c. Most theories did not take into account acculturation and assimilation in the students' overall development, and thereby discarded the importance of adjusting to a campus environment that may differ from their cultural frame of reference; and

d. Most theories adhered to White values that may, in practice, have been quite different from non-White value systems.

However, in contrast to the perception that broad theories do not accommodate African American students' development, Pope (1998), in a study examining the relationship between the psychosocial and racial identity development of African 
American undergraduate students, revealed findings that students with higher levels of Black consciousness had predictive developmental tasks of Developing Purpose and Developing Mature Interpersonal Relationships.

\section{Critical Race Theory}

The backstory of the movement. Critical Race Theory (CRT) emerged during the late 1970s, which is considered the post-Civil Rights era in America. CRT conceptual roots grew out of Critical Legal Studies, which had its early framework established by the legal scholars Alan Freeman and the "father" of Critical Race Theory, Derrick Bell (Delgado, 1995; Delgado \& Stefancic, 2001). Freeman and Bell argued that the impetus of the Civil Rights Movement and progressive gains of the 1960s had stalled and even rolled back due to the slow pace of racial reform. They were later joined by other attorneys, activists, legal and interdisciplinary scholars of the Critical Legal Studies movement to challenge subtler, microaggressive manifestations of racism. As explained by Delgado and Stefancic, CRT integrates "the same issues that conventional civil rights and ethnic studies discourses take up, but places them in a broader perspective that includes economics, history, context, group- and self-interest, and even feelings and the unconscious" (p. 3).

Tenets of critical race theory. Critical Race Theory involves five insights or tenets. First, CRT accepts the assumption that racism is not an outlier, rather a normal and perpetual artifact of American society. CRT explores how race has been socially constructed throughout the history of the United States. Harris (2008) reiterated that issues of race and racism continue to be significant in determining inequity and success for African Americans and other underrepresented populations. Further, CRT examines 
how underrepresented populations (people of color and women) have been challenged by the hierarchical system of racism. Therefore, the perspective needed to explore the experiences of African American collegiate men is the understanding that race and racism (overt or covert) exist in their everyday lives as natural phenomena (Delgado, 1995; Delgado \& Stefancic, 2001; Yosso, 2006a, 2006b).

Second, Critical Race Theory challenges hegemonic social norms (such as gender norms) and counter knowledge claims that educational institutions make toward objectivity, meritocracy, color-blindness, race neutrality and equal opportunity. CRT's commitment to social justice sheds light on the "interests convergence" between privilege and civil rights. Interests convergence is exposed when the "gains" of underrepresented groups are only met when they promote the self-interests of the majority (Delgado, 1995). CRT scholars argue that traditional knowledge claims "camouflage" or serve as smokescreens to preserve or advance the self-interests and power of American social and racial hierarchy (Yosso, 2006a, 2006b). As described by Delgado and Stefancic (2001), "Because racism advances the interests of both white elites (materially) and workingclass people (psychically), large segments of society have little incentive to eradicate it" (p. 7).

CRT affirms its third tenet's commitment toward social justice—one that underrepresented populations find empowering and one that is socially transformative (Matsuda, 1991; Yosso, 2006a, 2006b). This social justice perspective exposes the hegemonic self-interests of the dominant group and seeks to work toward the elimination of racism, sexism, and poverty as well as the empowerment among African Americans and other oppressed groups (Delgado-Bernal, 2001). 
The lived experiences of marginalized groups are legitimized in CRT's fourth tenant. Critical race theory affirms the experiences of people of color are valid and recognizes their experiential knowledge is "legitimate, appropriate, and critical to understanding, analyzing and teaching about racial subordination” (Yosso, 2006b, p. 7). Moreover, it is an essential element in this study towards deepening the understanding of what is known about African American collegiate men's experiential knowledge. Counterstorytelling, which establishes space for a narrative counter to majority knowledge claims, provides an opportunity to value the voices of those who have been overgeneralized and silenced.

Lastly, Critical Race Theory provides an interdisciplinary perspective and welcomes multiple methods to examine critical discourse in education (Yosso, 2006a). According to Delgado (1995), CRT dismantles intellectual disciplinary boundaries to critically examine race and racism in a historically and contemporary context. CRT is transdisciplinary because it incorporates scholarship from ethnic studies, women's studies, sociology, psychology, history, humanities, law, and other disciplines (Delgado, 1995).

\section{Summary}

In this chapter, I presented a review of literature examining the lived experiences and psychological influences of African American collegiate men from a historical, social, and theoretical context. These contexts will provide the footing necessary toward exploring the research questions presented in Chapter One. Chapter Three will further broaden methodological strategies of Critical Race Theory. 


\section{CHAPTER THREE}

\section{METHODOLOGY}

The selection of a qualitative research design and a critical race theoretical and methodological approach was derived from the purpose of this study towards understanding how the lived experiences of African American college men inform the construction of masculine and ethnic notions of their identities at a predominately White institution (PWI). A particular focus of this line of inquiry is to explore how these undergraduate men understand and develop healthy performances of their ethnic and masculine identities, despite disproportionate racial, hegemonic, and social barriers. Furthermore, this study explored the perceptions and critical incidents that these African American college men understand as most salient toward successfully negotiating the intersectionality of ethnicity and masculinity. It is intended that the counterstories of these college men will give voice to the authentic meaning they prescribed to their lived experiences as African American men at a predominately White institution. The research questions that guided this study include:

1. How do African American college men characterize their ethnic identity?

2. How do African American college men characterize their perception of their masculinity?

3. How do African American college men perceive their performance of masculinit(ies)? 
4. How do the ethnic and masculine identities of African American college men intersect?

5. How does being in college impact African American men's identities?

This chapter describes the qualitative methodological approach that was be used to investigate the lived experiences and perceptions of African American college men at the Metropolitan University. The outline of this discussion include descriptions of the: (a) setting, (b) selection criteria of participants and recruitment, (c) data collection, (d) analysis procedures, (e) techniques that was be used to account for trustworthiness, and (f) ethical considerations,.

\section{Rationale for Qualitative Inquiry}

Creswell (2003) offers a valuable framework for researchers to consider in designing a research plan or proposal. Building upon the research design strategies of Crotty (1998), Creswell employs the practical and philosophical underpinnings of research (epistemology, theoretical perspectives, methodology, and methods) to determine what particular approach of inquiry to use: quantitative, qualitative, or mixed methods.

Creswell (2003) combines knowledge claims (assumptions), strategies, and methods as essential elements of inquiry into the three research approaches, thus establishing an alternative process for research design. He presents three questions as a conceptual framework in designing a study (p. 5):

1. What knowledge claims are being made by the researcher (including a theoretical perspective)?

2. What strategies of inquiry will inform the procedures? 
3. What methods of data collection and analysis will be used?

In order to explore the counterstories of the African American college men involved in this study, I am guided by advocacy/participatory knowledge claims as described by Creswell (2003), since postpostivist or quantitative assumptions inadequately capture the counterstories, voices, and concerns of marginalized groups or individuals. Creswell's perspective is akin to "emancipatory," "liberation," “orientational" (Patton, 2002) or "critical" perspectives of inquiry. Taken as a whole, this social justice approach is a naturalistic or qualitative strategy of inquiry that goes beyond social constructivist assumptions as it seeks not only to examine and understand society, but critique and advocate for change. Specifically, critical race theoretical and methodological approaches was be used throughout this study to introduce and answer research questions, collect and analyze data, and to advance the "voice" of African American college men. I will further discuss these methodological approaches in the next section of this dissertation.

The use of qualitative approaches in educational research, particularly in collegiate environments, have become valuable strategies of inquiry, as opposed to what was once perceived as less rigorous, misunderstood, or uniformly rejected, favoring deductive, quantitative approaches (Upcraft \& Schuh, 1996). As defined by Patton (1990), Schuh and Upcraft (2001), "qualitative methodology is the detailed description of situations, events, people, interactions, and observed behaviors, the use of direct quotations from people about their experiences, attitudes, beliefs, and thoughts; and the analysis of excerpts or entire passages from documents, correspondence, records and case histories" (p. 27). 
For the purpose of this research, I used Creswell's (2003) characterization of qualitative inquiry: "a qualitative approach is one in which the inquirer often makes knowledge claims based primarily on constructivist perspectives (i.e., the multiple meanings of individual experiences, meanings socially and historically constructed, with an intent of developing a theory or pattern) or advocacy/participatory perspectives (i.e., political, issue-oriented, collaborative, or change oriented) or both" (p. 18). Qualitative inquiry uses strategies, such as narratives, phenomenologies, ethnographies, grounded theory, or case studies.

\section{A Critical Race Approach in Educational Research Design}

Critical Race Theory (CRT) is an emerging interdisciplinary theoretical perspective and methodological strategy in qualitative research (Johnson, 2010; Solórzano \& Yosso, 2002). CRT offers an alternative framework that "deconstructs" traditional theoretical and methodological assumptions of inquiry by critiquing dominant ideology, addressing issues of race and racism, while restoring those placed at the margins of society, to the center of all aspects of research.

As a developing perspective in educational research, "CRT scholars believe and utilize personal narratives and other stories as valid forms of 'evidence' and thereby challenge a 'numbers only' approach to documenting inequity or discrimination, which tends to certify discrimination from a quantitative rather than a qualitative perspective" (Dixson \& Roussseau, 2006, p. 35). Solórzano and Yosso (2002) expand the work of CRT and introduce a critical race methodology that centers the experiences and stories of students of color. Using counterstories and personal narratives to share the knowledge and experiences of African American male collegiate voices, which are often unsung, 
CRT will expose, analyze, and challenge stories of the majority and racially privileged. In the section that follows, I will present the research strategies of a critical race methodology.

Critical race methodology. Critical Race theoretical and methodological approaches will be used to guide decision-making throughout the study. There are five major tenets that form the perspectives, research methods, and pedagogy of Critical Race Theory as it is applied to educational research: (1) The centrality of race and racism and their intersection with other forms of subordination; (2) the challenge to dominant ideology; (3) the commitment to social justice; (4) the centrality of experiential knowledge; and (5) the transdisciplinary perspective.

A critical race methodology in education upholds the fundamental premise that race and racism are endemic phenomena and remain permanent stitches in the fabric of American society. Although race and racism is central to critical race analysis, it is also examined at the intersection of other forms of subordination, such as gender, class, immigration status, phenotype, surname, and sexual orientation. A critical race methodology in education places race and racism, and other marginalized intersections, at the center of the research process. Moreover, a critical race methodology can be used to gain better insight about the conceptual, theoretical, methodological, and pedagogical inquiries related to the experiences of people of color.

The second tenet of critical race methodology in education requires the researcher to challenge dominant scientific norms of objectivity and neutrality — traditional research paradigms, methods, texts, theories, and deficit-informed inquiries that silence or distort epistemologies of people of color. The third tenet ensures that research is connected with 
social justice concerns, such as transformative solutions to racial, gender, and class subordination. It also acknowledges that multiple layers of oppression and discrimination are met with multiple forms of resistance.

The centrality of experiential knowledge is the fourth tenet of critical race methodology. Using methods such as family history, autobiographies, storytelling, scenarios, narratives, parables, and chronicles, critical race theorists see strength in this knowledge and are informed explicitly on the lived experiences of people of color (Yosso, 2006a, 2006b). Critical race methodology places experiential knowledge at the center of research and connects this knowledge to other critical research and interpretive perspectives that are racialized, gendered, and classed. The last tenet appreciates transdisciplinary perspectives and uses the knowledge and methodological foundations of ethnic studies, women's studies, sociology, psychology, history, humanities, law, and other fields to guide research that better contextualize the effects of racism on other forms of subordination.

The methodological underpinnings of this critical race inquiry shed light on the authentic stories and lived experiences of African American men, thus countering prevailing narratives of who they are and their collegiate experience. By listening to the counterstories of college men who thrive at the intersection of masculinity and ethnicity, Solórzano and Yosso (2002) contend that counterstories serve at least the following four functions:

1. They can build community among those at the margins of society by putting a human and familiar face to educational theory and practice;

2. They can challenge the perceived wisdom of those at society's center by 
providing a context to understand and transform established belief systems;

3. They can open new windows into the reality of those at the margins of society by showing possibilities beyond the ones they live and demonstrating that they are not alone in their position; and

4. They can teach others that by combining elements from both the story and the current reality, one can construct another world that is richer than either the story or the reality alone.

The fundamental use of counterstories and the five tenets of critical race inquiry are not new in and of themselves, yet together, they provide a compelling critique of rhetoric and educational models, cloaked as "shared normative values" and practices (Solórzano and Yosso, 2002). Solórzano and Yosso's educational perspective using a critical race methodology was used to answer the theoretical, conceptual, methodological, and pedagogical research questions that center the lived experiences of African American collegiate men at the intersection of ethnicity and masculinity. Based upon the methodological premise of this qualitative study, once participants hear their own voices and the stories voiced by others at the margins of societal and educational discourse, they empower themselves, discover that they are not alone, and learn how to defend themselves from as well as frame arguments in their formidable striving for achievement and identity.

\section{Research Setting and Recruitment of Participants}

Setting. The research site, Metropolitan University, is a large public metropolitan research university accredited by the Commission on Colleges of the Southern Association of Colleges and Schools and centrally located in the United States. Total 
student body is over 22,000 students, 15,772 are undergraduate students, 2,314 (10.4\%) of the total population are Black/African American, and with 2.8\% distinguished as fulltime, degree-seeking undergraduate African American men.

The University was selected because of its institutional mission for diversity, lead by an executive office of diversity. The University's specific commitment to formally educate African Americans was established with its separate "Municipal College for Negroes" in 1931. It was not until after World War II, that state statutes favoring racial segregation ended and the University soon became desegregated, closing the Negro college program and opened doors to the African American community in 1951 ("A brief history").

The University has 14 services and organizations that support and promote diversity initiatives for faculty and staff; over 30 organizations and services for underrepresented student populations; more than 15 registered student organizations, associations, and initiatives for African American students, whereby seven of these student organizations and initiatives are specifically established affinity groups composed of African American college males (five are Black Greek-letter fraternities). Most of these groups have established missions and programs that support the development and retention of African American men, such as the African American Male Initiative (AAMI), which is based out of the University's Cultural Center. This site was also selected because many of these groups became an opportunity for African American men to serve in leadership roles, including with student government. For instance, within the last five years, African American men were elected as Student Government Association (SGA) President for two consecutive years. 
Lastly, this site was also selected because of my affiliation with the University and because I developed professional relationships with key "gatekeepers" that assisted in recruiting participants.

Recruitment of participants. This study used purposeful sampling to recruit participants for the study. Creswell (2003) and Patton (2002) describe purposeful sampling as sites or individuals purposefully selected to best answer research questions as well as to aid the researcher in understanding issues directly related to the purpose of the study. Patton (2002) suggests, "the logic and power of purposeful sampling lie in selecting information-rich cases for study in depth" (p. 230) [emphasis in original]. He defines information-rich cases as "those from which one can learn a great deal about issues of central importance to the purpose of the research, thus the term purposeful sampling” (p. 46). For this reason, I selected African American male participants that provided meaningful and information-rich counterstories.

This study used a criterion based purposeful sampling strategy. Shuh and Upcraft (2001) describe criterion sampling as a strategy to select participants based on predetermined selection standards or specifications. With criterion sampling as a priority, this study also used a homogeneous sampling strategy. A homogeneous sampling approach is used to select a small subgroup of individuals with similar characteristics and describes them in depth, such as in in-depth focus group and individual interviews (Patton, 2002). The rationale to use this combination of purposeful sampling was directly related to the specific intent of the study, which was to investigate the intersecting characteristics of masculinity and ethnicity of African American college men at a predominately White institution. 
To aid in recruiting participants, I sought out faculty and administrators who have frequent access to and interaction with African American male students. These administrators and faculty served as participant nominators (see Appendix A for Participant Nominator letter). These nominators included student affairs professionals, diversity recruitment/admissions professionals, cultural center administrators, members of the Black Faculty and Staff Association, and Black student organization advisors. As shown in Table 1, I asked each nominator to use the selection criteria to recruit potential African American male participants. While these nominators were expected to use these selection criteria to assist in the process of recruiting information-rich participants for this study, their recommendations were inherently subjective. Although the selection criterion was explicit, each nominator used his/her own judgment in identifying potential participants. On the other hand, participant nominators aided this study by limiting potential selection biases of this researcher. Therefore, in this case, the tangible benefit of participant nominators outweighed the potential limitations inherent in selection subjectivity. 
Table 1

Description of Predetermined Criteria

Criteria Description of Criteria

\begin{tabular}{ll}
\hline Male & $\begin{array}{l}\text { This study will examine the intersection of } \\
\text { masculinity and ethnicity on participants }\end{array}$ \\
Black_-African American & $\begin{array}{l}\text { This researcher is interested in examining the } \\
\text { experiences of African American men because of } \\
\text { the sociohistorical significance of race and racism } \\
\text { in the United States }\end{array}$ \\
Undergraduate & $\begin{array}{l}\text { This researcher is only interested in investigating } \\
\text { undergraduate experiences of degree seeking } \\
\text { African American men (freshman, sophomore, } \\
\text { junior, or senior) }\end{array}$
\end{tabular}

Willingness to discuss race and racism

It is important that participants are perceived to take the time to willingly discuss issues of race and racism in this study

Willingness to discuss masculinity It is important that participants are perceived to take the time to willingly discuss issues of manhood or masculinity in this study

Patton (2002) emphasizes that determining sample size is not absolute, but depends on what the researcher wants to know and defines as the purpose of the study as well as the usefulness of information received. Seidman (1998) argued the importance of achieving a "saturation" of information, or similarly, what Patton (2002) refers to as cases that are "information-rich," "in-depth," and "redundant" information. Essentially, both suggests that when there is no new information reported by participants, it is the researchers' responsibility to assess if there is adequate information to begin addressing the research questions of the study. Although there is not a method of predetermining a concrete sample size, Patton (2002) suggests setting a minimum sample size to avoid 
ignoring practical issues, such as budget and time. For the purpose of this study, nine African American males served as participants in in-depth, semi-structured interviews and twelve in a focus group.

\section{Data Collection Methods}

This study employed purposeful sampling to find information-rich participants most familiar with the phenomenon being studied (Patton, 2002). As the investigator, I prepared for a potential challenge of identifying adequate and appropriate participants for this study - particularly given the underrepresented percentage of enrolled African American undergraduate males at the study's institution.

Data collection for this study consisted of screening and demographic surveys, a focus group interview, and one semi-structured in-depth interview with each participant, which lasted between 80-120 minutes. Four major emergent themes evolved out of the in-depth interviews and no additional individual interviews were necessary. Upon approval of the Institutional Review Board, I contacted selected participant nominators by phone or email and shared the predetermined criterion to identify and recommend potential participants for this study. I requested that each nominator send me the names and emails of potential participants. Then, I sent emails notifying 76 recommended students (see Appendix B for Nominated Participant email) that they had been nominated to participate in this study and to set-up a brief screening interview by phone, based on their interest to participate (see Appendices $\mathrm{C}$ and $\mathrm{D}$ for preamble phone script and prescreening questions). After the pre-screening interview, I contacted each nominee by an emailed letter and phone call to invite each as a study participant (Appendix E) as well as followed-up with nominees not selected to thank them for their involvement 


\section{(Appendix F).}

The next sections outline the data collection process, including the screening questionnaire, demographic survey, focus group and individual interviews. Once participants were identified, data collection extended four weeks. Upon obtaining informed consent (Appendix G), all interviews were audio recorded using two digital recording devices; one device served as a backup. The privacy of all participants and potential participants was protected and confidential throughout this study. Pseudonyms were used to protect the identities of all study participants.

Phase I: Questionnaires. Two types of questionnaires were used during the initial phase of this study — a pre-screening questionnaire (Appendix D) and demographic survey (Appendix H). This pre-screening interview served as a pre-focus group survey. This pre-screening further enabled me to identify, as accurately as possible, eligible men to serve as focus group (and potential in-depth interview) participants in this study. These questions aided in ensuring that participants meet the criterion of the targeted population I investigated. This brief screening process was done by phone in as little as five minutes. Out of the 76 students recommended by nominators, 24 responded that they were interested and 19 African American men were available when contacted to participate in the phone screening. This short phone screening allowed me the opportunity to personally introduce myself to potential participants and served as an initial means of establishing rapport (Edmunds, 1999).

Since the pre-screening was designed in a similar fashion as a mini-survey, candidates who were not invited were left feeling that they have completed their role in the study, while participants who met the criterion were invited to join the group. Upon 
consent, demographic questions such as age, gender, ethnicity, parents' education, academic classification, and socioeconomic status were surveyed of all participants prior to group interview. Face-to-face and focus group interviews served as primary data collection techniques in this study.

Phase II: Focus group. Focus group interviewing can be used as a stand-alone research method or can be used as a technique in conjunction with other data collection methods (Edmunds, 1999). In combination with other research methods used in this dissertation, such as questionnaires and interviewing, a focus group can be used preliminarily to prepare for specific issues within a study. This form of group interviewing is also very useful in following up and clarifying inferences and findings in other data, such as individual interviews. In conjunction with individual interviewing as a form of data collection, focus groups are commonly used in an explanatory or preliminary capacity - though focus groups can be useful in both generating and answering research questions. Primarily, this focus group was used to refine and generate probing questions for the interview guide of individual interviews-Phase III of this study. The focus group interview guide was used to frame a free-flowing dialogue between group participants (Appendix I).

To encourage dialogue, reflective illustration expressions were encouraged from the focus group participants (as described in the interview guide) as a "creative" alternative to oral inquiry alone (Patton, 2002). With pens, markers, crayons, and construction paper, participants were asked to use words, drawings, and other expressions to illustrate what they felt and/or thought about ethnicity and race. Then, after sharing their thoughts and illustrations with the group and responding to follow up questions, 
they repeated the same process about manhood and masculinity on the other side of the paper. The illustrations they created provided participants the opportunity to self reflect, established context for their own meaning, reduced a pattern of groupthink, and established rapport among other participants and the researcher. As a result, the conversations were enjoyable and thought-provoking, which yielded two hours of information rich data, which could have continued if I were not considerate of participants' time. To avoid the possibilities of researcher bias, I only facilitated the exercise and discussion. These reflective illustrations were used throughout the focus group and in-depth interview process.

Focus group interviewing was appropriate for this study because it investigated what participants think as well as to explore why African American collegiate males have particular perceptions about their identity. An equally important advantage of group interviewing was the group's interaction and sharing of perceptions. When participants interacted among themselves it replaced direct interaction of the researcher, which was ideal when seeking to gain a deeper understanding of participants' perspectives and experiences. Morgan (1988) argued, "While individual interviewing is also interaction, the key point is that focus groups offer a stronger mechanism for placing the control over this interaction in the hands of the participants rather than the researcher" (p. 18).

What must be acknowledged, however, are possible limitations in data collection, which can become relatively chaotic because the control of focus group interviewing relies more on the groups dynamic than the researcher. To limit the probability of an unmanageable focus group, a smaller or "moderate sized" group is suggested to resolve this potential conflict in instances where groups are sources of data. Moderate size focus 
groups vary in the literature from six to eight (Edmunds, 1999), five to ten (Holstein \& Gurbrium, 1995), and six to ten (Morgan, 1988; Patton, 2002). For this study, I selected 15 of the 19 African American males who were likely to produce information-rich data to determine the size of the focus groups and 12 participants were available to attend the focus group.

The focus group setting was in a familiar location for all invited participants. It was secure, window shades were drawn for privacy, and refreshments were available for participants, which assisted in promoting a welcoming atmosphere for discussion. As mentioned above, when used in combination with individual interviewing, focus group interviewing provides the opportunity to create a more in-depth and structured individual interview guide. Utilizing a focus group in the initial or earlier stages of this study was ideal, particularly because the population has not been significantly explored (Morgan, 1988).

Phase III: Interviews. This study used in-depth, semi-structured interviewing as my primary approach of data collection (Seidman, 1998; Patton, 2002). Open-ended questions were used throughout the in-depth interviewing process. An advantage of an open-ended interviewing approach was that it allowed me the flexibility to fully understand and explore questions about the lived experiences and perceptions of the African American college men participating in this study.

Interviewing is a dynamic, and sometimes intimate, method of learning and sharing stories between the researcher (the listener) and the participant (the storyteller). Seidman (1998) notes that, "telling stories is essentially a meaning-making process" (p. 1). Given the significance of this process, people select particular details of experiences 
that they must reflect upon, assign order, and reconstruct from their stream of consciousness in a manner that best represents the meaning they make of those stories and experiences. Recounting narratives of experiences or storytelling has been a human quality of making sense of the world throughout history. An assumption in interviewing is that the meanings people make of their experiences affects the way participants perform those experiences. In this study, in-depth interviewing was the method I used to place behavior or the performance of participants' stories into context, forming a counterstory.

The 12 focus group participants were invited to engage in a in-depth, semistructured interview, however, two could not participate due to academic commitments and one did not show up for the prearranged interview time and never offered a rationale for his absence. As a result, nine eligible and interested African American men provided information-rich data for this study. Seidman (1998) proposes the use of a series of up to three separate interviews of a single participant. Introduced by Dolbeare and Schuman (1982), this three-interview process seeks to place the meaningful experiences of participants' into context of their lives and lives of others around them. The first interview establishes context by centering on life history, which was achieved by students' participation in the focus group interview. The second interview, the in-depth individual interview, allowed participants the necessary opportunity to reconstruct contextual details of their narratives, which could provide me with information-rich data. If more information was needed, a third interview may have been used for participants to actively reflect upon the meaning associated with particular experiences to obtain information-rich data. After reviewing the information collected, I determined no 
additional information was needed to conduct a third interview; however, participants were contacted by phone or email to clarify their interview statements or typos on the demographic surveys.

Interview Guide. An interview guide was used in an effort to ensure the same baseline of inquiry was explored with each of the nine African American collegiate male participants in this study (Patton, 2002). Informed by the research questions, review of literature as well as insight from the focus group in Phase II of this study, I developed a series of open-ended questions to explore, probe, and guide the interview process. An interview guide is designed to allow the researcher the flexibility to also develop new questions during the interviewing process as patterns, themes, and experiences emerge (see interview guide in Appendix J). This open-ended interview guide provided me the opportunity to conduct a free flowing style of interviewing, much like a focused conversation, as opposed to a rigid questioning and answering session. This style allowed me to cover most, if not all questions included in the interview guide.

Phase IV: Critical incidents. Critical incidents were used as a supplemental inductive data collecting technique during and after each individual interview in this study. Commonly used in direct observation or retrospective self-reporting of participants, this technique was used to gather descriptive data of past major events or experiences as recalled by African American male participants through their reflection and documentation. Critical incident reporting enhances data collection by uncovering insight and encounters that might not have been disclosed through the group or individual interview process. Critical incidents were documented during the group interview and indepth interview process, however, none of the participants elected to submit their 
reflections after their interview (Given, 2008; Patton, 2002). During the group interview process, critical incident responses about actual occurrences in their lives were prompted from participants after sharing their thoughts from the reflective illustration exercise. Critical incident responses were also shared during in-depth interviews after they were prompted to reflect upon a situation or time they had a "heighten sense" of themselves as African Americans or as men (see Appendix J).

\section{Data Analysis}

Unlike quantitative research designs, Patton (2002) asserts that there is no "hardand-fast" characteristic between data collection and analysis in qualitative research. In a similar implication, Creswell (1994) offers that data analysis is eclectic and there is not a "right way." Qualitative inquiry has an emergent design, whereby themes and patterns take shape from document examination, field observation, and interviews during and after the data collection process (Creswell, 1994, 2003; Patton, 2002; Upcraft \& Schuh, 1996). For this reason, Creswell $(1994,2003)$ further suggests that analysis occur "simultaneously" with the collection, reduction, interpretation, as well as reporting of narrative data. Therefore, data analysis was ongoing during this study, which provided me the opportunity for continuous reflection, memo writing, journaling, postulating analytic questions, and formulating new research questions throughout this study of African American college men.

All data and documentation was systematically organized, interviews transcribed verbatim, and arranged into manageable and consolidated subgroups. As described in Creswell (1994), Tesch (1990) referred to this process as de-contextualization and recontextualization. For instance, demographic information such as age, academic 
classification, academic discipline, and geographic origin is displayed in Table 2.

Observational notes during interviews, group and individual interview transcripts were thoroughly read in order to obtain a baseline understanding of the data (Creswell, 2003; Patton, 2002). While allowing myself time to take notes and purposefully reflect about the data, I began to cluster emergent patterns and label themes within the counterstories of all participants in preparation to begin a detailed coding process.

Accordingly, keywords and phrases were identified from the emerging patterns and themes into specific categories for coding. Notes in the margins of transcripts and highlighting texts are traditional qualitative techniques that I employed during the coding process (Creswell, 1994, 2003; Patton, 2000). Additionally, I introduced the use of Dedoose, an application for managing, analyzing, and presenting qualitative and mixed method research data, to assist with the coding of all participant transcripts (See Code List in Table 3). Using computer-assisted qualitative data analysis software (CAQDAS) to analyze data during coding, data comparison, storage and retrieval delivers an efficient method of analysis, particularly when reviewing hundreds of pages of transcripts, analytic memos, and notes. It is important to note, computer-assisted qualitative data analysis software only played a role in analysis, much like in quantitative statistical analysis software. Patton (2002) asserts that, "the analysis of qualitative data involves creativity, intellectual discipline, analytical rigor, and a great deal of hard work. Computer programs can facilitate the work of analysis, but they can't provide the creativity and intelligence that make each qualitative analysis unique" (p. 442).

Ethical Considerations. In exploring the lives of African American collegiate men, as the primary researcher, I had to be thoughtful about the background, feelings, 
experiences, and all data collected from participants before, during, and after qualitative interviewing. Although it is impossible to have had advanced knowledge about how the interview experience impacted participants, it was critical for me to understand that their recollection of memories, expression of lived experiences, and discussion of their racial, ethnic, and masculine identities might be mixed with joy and pain (Patton, 2002; Seidman, 1998). Therefore, it was important to respect and minimize adverse effects of these possible risks involved in conducting individual and group interviews, while adhering to ethical protocols and the aforementioned methodological strategies and techniques of qualitative inquiry.

The method of collecting data using a focus group raised unique ethical considerations because information shared with me, as the researcher, was also inherently shared with other participants. It was incumbent upon me to be aware of sensitive questions and topics of discussion that participants may have disclosed within a particular group and/or setting. Morgan (1988) suggests emphasizing the protection of individual participants, while assuring them that all group discussion participants are "a part of the shared milieu" (p. 40). This strategy of care and assurance not only affirms participants confidence and trust during the interviewing experience, it also conveys a salient sense of shared purpose among participants.

Institutional review board. To reduce the possibility of risk, the Institutional Review Board (IRB) evaluated and approved all research procedures prior to conducting this study. The IRB process protects participants from human rights violations as standardized by federal regulations. Accordingly, by law and the University's review 
board, I am required to safeguard participants from the risk of emotional, physical, psychological, social, economic, or legal injury.

Confidentiality and informed consent. Due to the subpopulation of African American college men that were involved in this study, I took appropriate steps to protect the identity of participants. All participant and potential participant identities were held confidential throughout the research process. Additionally, all participants of this study used pseudonyms instead of their actual names to protect their identities. Participants were provided an informed consent form to sign prior to engaging in this study. All participants understood (1) the purpose and procedures of the study, (2) that participants' time and contribution to this study were completely voluntary, and (3) that was their choice to withdraw from the study at any time. I have a significant responsibility to ensure their experiences are documented accurately; they have the right to ask or decline questions, and can obtain a copy of their interview transcripts and results of the study.

\section{Trustworthiness of Data.}

In quantitative research, the term validity is used to describe the accuracy or credibility of an instrument that is designed to measure what it is supposed to measure, through prescribed standardized procedures (Creswell, 2003; Patton, 2002; Voght, 1998). In qualitative research, the researcher serves as the instrument, whereby credibility and verification of data are described in terms of the trustworthiness and authenticity of the study. Specifically, Patton (2002) suggests that the researcher must maintain a high-level of fairness, balance, as well as conscientiously reflect the multiple perspectives, interests, and realities of participants' experiences and collected data. In critical inquiry, Patton further describes employing a critical change criterion for judging the quality of 
qualitative research. Throughout the design, data collection, and analysis of the study, trustworthiness is established when research seeks to raise consciousness, critique society, identify inequities and injustices, and shift the balance of power to participants.

Furthermore, Creswell (2003), Glesne (1999) and Patton (2002) recommend the use of one or more strategies to verify the accuracy of data. These particular strategies were also used in this study:

1. Triangulation — use of multiple data collection sources, methods, analysis, or theoretical perspectives. Triangulation is not just the simple combination of multiple practices, but it links a coherent justification of themes while counteracting threats that may limit the credibility of research (Glesne, 1999). This was achieved by using the following data collecting methods: a group interview, individual interviews, demographic information provided by participants, critical incident reflection during in-depth interviews, reflective illustrations from participants, and reflective and analytic memos taken through the study.

2. Member checking - providing the opportunity for participants to determine that they were accurately represented. This was achieved by verifying the accuracy of their demographic questionnaire and I followed up with participants on unclear transcript statements.

3. Peer debriefing - offers external review and input to further develop an accurate description of this study. An assistant professor, with an expertise in critical race theory and qualitative research, external to the Educational and Counseling Psychology Development offered feedback and served as a "peer 
debriefer" (Cresswell, 2003).

4. Rich, thick description_-Provided by in-depth interviews and perspectives form participants as well as descriptive writing that allow the audience (the reader) to be transported into the heart of the setting, discussion, and context of the study. I shared a detailed description of participants' experiences and rich quotes.

Summary

In this chapter, I have explained how I explored the collegiate experiences of African American men using qualitative analysis through screening and demographic questionnaires, individual and focus group interviews, reflective illustrations from participants, and examinations of critical incidents at a predominant White institution. Faculty and staff who have frequent interaction with African American collegiate men were used as nominators in the selection process of participants involved in the study. A critical race lens was used in this study's theoretical and methodological approach to further explore the lived experiences of African American college men at the intersection of masculinity and ethnicity. 


\section{CHAPTER FOUR REPORTING FINDINGS}

The impetus of this study was to understand how the lived experiences of undergraduate African American college men inform the construction of masculine and ethnic notions of their identities at a predominately White institution, despite disproportionate racial, hegemonic, and social barriers. Specifically, this research examined perceptions and critical incidents that nine African American college men understood as most salient toward successfully negotiating the intersection of ethnicity and masculinity. The counterstories of these college men gave voice to the authentic meaning they prescribed to their lived experiences as African American men at a predominately White institution. The following research questions guided this study:

1. How do African American college men characterize their ethnic identity?

2. How do African American college men characterize their perception of their masculinity?

3. How do African American college men perceive their performance of masculinit(ies)?

4. How do the ethnic and masculine identities of African American college men intersect?

5. How does being in college impact African American men's identities?

This chapter presents the findings for each guided research question. A critical race theoretical and methodological approach provided the framework for the study 
qualitative design and data analysis. Four major findings emerged from this study into the themes that follow: (1) dimensions of race and ethnicity; (2) dimensions of masculinity and manhood; (3) intersection of ethnicity and masculinity; and (4) college networks and relationships. These themes are used in this chapter to organize the findings and share the rich counterstories voiced by these African American college men.

\section{The Participants}

The demographic characteristics of the participants are presented in Table 2. Nine participants were interviewed for this study. All participants self-identified as Black for their racial identity and African American as their ethnic identity. For anonymity, participants were asked to choose a pseudonym instead of using their actual names. At the time of the interview, their ages ranged from 18 to 21 years of age; they were traditional college age undergraduate college males. Two of the nine participants were also fathers and none of the participants were married. Only one participant selfidentified his sexual orientation as gay. However, it is important to note that the status of participants' sexual orientation was not directly asked during in-depth interviews, as sexual orientation was not a criterion for selection.

All participants were current residents of the state of the institution, where four participants described living in a city (urban), three described living in a surrounding suburb of the city (suburban), and two described living in counties outside of the city or in the country (rural). Only one participant experienced part of his high school experience outside of the state because his family lived in Germany due to a two-year military deployment of his father. Four of the nine participants grew up with both parents in the household and the remaining households were headed by their mothers. 
Participants' parents' education ranged from a GED to a Medical Doctorate degree. Most mothers ( 5 of 9) of participants earned a degree beyond high school and most fathers (6 of 9) had not earned a degree beyond high school.

Most participants $(66 \%)$ were not first-generation college students. The academic classification of participants was comprised of two seniors, five sophomores, one junior, and one freshman, with diverse academic major courses of study and disciplines. The mean grade point average (GPA) of participants was 3.0. The participant profiles that follows in the next section was derived from the pre-screening questionnaire, demographic questionnaire and in-depth interviews.

\section{Participant Profiles}

Anderson. Anderson is a 19-year-old sophomore Political Science major, who initial considered Pre-Law. He was raised in a small rural county within the state, where his family and faith play a dominant role in his life's journey. He lives in the University's off-campus housing apartments with a roommate. Anderson is very involved on campus and enjoys opportunities to serve in campus leadership roles. Currently, he is the Diversity Chair for the Student Government Association and serves on the Executive Board of the University's gospel choir. He served these roles with passion and with much pride.

Anderson still has time to consider his options upon completing college, however, he is now considering pursuing a career in education. He plans to attend his current institution as a graduate student to earn his master's degree in education or secondary education. As a teacher, his areas of expertise will be history and government. 
Chris. Chris is a 20-year-old sophomore Premed-Biology major. He grew up in a small county in the state, 83 miles from the city where he attends the University. He was raised by his foster parents and adopted by them at an early age. Chris has a blended ethnic heritage because his biological father is Hawaiian (Pacific Islander) and his biological mother is African American. Since he never really spent time with his paternal family, he only identifies as Black and African American. It is important to note that the demographic profile of his parents included in Table 2 denotes the characteristics of his adoptive parents, not his biological parents.

Chris was most active with football in high school and although he practices with the University's football team, he volunteers his time with pre-college support organizations at the University, such as Upward Bound and Go College. He also has interests in joining a historically Black male collegiate fraternity, within the National Pan-Hellenic Council (NPHC), while in college. After graduation, he plans to attend medical school and become a surgeon similar to his adoptive father. He aspires to manage his own medical practice as a plastic surgeon.

DJ. DJ is a 20-year-old junior Premed-Biology major from a suburban area near the state capital. He described attending a high school where the majority of his peers were White and more affluent, differing from his lifestyle with his middle-class family at home. He has two older brothers, one of whom is studying law in New Orleans. His mother, who eventually obtained her master's degree, raised them all.

He is involved with two registered student organizations on campus that are specifically designed for African American males-Collegiate 100 and Student African American Brotherhood (SAAB). Collegiate 100 is a service, peer support, and 
community development organization, which is nationally affiliated and established by the local city chapter of 100 Black Men of America. SAAB has developed into a nationally affiliated peer mentor and peer success organization for collegiate men of color, particularly for the achievements of African American men. DJ is also a participant of the Louis Stokes Alliances for Minority Participation program, which is funded by the National Science Foundation to increase the presence of underrepresented populations in the STEM (science, technology, engineering, and mathematics) disciplines. After graduation, he plans to attend medical school to pursue a career in osteoplastic medicine.

Gee. Gee is a 21-year-old father of a two-year old son. He is a senior Sports Administration major whose family now resides in the state after his father retired from the military. He moved around a lot due to his father's service in the military and spent half of his high school experience in Germany. Just prior to attending the University, he completed the remaining two years of high school near a military base in the state. He appreciates the diverse experiences he had abroad, while traveling as a military family in service to the country.

Gee has played various sports growing up and played basketball during his later years of high school. He had an interest in playing collegiate sports, but focused his attention on the business side of sports and his overall college experience. With the responsibilities of being a father and a student, he managed his time well enough to become an active member of the Sports Administration (SPAD) Club and frequently volunteered selling programs for Athletics during sporting events. After graduation, he plans to pursue a career in athletic marketing and sports entertainment. 
George. George is an 18-year-old freshman Business Marketing major. He is from a middle-class suburban neighborhood, just outside of the city of the University. George is a very passionate person when he speaks of his family, his art, and his college experiences. George comes from a family of artists, so he is quite comfortable in embracing abstract concepts and eclectic perspectives.

George is active on campus with several registered student organizations, serving on the diversity and homecoming committees for the Student Activity Board, participating in residence hall programming and activities, as well as serving as a African American Male Initiative (AAMI) participant. AAMI is a national initiative to recruit, retain, and graduate African American undergraduate males at colleges and universities. As a freshman, he still has time to figure out exactly what he wants to do after graduation, however, he has expressed a desire to pursue a Master's degree in his chosen field of marketing.

Humphrey. Humphrey is a 19-year-old sophomore Pan-African Studies major from the same city as the University. Both his mother and his father raised him until his parents divorced during his early teenage years. So, as a young teenager, Humphrey took on more responsibilities with this family after his father was not a part of the household anymore. His culture, family, and friends are significant factors in his life.

Humphrey has eclectic interests; he took advantage of the opportunities that the University provided through student involvement. He serves as a peer mentor for African American first-year college students, an event coordinator for the Vietnamese Student Association, and has been active with the African Student Union. College was also an environment where he began to openly share that he is gay to some old and new friends. 
He did not necessarily "come out" to his family while growing up, but his parents independently knew he was gay. Upon graduation, Humphrey seeks to pursue his doctorate and career as a professor Pan-African Studies.

Jay. Jay is a 21-year-old senior Electrical Engineering major who is also pursuing a minor in mathematics. He grew up in the urban area of the city with his mother, sister, and four brothers. He described himself as always being the "smart kid" growing up, with his own style and taste in music and clothing, he stood out in the 'hood.' From urban apparel to skinny jeans, from listening to Wiz Khalifa to Animal Collective, he did not try to fitting in with a particular 'type' of peer group in high school.

In college, he continued to be himself, but also discovered opportunities to become involved with honors and co-curricular student organizations, such as the National Society of Black Engineers, became a Louis Stokes Alliances for Minority Participation Scholar, president of another prominent Black scholars' student organization, Collegiate 100, and is a member of Alpha Phi Alpha Fraternity, Inc. After graduation, he plans to pursue his career as an engineer as well as further his education by seeking a Master's of Engineering degree at the University.

La'Von. La'Von is a 19-year-old sophomore Biology major, but is considering changing his major to Psychology or Chemistry. He was raised by his mother and they lived in a government subsidized, low-income area of the city for much of his life. Although he grew up in a rough part of the neighborhood, he credits his mother's encouragement and confidence in knowing that his success was not defined by his circumstances. Without a college education of her own, she raised him to understand the 
importance of a college education and found means that permitted him to attend the University.

Although he is only a sophomore at the University, he became the president of the African American Male Initiative and is a participant of the Louis Stokes Alliances for Minority Participation Scholars program. He is a very outspoken person and holds honor as a top virtue in his life. La'Von definitely intends to pursue graduate studies and pursue a career as a pharmacist, psychologist, or a profession in the medical field.

Redd. Redd is a 21-year-old sophomore political science major and grew up in a similar urban area as La'Von. His cultural environment is a major part of his identity and what drives his passions today. Redd got into a lot of trouble as a young kid. He was in and out of juvenile disciplinary facilities well into his teenage years of high school. Also, Redd has a son and a daughter. He became a father at the age of sixteen. He was essentially forced to take on other responsibilities that he was not prepared for at a young age. His love and success with football allowed him to consider and seek out athletic aspirations.

In pursuit of playing collegiate football, he transferred into the University from the local junior college. Although he was not quite eligible for a scholarship to join the team, he still seeks to fulfill his dream of playing football. Meanwhile, he became a very active leader with the Student African American Brotherhood by facilitating topical discussions about the challenges and successes of African American college men. Redd has a passion for the children in his local community, particularly with regards to food, shelter, and mentorship. Beyond football, he hopes to pursue a career in law enforcement and create youth prevention programs in the urban community. 


\section{Presentation of Findings}

The themes that emerged during the data analysis process provided insight and lifted the voices of the lived experiences of nine African American college men at the intersection of ethnicity and masculinity. The major themes were confirmed to represent the counterstories of all and the overwhelming majority of data collected from participants' in-depth interview transcripts and demographic profiles. The interpreted counterstories are not intended to be representative of any individual participant, rather they are to be used to present themed representations of the collective insights of participants' perceptions and characterizations of manhood and masculinity, race and ethnicity. Therefore, a critical race theoretical and methodological approach was used to center the participants' stories across major emergent themes and categories.

\section{Dimensions of Race and Ethnicity}

Dimensions of race and ethnicity is the major theme addressing how African American college men perceived their ethnic identity. It is important to note, most of the participants had not thought directly and deeply about the meanings and perceptions associated with distinguishing race and ethnicity. What was most revealing were their perceptions about how their cultural environment delineated their racial and ethnic identities. Although, all participants have used Black and African American interchangeably, they all had a salient understanding of their Black racial identity and their African American ethnic identity. Particularly, how their understanding of race and ethnicity intersect, overlap, and sometimes stand in conflict. Due to a legacy of negative racial perceptions and experiences, the participants describe racial stereotyping, being feared, and their understanding and strategies used to negotiate society's racial animus. 
Ethnic Identity as Culture. Unlike their racial identity, all participants had a greater understanding about how they personally described and expressed their ethnic identity. In contrast, the terms Black and African American were often used interchangeably, without much difference. As presented in the next section, race was more of a nebulous topic for participants. However, they fundamentally associated the term race with their skin color along with the impact of racial stereotypes historically defined by a White dominant social structure.

Participants talked about their ethnicity more intimately than they spoke about their racial identity, primarily because their ethnic identity was more representative of their culture, heritage, and lived experiences as African American men. As African Americans, their ethnic identity held an interpersonal meaning because they associated it with a name that was chosen by Africans Americans as opposed to a racialized term given to them by society's White dominant social structure. As Redd explained, "Well, I think ethnic identity focuses more on culture; where you came from, your background and race is just, like a way that society can define you as one person, as a group." Anderson said, "I would identify myself ethnically" despite how society or other African Americans may identity themselves racially. Consequently, he further explained, "I just feel like an ethnic group is those that you are, like, those that have the same culture as you, those that have the same upbringing maybe as you."

Humphrey believes that he must look at the significance of his ethnic identity from a historical context to begin to have a better understanding and appreciation about the contemporary perceptions of African Americans' ethnic identity. He said, 
In the 60 's and 50's and stuff like that, nobody really referred to themselves as African American, we were Colored or we were Black. It kind of just changes with time on how people identify themselves as far as the African American, Black and Colored and Afrocentric type identifications go. Now, I think it's more the contemporary thing to do is call yourself African American...for some reason ethnicity, especially just in college, it's super important. People really take pride in their ethnicities and things like that.

Jay shared his perception about his ethnic identity and asserted, "I think the most thing that my ethnic identity taught me about myself was to question a lot of stuff." On one occasion, Jay recalled having an in-depth discussion with his fraternity president, both strongly disagreeing with a film's premise that suggested the African American community is in a state of crisis because they were not "spiritual" enough. On the contrary, he argued that the challenge faced by African Americans was not spirituality, but rather how slavery impacted the knowledge of African American culture and heritage. Jay explained,

I'm like, I just can't get with that because I think we, as Black people, put religion in more stuff than anybody, to be honest. I was like, more spiritual? It's more than that. It's because we didn't get a chance to be established just because we had 400 years taken away from us, so we don’t know where we come from. We don't know our heritage and it's more towards that and it's like we're tryin' to build an identity, now. I feel like that's more what separates us. That's why it feels like we're not really assimilated because everything we do, it has to be us, it has to have our mark on it. It has to be like, 'that's Black people.' 
Unlike race, participants draw upon the historical significance of their ancestry. Participants also expressed a pain and appreciation for what African Americans had to endure to establish an ethnic identity in American society. Although many expressed slavery and the struggle for civil rights were impediments toward a deeper understanding of their culture, they expressed a pride in defense of what African Americans have accomplished and a commitment to what they did understand of their African American cultural values.

Community Commitment. The presence of African American men who "step up," serve, and give back to their local communities or the African American community in general, was a salient theme that was characteristic of African American culture for six of the nine participants. For Chris, "real" African American men just don't help themselves, they help their community; and they can also be found in African American churches.

The real men aren't seen, you really don't see the real men...People now want to be put on a pedestal for doing good things. When [you do] good things, you don't necessarily have to be on a pedestal, you can just help one person out. You don't have to help, well, I mean it'd be nice to help some people out, but good work isn't always noticed. God always notices and that's what really might get you there. Say a man helped about a thousand people, but you've helped one man to become the President of the United States of America, that's a big deal...I say these Southern Pentecostal, Baptist, Missionary churches are where you find them. You don't find them out in the open.

Chris also said, 
Being in your culture, being active inside your community. You got to be active in your community. We need the village to come back, as my dad told me, because the village is gone. We need strong Black males to get into our kids mind to stop them from going to jail. Too many men aren't taking the responsibility to help each other out...I say it's a very, very strong responsibility for us to step up, because I say our real men are gone.

Comparably, La' Von also believed that it is important for African American men to be compassionate and give back to their communities. Yet, differing from Chris, compassionate and giving African American men "may have his problems," and consequently, they may not be necessarily found inside of the church, but rather on the streets of urban communities. La'Von argued,

When I think of the Black man, he may have his problems, he may sell drugs and do what he do, but you know he got a good heart. And having a good heart is part of being a good man. So I think that's one of the most important things is, Black men have big hearts. No matter what we out here doing, no matter what we trying to get, it's usually not just for our benefit. We trying to help somebody else out. Someone that can't help themselves out. You know, someone who can't go out there and do things that we're willing to assist to help themselves.

Participants' perception of their ethnic identity was tied directly to their culture as well as their family and within their communities. What is significant about this theme is that all participants also expressed that in order to understand their culture, they must be an actively involved or contributing in some way in their communities or play a significant role within their families. Essentially, their community was a representation of 
themselves and they were a representation of their communities. This attitude was necessary to prepare them for a society that may perceive them negatively, affirm who they are and their communities.

Race and Racial Stereotyping. When participants initially spoke about their understanding of race in their lives, all defined race phenotypically, 'black,' referencing the color of their skin. However, in further responses to probing questions during each in-depth interview, the significance of race with regard to the color of their skin remained, but was much more pervasive by the messages passed on to them by family members and then internalized overtime. La'Von described the underlying dialogue about how the color of his skin created a barrier between himself and others:

You know, just subconsciously, the color of my skin might make some people not wanna, like, mess around with me, especially, like, the professional world; unless I really look like I'm down here to handle business. They may think I'm playing just 'cause the color of my skin...I mean, I would guess, 'cause it's not really something that you think about. 'Cause I've been Black my whole life. I mean obviously you have your situations where it's, like, 'okay, yeah, everybody recognizing that you're Black.' Like, when you walk down the street and someone just crosses the street. Happens to me, like, on campus all the time. La'Von was not happy about the situation, but just like all the other participants in the study, being subjected to racial stereotypes and having to expect similar racial barriers in his life experiences did not surprise him. Anderson shared his perspective about "always" being stereotyped by society, in the past and how it impacts his future. Anderson explained, 
I just believe that that's the way it's always been. I think that they've always put us in the same stereotype that they put us in now. I feel that $40-50$ years ago, that the stereotype was still, 'we do this, we dress this kind of way, we go out, we drink this kind of stuff, we listen to this type of music, we're always in this crime system, this criminal justice system,' so I feel that that stereotype kind of carried over to 2012. That's the way it's always been.

For Anderson, these racialized stereotypes have, in effect, become social norms that African American men have come to accept as an underrepresented population in college and in society, particularly within an environment of seemingly diminished opportunities for other underrepresented populations. Anderson rationalized:

Just like, when we look at White people and we see that they've always been the majority, we see that they've always been able to succeed over other minorities. We see that they're able to get better housing, better jobs and stuff like that and that's how it's always been, so that's what we see now in 2012. I just think the stereotypes have always carried over.

Whether it was a mother, father, grandparent, uncle, or someone in their lives from school or at church, the majority of participants shared that they learned at an early age what effect these stereotypes may have on their lives. They were taught these lessons to prepare them in the event these African American males become subjected to racialized experiences. George said he was around six or seven when his parents taught him similar lessons - his father taught him the majority of these lessons. George recalled, "I mean it's not that I understood it, it's that I locked on it...then as situations come up...I'm like, 'oh, this is what they trying to say!" His father once explained to him: 
Like, 'I know what you're gonna have to go through because I had to go through some of it. I mean, obviously it won't be as hard for you cause I actually had to go through it in a time where that was prevalent.' But I heard it from them, I heard it from advisors or whatever and then I also heard it from here [at the University]...AAMI was saying that.

Anderson shared a critical incident that happened to him while playing soccer. At an early age, it was one of the first times he had to consider how his race might negatively impact his life. Anderson recalled, I can only remember maybe a few times that I've had to actually think about it and that was just like growing up. Like I said, I've always been aware that I'm Black. I've always been aware that I'm an African American. I've always known that there's always 'strikes' that are at us before we're even out of the womb... I remember like, a time where I first started playing soccer and soccer is a predominantly White sport or predominantly a Latino sport. So, at that time, I knew that a lot of people on that team had played soccer for several years and they were the sons of doctors, lawyers, you know, that's usually what it is. I came up in an upper-middle class family so I was on the same level as them, but my parents weren't doctors and lawyers and stuff like that. But, I guess I first became aware like, one of the times I was actually aware of my race was when I knew that I was putting in the same amount of work that they were, I knew that I was just as good at soccer, if not better than they were. But yet, it was like I had to suffer because I knew that they're parents were higher up in the rank or something such as that. So, I was benched and stuff like that, even though I knew that I had the 
same amount of skills that they had acquired. But, I think that's one of the times I realized, you know, [my race].

All participants attempted to rationalize why they were being stereotyped or were the subject of racial stereotyping in society. Some participants perceived they were stereotyped out of fear or because the majority of society had a limited knowledge of people of African descent. Gee described learning a lot about the "different sides of racial attitudes" while living among diverse populations of peoples in New York, Tennessee, Kentucky, and Germany. He described walking downtown in a major city in Germany with a White male friend (whose parents were also stationed there in the military) when a White German male, that they did not know, bumped into his friend. The German male got upset and Gee told the German to "Chill." As he recalled, "[the German] apologized to me and was like, 'Tell your friend I said I'm sorry for bumping into him.' And that threw us both off!" He said it was "weird" because the Germans gave him "respect, just because you're Black." On the contrary, it was explained to him by a German American male friend that Germans were "scared of Blacks."

La'Von proposes that the White community may perceive African Americans negatively due to a lack of understanding.

I still like think [White people are] a little scared of Black people...it's so commonplace to hear that being said. I think they actively try to resist that fear...I know some White people that grew up in Black neighborhoods and like...being Black doesn't mean nothing to them. They been around Black people their whole life, they're used to that... what you don't know, you fear. That's human nature. 
To be stereotyped, to be feared, and to be looked upon as the 'other' was a tremendous burden to carry with them, especially when they were not certain why they were pigeonholed by a society who did not know, but focused on negative perception of who they are and who they may become as African American men. Yet, in the all of their counterstories, they did not express hopelessness. The racial stereotypes of society were, in effect, tied to their resilience.

Impact of Others Racial Perceptions. All participants described several ways by which they understood how the majority of society perceived them and a large majority of participants ( 7 of 9) had considered how society continues to impact how they see themselves. Moreover, all participants were filled with a strong resolve not to become paralyzed and victimized by racial stereotypes. When DJ was asked if his race was a major part of his identity, he had mixed thoughts about the notion. He responded, "Yes and no," but acknowledged that the racial perceptions of others were influencing factors about how he thought about his race and ultimately himself. DJ further explains, I mean obviously, other people see your race more than you 'cause to you, you're just you. I think other people shape the way it affects your life. For instance, if you grew up in total darkness and you were a Black male or a White male, nobody would know. Nobody would know the difference, so your race would play no part of your life. But, when other people say something about it and even if you looked in the mirror that would be what you knew. But, if other people say stuff, it changes and it kind of shapes your perspective, not necessarily that you believe everything that they say and that they think, but you get an understanding of what other people do see. 
Redd asserts that there is "a whole bunch of negativeness about Black people," such as being "selfish... aggressive...fight...It can go down the line." He also explains that society, "they don't see Black people everyday" or "wearing suits-and-ties." Beyond the overt impact of racial stereotypes, Redd admits that he does not think deeply about the meaning behind his racial identity or, for that matter, have given significant thought about how society might describe his racial identity. It was not a topic he spent a considerable amount of time discussing with family or peers in high school, however, he understood and have experienced the impacts of racism and racial stereotyping.

On the contrary, Chris was explicit about how society "racially acknowledged [him] as being ignorant, stupid, failure, never complete anything." Based on society's perceptions, he said, "I know that's what my racial [identity] tell me that I'm obligated to be." As mentioned earlier, for all participants, these types of social perceptions did not diminish their resilience. Chris explains, "it tells me I need to stand up and change. Change what other people think about me." Similar to all participants, they were taught early lessons about what racial prejudices they could be subjected to. Chris learned to, "just ignore those stereotypes that people put on us."

Intersection of Race and Ethnicity. Guided by the tenets of critical race theoretical and methodological strategies, I was able to offer a space for participants to be able to elevate their own voices, by centering their interpersonal and intergroup understanding, to critically think about how they dismantled and made meaning of their racial and ethnic identities. Participants revealed an intracultural dialogue about how they understood their racial and ethnic identities based upon their environment and how 
they adapted to how a predominately White society's perceptions of them racially and ethnically.

These African American college male participants noted that the perception of their racial and ethnic identities were informed by their lived experiences within their sociocultural environment and how they were taught to modify their language, style of dress, behavior, and other cultural expressions of Blackness to adapt within a predominantly White society. Seven of the nine participants attended high schools that were considered predominately White and most participants lived in communities that were predominately White. All participants recalled critical incidents when they either modified the way they spoke, attitudes, and behavior to avoid being singled out, left feeling isolated, or racially stereotyped within or outside of their communities and within their schools.'

For some participants, there was a challenge in negotiating the intragroup struggles of locale and class for African Americans who had urban and/or low socioeconomic status backgrounds, but tended to see themselves more racially or narrowly with regard to their identity. There were those African Americans who understood broader understanding of their racial and ethnic identities; who understood the historical significance of race and began to make distinctions about their racial and ethnic identities.

Anderson is from a predominately White rural community and explained how he understands his ethnic identity, 
I would identify myself as ethnically, maybe? Because I am African American...I just feel like an ethnic group is those that you are like, those that have the same culture as you, those that have the same upbringing...

Redd finds it difficult to relate to or know how well other African Americans relate to him if they were raised outside of predominately African American urban communities. Redd understood that, They are Black, but they don't have the same struggles as me and like a few other guys...Because you have the Black that came up in two-parent households and then you have the Black that came up with one [parent] and struggled and that's an issue. [SAAB] had a talk about that actually the other day and it was a lot of bickering and arguing going on and I was agreeing with both sides because I'm not one-dimensional.

Redd also critiqued his community, Where I'm from, you don't see suits-and-ties, you see pants saggin, a whole bunch of chicks running through, so it's kind of hard to fight a stereotype when no one else wants to fight with you.

Similarly, La'Von grew in the urban area of the city, but his mother was able to later move them out of the "hood" and into more of a suburban area of the city. As a result, La'Von was able to speak about the intracultural shift between one African American community that was prescribed more negative racial stereotypes to another African American community that received less racial stereotypes. La'Von said, I mean, I guess not, cause like I said, I lived in the hood, moved out the hood, and I had a really good mother. So I'm not like that gangster guy...I don't look that 
threatening. You know, I look probably like a normal Black person. I know I don't look like a suburban Black person. If someone see me walking down [a street in a popular part of the suburbs] they'd probably be shocked. But you know, not nobody walking down [a street in the hood] be scared of me. You know what I'm saying? I guess I'm in-between. That's one of my deep, internal struggles is like trying to like fit in, especially when I was younger. The real hood kids be like, 'you're from the suburbs. You don't know struggle,' such and such. And then you just a little too hood for the suburban Black kids. So it's like, kinda like in my own little group.

Participants realized that their experiences as African American men were collectively varied by their respective communities, but linked together by their shared expressions of culture and heritage. Many of the participants shared that were, at times, culturally isolated, as mentioned by La'Von and by Redd. Discussing these variations between the 'hood' and the 'suburbs' with other African American men during the focus groups as well as during the in-depth interview provided them the opportunity to learn more about themselves in the reflection of the experiences and perceptions of other African American men. Doing so might demystify some of the cultural isolating obstacles placed in the path of African Americans, particularly African American men who might not engage in opportunities to critically think about the how and make meaning of their identities.

Culture as the environment. All participants indicated that their environment influenced how they perceived their ethnic and racial identities. Their background, primarily the geographic areas where they and their families lived, contributed to how their daily experiences were framed by unique understandings of racial stereotypes and 
their background as African Americans. When asked to describe their ethnic identity, all participants defined their ethnic identity as an extension of their cultural background, although it varied as ascribed by where they lived, the perceptions of society and their communities, including their own interpretations. DJ noted,

It depends on the group that's looking. If you asked another Black male about my cultural identity, they would just be like, 'He’s Black. He's just like me.' But, depending on the person who's describing you, depending on their backgrounds, what they've seen in their life, their environment, they'll have a different definition.

Based upon the participants' group and in-depth interview statements and their demographic profiles, their geographic environments were respectively established by rural (2), urban (4), and suburban (3) communities. Each environment had social cues and stereotypes about how they came to understand their ethnic and masculine identities.

Rural. Anderson and Chris were the only two participants from rural communities. They describe how growing up in rural community shaped their perception about their ethnic and racial identities. Growing up in a predominantly White rural community, Anderson reflected how engaging in shared experiences with other African American families in his small rural town, such as church, was a contributing factor toward affirming his ethnic identity. Anderson explained,

I was raised in [a small rural town] so that's a predominantly White community, but when we would go to functions we would be with other African Americans. Say like, a church function or if we would go out to eat just with any ole body it 
would probably be somebody that we would be in conjunction with in the same ethnic group, African Americans.

When asked of his perception of how others described his racial identity, Chris said, "I don't think they would. I mean, some people see me as being country." He continued, "I have a hard time trying to understand what country is when you just being yourself." Chris was also asked if his racial identity a major part of his identity, he responded,

No. Because I come from a place where... where I've been raised has many White people, and they didn't see color down there in that city. But, as we ventured off, we'd get 5 miles into the country and it would be a totally different thing. They would be like, "What are these coons doing here." I don't see Black and White. I don't, because I think in order for us to be successful we all as human beings, have to look after each other.

Because of the predominantly White rural environment Chris was raised and because of his multicultural background, he was also asked how did he describe his ethnic identity:

I don't even know because all I know is Black, I haven't vibed with my [biological] dad. I've only chilled with my [biological] dad two times and I'm 20 now. I haven't even met my grandmother. I really don't know that much, I just know I got Hawaiian in me.

Chris also described his African American identity:

Oh, yeah. I know my African American identity. I just say being yourself, don't let, I don't let the environment get to me. That's all I can really say about that... 
When it comes to my ethnic identity, I feel that the African inside of me has stuck with me the most. I don't, the only reason why I'm 100\% real because, I know this is serious business, but not too many people know I'm half Hawaiian. I don't feel that connection with my Hawaiian people.

It is important to note that Chris did not initially indicate the ethnic backgrounds of his biological mother (Black/African American) or father (Hawaiian/Pacific Islander) on the demographic survey; Chris listed the racial and ethnic backgrounds of his adoptive family, both Black/African American. His adoptive family provided the basis for his understanding and appreciation of his African American culture. The small rural town in which he was raised "did not see color," however, he acknowledged that his county was very racist, so he had a holistic understanding about the racial perspectives of his broader community.

Linking Rural to Urban. Redd had not always lived in an urban environment. He spent many summers in a rural county in the state with family. He appreciated those experiences "in the country," which were culturally different than his experiences in the city. For example, he shared that he enjoyed riding horses, an experience he admits that most people from his neighborhood would not have experienced and would be considered what White people do. Redd recalls the cultural transition he must make when living between a rural and urban community. Particularly, Redd shared his perception that he must assert himself aggressively when shifting back to an urban community:

I used to spend my summers down in [a rural county], so it was like a different type of culture, some more people. I noticed like, when I go to, I used to go to [another rural town in the state] when I was young and everybody use to wave, 
there wasn't no mean muggin' goin' on [like you would see in my urban environment]. I used to catch myself when I'd come back home from the summers, I used to catch myself waving at people and they'd be like, 'What are you doing? Why are you waving at me for?' And I'd be like 'okay,' like, I'd give them the head nod and 'what's up.' It's a different culture down there, everybody is loving and caring and not aggressive. But, up here, that would be considered 'soft'.

Urban. Jay differentiated himself from his White counterparts and his African American counterparts because of his eclectic attitude and interests as well as because of his overall independence. Jay never tried to fit it any particular group, but he shared that he was racially stereotyped because he was often times the only African American student in AP classes in his urban high school. Jay acknowledged that he has an "urban demeanor," although because of his high academic achievements, he did not fit into the stereotype of an urban African American male. Jay explained,

So, just that demeanor, I think I have more of like an urban demeanor or something and so people don't realize how smart I am or to the extent of how smart I really am...It goes back to like I was saying, when people who don't know me would see me and don't think I'm smart. It's just when you see just that color, you have these stereotypes and stuff and that's more what I see. Like I said in the focus group, I really didn't have to go through a lot of this stuff like they was talking about. It's more on an extreme level, especially with people that live like, in rural areas and you can see more of the hate cause they're more open with it. But, when you're in the city it's more concealed, but you know it's there. You 
know people talk about you. You know people use the N-word. You know they make little comments and stuff too.

Linking Urban to Suburban. La'Von, reflected upon his experiences of living most of his life in an urban area and then living in a suburban area. Essentially, La'Von described a transitional process that was necessary for him to adapt his cultural attitudes and perceptions within each environment.

I think it's cultural...I think it only makes sense that I hold some of the views of both of them because I kinda lived, I kinda did both, I lived in the hood a little bit, and I kinda lived out of the hood a little bit. So like even though I kinda had to have that hardness about me, that aggressiveness about me to survive, you know when you move out you gotta understand there gotta be some softness about you, understanding about you, that if you had stayed in the hood you never would have been able to acquire. I think it depends on where you come from, like I don't know that many guys from the hood who feel like showing your emotions is a key component of being a man, you know, and I don't know that many guys from the suburbs who feel like being aggressive is the key component to being a man. Just me having kinda having lived in both environments kinda have like a fusion or synthesis type view on it.

Suburban. DJ was raised in a predominately White suburb neighborhood, about 30 minutes outside of the center of the city. DJ described himself as a high achieving student in high school and in college. Because he attended a predominately White high school, he often had experiences of racial stereotyping. He recalled an incident where he 
did not meet the prescribed expectations or stereotypes of his White student peers as an African American male and was often accused of being "White" or "not Black" enough. I mean growing up, obviously, I always knew I was Black and stuff and family reunions, but growing up in [my suburban neighborhood], where it was predominantly White, I mean it was obvious that I was different, that things were gonna be a little different for me. I always knew, but in [my suburban neighborhood] there was a lot of the stereotyping of, 'Oh, you're Black. You're gonna do this. You're gonna do that.' You're gonna fit all the stereotypes. But, I didn't find myself fitting a whole lot of the stereotypes cause most of them were negative. But then, once I got to college, it was cool because I got to see that I'm not the only Black guy who's not just getting into stuff.

The negative stereotypes were more like, ‘Oh, you're Black - you don't smoke weed?' 'You're Black - you're not gonna rob somebody?' Or like crimes, for the most part. Some of the positive stereotypes were just like that I was outgoing, that I was social. Like once, one of the kids from my high school, he would always say, 'Oh, it's cause you're Black.' If I made all A's he would be like, 'Oh, you're just...' Like everything he said was it's just cause I was Black, but I think he was just being silly. But, I think they did see like, if I was ever outgoing or if I talked to everybody, if I knew a lot of people, they would be like, 'Well, it's because you're Black.' I think they kind of saw it as like, 'Since you're Black, you're different. You kind of stand out.

Yea. It was crazy to me because hearing like, a White kid say, 'You're White.' It's like why would you even say that, first of all? I would tell them, 
"First of all, if you're saying negative stuff, like you're downing yourself." I'm like, just because if I want to achieve, I'm being 'White' and I'm not being 'Black' anymore. It's because I'm doing something other than a stereotype. That makes me not Black, that makes me less Black. That's something that I feel like I still see a little bit, a lot less [here in the city], since getting to college where I feel like people are a lot more accepting and cultured, I guess. But, in high school, it was definitely a feeling that people just didn't understand more than what they had seen on the news, on TV, of what they expected to see. That was all they really could think about.

So, if you did something different then you weren't...like they're idea of Black, you weren't doing that. Everybody's got their own preconceptions about what it means to be Black and to a lot of them, like from [my suburban neighborhood], being Black was a lot of the negative stereotypes and just the stereotypes in general. But, none of them ever really saw the high achieving, Black man, like the Black doctors and lawyers. They didn't really see that, so they couldn't really relate to that or picture that.

As DJ mentioned, because he was an outgoing person, he socialized with everyone, Black or White, but he was stereotyped by his White counterparts for not living up to their expectations of what a African American male should be. Out of a senior class of one hundred and forty-six students, seven were African American. He shared the perceptions of the other African American students, particularly how they did not stereotype him as being "too White" or "not Black" enough. He said that they looked up to him and his achievements: 
A lot of the other Black students just like only hung out with other Black students. I wasn't that way, I kind of hung out with everybody. I think they respected me for that, but none of the Black students ever said I was acting White or doing anything like that. They were like, 'You're achieving. You're doing good.' They seemed like they were proud of me and some of them kind of seemed like they looked up to me. Whereas, the White kids, they more looked at it like, 'Why are you doing this?' Not like they were intentionally trying to push you down, but that's really what it comes down to.

DJ further explained that, I feel like Black culture, a lot of times, is more accepting. Especially, the Black culture that's in predominantly White areas because you know you have no choice but to interact and, not necessarily just deal with, but interact and thrive with what you have around you.

For all participants, they seemed to develop the necessary skills and instinct to more than cope with the social impact of race, but to be resilient at the intersection of race and ethnicity. Their families served as a socializing agent and prepared them to live and 'thrive' in their communities. In the next theme, participants explain how they use 'code switching' to tailor their social skills to successfully adapt in environments where they are underrepresented.

Code Switching. An overwhelming majority of participants (eight of nine) indicated that they practiced modifying their language, style of dress, behavior, and cultural insight for the purpose of adapting to, or fitting in with a dominant White society or navigating between that White society and the cultural characteristics of their own 
environment. Many of them referred to this practice, as it is commonly known, as "code switching." Some have simply shared incidents where they acknowledged the need to "shift" or "switch" their style of language or cultural expressions with those who were not African American to be able to communicate effectively with them. By doing so, they effectively limited or hide their natural voices and performances of their ethnic and racial identities. Performance of this practice did not unsettle participants, as it was commonplace and lessons learned from their backgrounds, from their parents, teachers, other role models, and peers. Some participants mentioned that they used code switching as a method of survival.

Talking 'White'. Redd lived in a low-income urban community and recalled learning how he learned to code switch from observing his grandmother. He did not use the terminology 'code switching,' but referred to the same practice as turning the "hood off" and turning the "hood on."

I have a great like, my grandma is great with teaching me how to turn my hood on and hood off. So honestly, if you talk to them on the phone you wouldn't even know they was Black cause they don't talk like they're Black.

Chris said that he grew up in an upper-middleclass rural community with his adoptive family and his parents found it necessary for him to know how to best negotiate living in a predominate White society as an African American male. Chris enthusiastically remarked,

My foster family has like, zoomed me in on everything! Your looks, you always gotta have a fresh haircut, make sure you always looks presentable. Make sure you always have your pants above your waist. Just ignore those stereotypes that 
people put on us. They've taught me to code switch, to make sure I can talk to my race and be able to talk to White people at the same time.

Chris continued about how he observed the "switch" by his adoptive father, from home to the office.

Dad, (laughter), Dad's a thug, at home, Earth, Wind and Fire, Teddy Pendergrass, everything you could ever think of, but when he goes into that Doctor's office, its "Hello Sir, how are you doing..." blah, blah, blah. You can hear the proper English speak up! When he at home, "What boy, what the hell you want?" Just that switch. Yeah. You just gotta' be able to know the streets and the books. Code Switching to Establish Relationships. Gee used a form of code switching that allowed him to establish meaningful relationships with peers of diverse backgrounds. Gee said that one of his most valuable qualities about him is his communication skills. Because he was able to use his communication skills to code switch, it provided him the opportunity to learn and adapt to a broader range of cultures without changing himself. My communication skills. That's a quality I think is the best for me because being with that diverse background, being that my dad was in the military, I've seen a lot of different ethnicities and races and how a lot of cultures like to interact with each other. I've actually adapted with being able to communicate with different races and genders...I witnessed these cultures, I've learned from those cultures, but it didn't change me really. It just lets me know, 'Okay, this is what they do.' I learned how to adapt with their cultures at that time. 
Unlike Gee, Jay did not make it a habit to code switch with a diverse group of friends. However, because of his "urban demeanor," he did find it beneficial to code switch in establishing career networks in a professional environment.

I don't code switch with people in my environment, but I will code switch when I'm at work. So, the way I talk at work is, in a way, more proper and way more structured than I would anytime else. But, when I'm just around a group of people, it don't matter what race, what age or anything I'm gone be the same no matter what.

Jay also explained his rationale behind code switching and recalled an instance where he found it helpful to code switch with a White roommate while living on campus, When you're with your race or you're with your ethnic background group, you don't really bring that kind of stuff up because you're with them. It's like a commonality, so you don't have to bring it up. But, when you're with somebody else that's different, it's gonna' come up because ya'll see things differently and then it's more of like how do I adjust to that?...Like living in the dorm with a White person, I had to really adjust the way I talked to him, the way I came at him cause we was just raised differently.

When asked if he was being more conscious about his own race and ethnicity or the race and ethnicity of his roommate, Jay responded:

I think it has to be both, but if I had to put one over the other, it would have to be more of his racial [identity]. Just because, I would want to respect his racial [identity]. 'cause I could just go full-blown out with mine and have no disregard [sic], but, like I was saying, I still have to understand his too and some people 
don't return that kind of favor. I was lucky to have somebody who did and so we actually got along that way. But yea, it's just more like trying to understand his.

\section{Dimensions of Masculinity and Manhood}

Dimensions of masculinity and manhood is the major theme addressing the second and third research questions: how African American college men characterized and perceived their perception of masculinity. For most of the African American college men, masculinity was characterized by phrases that were derivatives of "handling" or "taking care of your business." This theme characterized their masculine performances as a student, as a father, and like a father would ensure their respective duties and responsibilities are accomplished. The attitude and determination associated with their characterization of masculinity is driven by being "strong," "emotionally strong," their faith, values, and respect. Participants learned most of these lessons of duty, strength, and masculinity at an early age from their fathers', father figures, as well as mothers' and grandmothers' who held significant roles in their lives. Manhood was a developmental process that assumed traditional male roles as the provider, problem solver, and protector. Achieving manhood involved taking responsibility for these roles through experience.

\section{Duty, Strength, and Masculinity.}

"Handling your Business" as a student. The phrase "handling your business" is used in this section to summarize an overall theme participants used to characterize their perceived performance of masculine characteristics with their sense of duty, responsibility, and being "strong" as an African American man. La'Von prioritized how he handles business by attending to his responsibilities as a student, being a "critical 
thinker," and distancing himself from the criminalized stereotypes of African American men. La'Von explained, I mean, when I say being about your business, I mean like, I guess for me, like at my current age, I mean it's like you doing something with your life, you're in college, you're trying to graduate, you got a plan. You want to succeed. You ain't out here doing drugs and doing other shit that's gonna affect your education, you know, that type of thing, you doing the type of things you gotta do to succeed when you get older. That's what I mean by handling your business. And when you get older, handling your business is just like you know like if you got a family, taking care of your family. You got bills, you paying your bills. You going to work. You ain't late to work all the time. You ain't coming to work drunk or high. That sort of stuff. I mean, it don't take a lot, you don't gotta be rich, you don't gotta be wearing a suit to be handling your business. You know, you just gotta be, you know, out there doing something with yourself. Not just sitting around not doing anything.

"Handling you Business" as a father. Eight of the nine participants described the significance of their fathers' as contributing towards their overall perception of their masculine identity. All participants described the significance of being or understanding the meaning of fatherhood as a function of their masculine identity. As a young father, Gee recalls an incident involving his son, where he suddenly exercised his duty as a father in response to an emergency. Also, he contextualizes the meaningful relationship and implied response from his roommate who provided supported to him throughout the incident with his son. 
Yea, me and my roommate, same roommate I have now, it was my sophomore year, we're here and we had just got done playing basketball. We had just walked into our apartment door, sitting in the living room talking and we'd been talking for like 20 minutes when my phone rings and it's my baby's mother. I answered and was like, 'What's up?' She was crying, bawling, just screaming, 'Get up here now, something's wrong with [Junior]! I don't know, we've got him in the hospital.' I grabbed my bag and I'm talking to her, I just get up with the phone and start walking to my room going, 'What's going on?' This is why we're so cool now, like I didn't have to say anything to him, my roommate, at all, I walked into my room, pulled all my gym stuff out of my bag and just threw in a couple clothes for overnight, zipped it up. By the time I walked out of my room and locked my door, my roommate was locking his door and that just let me know like, this is who I need to be with, like this is one of my friends. Didn't say anything to him, he didn't say nothing to me, I'm walking out the door and he's like, 'Let's go.' And we're going to [the other county], it's not like it's right around the corner, we've both got class the next day and all that he was like, 'Forget it, your little boy's in trouble, we're riding out.' Just as simple as that. 'I'll drive, just ride.' But that whole night and that whole month, as a matter of fact, just made me realize like well, it's real, this is becoming a man. Most teenagers, when your kid's in the hospital, if you have a kid as a teenager, first of all, you're not ready for that responsibility, I don't care what anybody tells you. I thought I was ready. I wasn't ready. 
“Handling your Business” like a father. Humphrey describes how his perception of masculinity was formed from lessons learned about his father, who compensated the absence of his own father by demonstrating what a "man is supposed to do" as an active father in Humphrey's early life experiences.

I guess I could say I learned a lot from my father because he grew up in a household with four women, his father was not really around, they didn't even really start talking until my father was in his late 20's. I think just him, he was trying to make up for what his father messed up on, so he always used to tell me that you try to make your kids better than you are. So, he was trying to be a better father so he did stuff like signed us up for sports, he went to all the games and stuff like that, so I think that taught us what a man is supposed to do, or at least attempt to do.

“Emotionally Strong”. Participants used terms like toughness, backbone, confidence, assertive, and hard to describe what they perceived as characteristics of masculinity. All participants used the word strength or being strong to describe an important characteristic of masculinity. For participants, "strength" was characterized in two different ways. One characterization restricted men from showing emotion and crying. The other characterization of strength included all of the terms acknowledged by participants in the aforementioned characteristics of masculinity, but permitted men to show emotion, even cry. Eight of the nine participants believed that men can show and through expressing their emotions, they were showing strength. While referencing how to show strength through his faith, Chris said that his father taught him men can me "emotionally strong" and not to "hide your feelings." 
La'Von captured the sentiments of the participants who described many of the traditional characteristics of masculinity, but did not completely agree with the hegemonic ideal of masculinity that men should not cry. La'Von explains,

Oh, man, I think this list, I think you have to be honest, you gotta be honorable, you gotta be inspiring, you have to, like, you know, be assertive and sometimes aggressive you can't be all, like, timid... There was a song and it's called, "Must Be Life" by Life Jennings and at one part it's, like, "you want someone who's as mighty as a lion, but as gentle as a bird". You know, you gotta be able to be, like, be a man, be strong, be assertive, but you still gotta be able to understand the, like, the frailties and stuff of like other people. You still gotta be able to understand emotion. Cause the truth is, if you don't show any emotion yourself, how can you understand it? It's gonna be foreign to you. And what type of, what good man can't understand, like, if you have a wife, and your wife is sad, your wife is crying, a good man should be able to help console her, a good man should be able to help bring her to ease. A man who shows no emotion won't be able to understand what she's going through. He won't be able to do that. I feel like that's important, a lot of Black guys, you know, well you know, you're a man, you're not supposed to show emotion, you're not supposed to cry, and I'm, like, dude, that doesn't make any sense. At least not to me, that doesn't. And you gotta be confident and inspiring. Inspiration, that's something I recently started just getting big on. Man, you gotta inspire.

Faith, Values, and Respect. The majority of participants ( 8 of 9) listed their faith, values, and respect of others as fundamental characteristics of masculinity for 
African American men. Anderson noted that, "I think that some of the values and morals that I possess is because I am Black. Being taught some of the stuff that an average Black family would be taught." All of these characteristics of masculinity were taught to them by family members, their mother, father, and the church as well as by people in their local communities. At early ages and as young adults, they continued to learn how to become men who were respectful, with strong moral values, not only as a personal expectation, but also on behalf of the African American community. Chris explained lessons learned from his father:

Dad says, make sure you are a man of God. Protect your family like it's your soul. I'd feel right now, if a man ever came at me with a gun, my dad would definitely jump in front of the bullet for me. That's the kind of protection he's told me that I need to have for my family... you got to have responsibility in order to gain other values in life. Like, you'd go from respect to responsibility to honesty. So, those things like that. In order for you to be who you are you have to have challenges, it's with those challenges comes responsibility.

Other than the obvious biological features of his gender, DJ references "situations" where he was expected to fulfill as performances of his masculine identity as an African American male. Particularly, DJ shared how more of his masculine characteristics became more pronounced in a committed relationship with his girlfriend. DJ explained, Let me think... other than the physical characteristics, like I said, a lot of the masculine characteristics come into play when you're in a relationship because like when you're not in a relationship a lot of those aren't really needed. But like when you're in a relationship, say like holding the door, being a gentleman, stuff 
like that makes you feel more masculine... Like my mom always told us to be assertive, not to demean women, but she was like women like a man who can handle business and who's in charge. Women want to be able to let their man handle things and when you're in a relationship that definitely comes out more than it would, I think, if you were not. I feel like being in a more serious relationship it does help you grow up, like, as a man and develop as a man because you're put in those situations. Some people, I'm talking about a committed relationship, not like just hooking up with a girl.

Traditional Roles of Manhood. An overwhelming majority of participants referenced their background experiences, lessons learned from their parents, family members, and role models in their communities, were the ultimate sources that contributed to their overall perception of manhood. The majority of participants cited that their fathers' had a major impact on what they a man to be was as well as provided a pathway towards manhood. It is important to note that they all had an understanding of the perceived roles of manhood, yet none of the participants shared that they have assumed all their perceived roles as men.

All participants shared that they understood manhood as a developmental process that is not yet complete for them, yet. Although two participants, Redd and Gee, are parents, they both believe that they are not fully prepared or had enough life experiences to say that they have fully occupy their prescribed roles as men; such as graduating from college, pursuing a career, and providing for their families. Furthermore, although many shared a diverse understanding about the roles and characteristics of men, the majority of 
participants conformed to the traditional roles of manhood; such as provider, protector, and head of the household.

“Provider, Problem Solver, Protector". George's perception of manhood is consistent with those of the other participants. He described many of the traditional roles of manhood, while embracing the expectations of the African American community by being compassionate. George explained,

I'd probably say, tough. We gotta be tough. Gotta be a protector and a provider. And I'd also say, you're a problem-solver, but also willing to, like,...if you don't understand something you can get help but also compassionate at the same time, 'cause you can't just be, like, brute every single second of your life.

George described how he perceived the role of his father within the family and manhood. He's definitely provider, problem solver, protector. He makes everything more comfortable. He makes us, he keeps us together, like, if there's a problem and mom gets mad at us kids, he's, like, it's okay, Kids apologize. Mom, it's all right. He'll basically hold everything together and then if we have any problems like if I need to go talk to him about something he'll either point me to a resource or he'll answer the question himself. He'll keep everything in check basically.

Similar to George, Gee's father played a fundamental role in his current understanding of not only manhood, but also fatherhood. As previously mentioned, Gee as well as other participants' journey to manhood is not complete. Gee shared one of the many lessons he learned from his father and will likely pass along to his own son; providing solutions to protect his family, women, and care for those he loves: 
I've got a lot of female friends now that whenever we cross the street, if I'm walking with a female friend, my dad always taught me if you're crossing the street and traffic is coming from this way, you make sure the female is on your right side. If traffic is coming from this way, you make sure she's on the left side, on the opposite side of traffic.

My dad taught me and my dad actually taught me that 'cause I asked him why he always did that with my mom. That's what's crazy about it cause we were walking, I think we were going to a Titans game, we had season tickets to a Titans game and I was in high school and I'd always seen it. We'd be walking on the sidewalk and he'd grab my mom and then grab me and put me on the other side of my mom. I was always trying to walk in between them so I could get [between] both of them and he'd always put me on the outside. Finally I asked him, like, I'm in high school and [I asked him,] 'why is it I've always been on the outside when we walk on the sidewalk?' My dad was, like, 'I'm the man of the family. I'm the man of the house. I get hit first.' By this time he's, like, 'Now, you're actually old enough that you should be in the middle, but it's always me and your mom because you were always the baby of the family, so if anybody gets hit it's gonna be us before you.' I was, like, 'That makes sense.' He said, 'So now, you understand what you're supposed to do.' Ever since then it's, like, any female I'm walking with, I don't even have to know you for real, it's just out of common [courtesy]...being a gentleman, gentleman courtesy, you're gonna be on the other side of the traffic, out of the danger way. 
Humphrey's perception of manhood and masculinity was the least representative of the group of participants. Humphrey expressed more of a progressive or diverse understanding of his manhood. Although other participants did not express the same progressive understanding of manhood (as described by Mutua (2006) in Black Progressive Masculinities) they might be at the precipice of developing diverse perceptions of manhood. Humphrey referred to the hegemonic roles and performances of masculinity and manhood as "outdated" and not representative of "contemporary manhood." However, Humphrey shared that he also conforms to many of the traditional roles of manhood. He described an instance with one of his female friends where he served in a traditional masculine role with her and his friend teasingly shared her thoughts. Humphrey explained, I've friends before, one of my friends, she's, like, I used to take on a masculine role with her. She's an only child, her daddy is her everything, so when we moved on campus she's, like, "Humphrey, I need help with my groceries, I need help taking these clothes upstairs." She would call me for everything, to do all the labor work for her. I remember one time we were just in the room talking, she said, "The only thing gay about you is you don't like pussy."

\section{Intersection of Ethnicity and Masculinity}

For the fourth research question, the intersection of ethnicity and masculinity is the major theme addressing how the ethnic and masculine identities of African American college men intersect. All participants shared experiences that they were stereotyped because of the overlapping association of their race and gender, for being Black men. There was an overwhelming consensus by all participants that they expected to be 
stereotyped and that it may manifest itself in many ways throughout their lives. All participants credited the media's negative portrayal of African American men to society's persistent racial stereotypes. The themes presented are Stereotyped Black man, Reframing Black Manhood and Masculinities, and Reclaiming Blackness.

Stereotyped Black Men. DJ shared how negative group stereotyping injured another ethnic group when it was monolithically marginalized by society, much like his experience as a "high achieving Black male". Without regard to his intellect or how progressive the African American men have become, DJ shared his frustration that society still see him stereotypically:

If the media portrayed nothing but high achieving Black males, then when people saw a Black male, if they haven't really been exposed to them out in public, regardless of what they were, if that's what the media portrayed, for instance, somebody who lives out in the backwoods of [a rural part of the State] who's never seen a Black person, but they watch TV. The first time they see a Black dude or Black male or female they would look at them and they would be like, 'Oh, they're probably high achieving,' because they're not raised with all the negative, they haven't seen that. For instance, a good example of this a lot of people view Middle Eastern people automatically they're terrorists because that's what you see on TV. That's what they show. That's what they're always showing on [TV]. Every night they're talking about somebody blowing something up, in some country over there.

So, people automatically make that association, but before that, before the whole 9/11 and stuff like that, the associations that people made with Indian 
people or people of Indian decent, Middle Eastern, a lot of people thought of, like, a doctor. That's a huge change from a doctor to a terrorist, but that shows the power of the media can change the views of a whole nation within, like, a year or within, like, a few days. I'm sure it only took a few days for everybody to know what happened and then automatically every person from anywhere over there, even [from an unrelated country], they automatically had a stamp on their head that said terrorist. It's the same thing for Black males. It's not terrorist, it's criminal automatically stamped on your head because of what the media portrays. Because when you watch the 11 o'clock news they're talking about a Black male suspect. I actually took a picture of the screen and sent it to my brother one time, cause they said White male. I was, like, “What? Really?” You don't see that. That's crazy, so I took a picture and sent it to my brother and he was, like, 'It's crazy. It's sad that it's that way, but it's...'

Anderson expressed a similar concern about the constraining and "peculiar" "cap" society has placed on his life and the lives of other African American college men. Anderson remarked,

I just feel like society would say you know you're supposed to be out drinking, partying, smoking. You're supposed to be out getting' all these girls and leading that kind of life, but I just think that it's peculiar or uncommon for people to see me actually living and standing up for what I believe in. So, I feel that others may see that to be kind of weird or not masculine or some sort. You know what I'm sayin'? 
I don't understand why that is. I feel like society has put a cap on what they believe a 19-year-old should be doing and what they believe an African American male should be doing. So, I feel that they've put that cap on there and if they see that that is not what one of us is doing, then it's kind of like a light bulb goes off like, why is that? He should be doing this, he should be doing that, he should be out here doing this. So, I just feel like sometimes, just because I live a different standard of life that I'm not considered to be like, a real man and masculine. Like I also said, coming up here...I even think that they're definition of masculinity is different.

Reframing Black Manhood and Masculinities. The focus group provided an opportunity for participants to shared personal experiences with other African American college men that grew up in cultural environments that were different from their own. For all of the participants, in the group and in-depth individual interviews, it was the first time that they had a focused discussion about how they uniquely perceived notions of manhood and masculine identities.

Reframing Black Masculinities. During the in-depth interview, Anderson recalled his observation of the focus group's varied perceptions of manhood and masculinity, which often conflicted with his perceptions. He remembered how one focus group participant from an urban environment shared how "men don't cry:"

He was just saying like, he knew that he was taught men don't cry and that's just like... that really stuck with me because I've always been able to express myself whether that's crying... and I know that one of the biggest, I just thought biblical you know, I'm thinking of David. David was a big man, he was a manly man and 
David even cried and I was just like, my parents taught me it's okay to express yourself. We tear up sometimes, that's just like expressing yourself to me. But, it was just really weird to see how I was raised and how some of these other people were raised, especially being raised here in the bigger city. I just felt like their definition of masculinity was different from mine because of their environments they were raised on.

Reframing Black Manhood. All participants did not consider their current "stage" in life as having enough experiences to fulfill and develop their unique cultural perceptions of Black manhood. They had an understanding of the general expectations of men in society, but all did not agree with society's negative expectations or stereotypes of African American men. La'Von described his distinct perception of manhood as a perpetual "striving" throughout his life's journey. In his journey, La'Von seeks to dismantle the hegemonic ideals of manhood and replace them with his own.

I mean a lot of people, like, they think of men they think you gotta be an alpha male and stuff. You know I think that's kinda true, but I don't wanna be the guy who's, like, oh, you not a man because you have a subservient role to someone else. You know, you not a man 'cause you're not the man in charge...I think being a man is about being okay with where you at. Being a man is about being content with your situation. I think you're not being a man if you wanna be somewhere and you're not striving to get there or you're scared to make that next step, then you're not being a man. But I don't care if you're on first, second, or third, as long as you're okay with where you're at? Then you doing what you're supposed to be doing. 
I was gonna be the first Black president. Of course, Barack Obama beat me to it. But, I'm not a man because of that. I'm not even old enough. So, I just feel like being a man is...striving to be where you wanna be. And never losing hope in the dreams and goals that you've set for yourself...I think that means I've settled into my manhood. You know, I think as long as you reaching, you're still reaching towards your manhood, you're still reaching toward who you wanna be as a man...I think it's a lifetime thing. 'Cause even though financially, I might have reached my goal as a man, knowledge-wise, I might still be striving for more knowledge and more wisdom. Things like that, so in that sense you're still gonna be battling with bettering yourself, improving yourself, progressing. You know, you might like, you know, I got like, where I wanna be financially, I'm content in that sense, but now your manhood ain't gonna be based on that no more, it's gonna be based off how well can you raise your kids. Can you be a good father? Can you be there for your kids? And you gonna be striving to meet those goals, and then after that you'll move on to new things, maybe, like, giving your life back to Christ. You know, reconnecting spiritually, 'cause you're getting older and you realize that your time on earth is limited, you know, things like that.

Similar to La'Von, participants expressed a striving for growth when they spoke about manhood as African American males. For participants, this striving was external (they wanted to be successful in life and for those close to them) and it was also internal (they wanted to explore who they were, not in the guise of society, but how they might become a better person); always striving to further develop themselves as African American men. 
Reframing Blackness. La'Von shared his thoughts, at length, about his Blackness, specifically with regard to the significance of his African ancestry and his American culture-Essentially, what does it mean to be African American and the peculiar link of slavery. Although complex, La'Von spoke at length about the intricacies of living Black, African, African American, and American all at once. La'Von expounded:

I think about it like this. It's, like, okay, if I asked another person. Say I asked a Cuban person, what race are you? They gonna be like, I'm Cuban. They're not gonna say I'm American. They're not gonna say I'm Cuban American neither. Same with like almost any other [ethnic group]. But if you ask a Black person, they're either gonna say I'm Black, or I'm African American. To me, the word African American is like inherently comes from something we had to fight for, that's why we won't drop the American. We won't give up the African either. Cause really we're not, we're just barely African at all...I feel like through slavery, we had to fight so hard for the title American cause the title American was the same as having citizenship...Africans aren't citizens. Niggers ain't citizens...So we had to fight really hard to get that American put on our name... So we wanna hold pride in what we are, but I guess it's difficult 'cause we don't know, like, exactly what part of Africa we from. But we don't wanna give up that American neither, cause we had to fight really hard for that. That really holds value for the Black people, to the African American people 'cause it's like without that, before that we was nothing, they considered us nothing. We was like animals. We was like 2/3's of a person. You know what I'm saying, so we had to 
fight for that, so we're not dropping that. But then we don't wanna fully assimilate. So we keep our African...

When questioned about whether his understanding of race and ethnicity changed based on situations or circumstances, Humphrey spoke about an "overlapping" as opposed to a "shift" in how he perceived his identities:

I wouldn't necessarily say they shift, I could say sometimes they overlap, but as far as shifting and having a totally completely different, I wouldn't say so... Because sometimes, not necessarily race and ethnicity are one in the same, but when you think about it, race is a part of ethnicity in some cases.

As a Pan-African Studies major, Humphrey went on to explain that he first noticed the "overlap" of his racial and ethnic identities when he began to truly learn more about his ethnic identity. He said that, "before it was probably more racially [defined] just because I didn't have all the background as far as the ethnic part of it goes. I had a little bit but not in depth information."

\section{College Networks and Relationships}

College networks and relationships is the last major theme addressing how college impacts African American college men's identities. All participants indicated that college had a profound impact on their ethnic and racial identities and concepts of masculinity and manhood. The most significant impacts were the opportunity to have their masculine, ethnic, and racial identities affirmed through co-curricular and academic networks and relationships that were established for African American students; specifically those established for African American men. In the next sections, the African American male participants shared how African American networks and 
relationships as well as how networks and relationships specifically for African American college men had provided opportunities to establish bonds that were affirming for the multidimensions of their identities and gave them a progressive path of success.

African American Networks and Relationships. All participants strongly suggested that the African American student honors and collegiate networking organizations and associations significantly assisted them in integrating to Metropolitan University, provided them opportunities to establish meaningful relationships with other high achieving African American students, and build relationships with faculty and staff to serve as their educators and mentors. The connections served as an important resource for African American male participants that came from predominantly White high schools. Those African American networks also aided participants with diverse social and cultural identities to find their place and establish meaning relationships with students, staff, and faculty. Humphrey recalled,

Once I came into the university, it was such a strong African American support system here at [the University] that I didn't necessarily feel like I needed support from anywhere else. I had my Connect Mentor, I had the Porter Society, I was in ASU (the African Student Union), I had all these Black people surrounding me and supporting me...the organizations got me connected to places on campus I needed to go, they're the organizations that seemed interested in my well-being, overall, as far as my transition to college. And so, they gave me advice on what to do, advice on how to better myself as far as academically and socially. Humphrey later became a Connect Mentor and took pride in knowing he was able to "make an impact in other African Americans lives." He also mentioned that, although 
there are many other non-Black retention and mentor programs that the University sponsored, he believed that they did not "seem to make as big of an impact on [the lives of African American students] because we can relate" to their lives more meaningfully.

For DJ, because he was from a predominately White suburb and high school, attending the University meant that he finally had an opportunity to build relationships with other African American male students.

'Cause, like, in [a predominantly White suburb], I always felt like I was the only one, but since I've been here, I'm not the only one. There's Black males in [the engineering school] about ready to graduate, there are Black males all over the place that are succeeding, so you're not the only one anymore. You can talk to them. If you want to talk to them about their experience, you can talk to them about that. If you just want to kind of stand back at a distance and look at what they're doing, kind of see how they made it through, then you can do that too. So, you can kind of have role models, I guess, and peers. Whereas, I didn't feel like I had any peers in [my neighborhood]. It was just me and them.

Heightened Ethnic Identity. Through other African American retention programs, academic courses that discussed the African Diaspora and centered the experiences of African and African American people, such as Pan-African Studies courses, and the overall University's Black community, all participants expressed that they learned more about their ethnic identity. Humphrey said, it "goes back to those PAS classes. Once I started taking them, I kinda feel like, since I came to college, I kinda just felt more Black than I have ever.” 
For George, attending college affirmed his ethnic identity through African American cultural experiences. He explained,

African American Male Initiative has kind of made it affirming. Cause it's like you're just surrounded by Black people, you're taught about Black people's history, whatever it may be, lessons, anything. And then, it's nice to be around people with the same ideas, same kind of drives.

Men and Masculinity Networks and Relationships. All participants indicated that college offered multiple opportunities for them to establish fundamental bonds and relationships with other African American college men, faculty, and staff. Specifically, with Black Greek-Letter organizations and other African American male programs, such as the African American Male Initiative and the Student African American Brotherhood, and Collegiate 100. They also had faculty and staff who advised or who had an association with African American male student organizations. Each of the organizations mentioned explicitly advocated for African American college men's academic and cocurricular success and, in effect, aids in supporting retention and graduation strategies of the University.

La'Von shared how he was promptly connected to one of the organizations once he enrolled into college. He said,

Well, basically Black people have the, like, I guess, lowest retention rate in college. So, organizations were created specifically to assist us. So when I came to college...I was immediately placed in these programs set up to help me succeed. That's the biggest impact, you know, the African American Male Initiative. 
La'Von proudly serves in a leadership role with the African American Male Initiative. He stated, "my masculinity, as far as my identity, as far as having a desire to be trustworthy and honorable has put me in a leadership position at AAMI.”

Chris is interested in joining a Black Greek-Letter fraternity and attended an educational viewing of a film intended to have the audience of African American men and women critically think about their purpose. He said,

It's just how, like yesterday I went to a meeting and watched a film with them. Do you have purpose? It tells you, I stayed for the whole entire time because it was interesting as hell. It was talking about us as being Black. What do they say about us being Black, males and females? They went from the male aspect into the female aspect and then to the kid's aspect, like what do we do to get the kids to where they would be able to succeed... What do we have to do as we are right now, as the next future for us to help our future?

During the in-depth interview, Gee, who was also a focus group participant of this study, discussed the importance and impact of African American men actively engaging each other socially and intentionally in dialogue to learn more about each other. He suggests a simple "what's up" can begin to make a difference. Gee also referenced his experience while participating in the focus group of this study, with other African American college males as an unexpected networking opportunity. Gee explained how he began to interact with some of the other focus group participants. It is difficult for him to believe that he did not to get to know some of the other participants sooner. He recalled,

We used to walk past each other on campus all the time and we didn't say nothing to each other, just because, like we said just as your manhood, you don't want to 
speak out to people you don't know. You don't speak to everybody, you just keep walking. But now, it's like you walk past him and it's like, 'Hey, what's up? How you doing?' It's just weird seeing how that one focus group for, how long was it? An hour? Two hours? That one focus group, for two hours, and now all of us are pretty much acquaintances now. I wouldn't say peers, we're more of acquaintances. We know each other and we speak to each other now. It's weird. Like that just threw me all the way off. I've been thinking about that since.

I feel like that focus group was like a reality check to pretty much almost everybody that was in that focus group, just because a lot of people don't like to come out and just talk about stuff like this. Like I said, me and my friends, if it comes up, it comes up and we're gonna talk about it. But, like a lot of people aren't like that. Hearing other peoples' opinions, now I've seen... I didn't know La'Von stayed in the same apartment complex I stay in. I've ran into him a couple times. I've ran into Redd, Jay. It's like just after that conversation it's like we're all cool with each other now. It's weird. It's show me pretty much how Blacks just pretty much have to sit down and get to know one another before stereotyping each other to notice we're no different, really. We've just got different looks and different mindsets and different places where we was raised, but we pretty much know the same stuff and think the same stuff.

Transcending the Stereotypes. All participants indicated that they had a tremendous desire to overcome the racial and social stereotypes that they have experienced personally, been taught at an early age to arm themselves against, and how they perceived racial stereotypes socially extended to African American men and their 
communities. Through their own life's experiences and through what they hope to achieve and wish to give back to their communities, they hope to offer an alternative perspective about who they are and who they will become, as African Americans and men. Anderson shared his understanding about racial stereotypes that he learned at a young age and how he sought to dismantle them. Anderson passionately reflected, My parents always told me that being born that's where I always had two strikes against me and that was that I was Black and that I was also a Black male. So, I feel that knowing that growing up and they taught me and they also taught my brother that. It just pushed me harder because I knew that those two strikes were already against me. So, I knew that, stereotypically, we look at Black men as they don't amount to anything, they're just good for nothin' but sleepin with [whoever], making these babies, wearing their clothes any ole kind of way, stereotypically. So, I feel that I was always one to try to beat stereotypes, try to say 'that's not what all black men are,' my parents raised me better than that. I always tried to beat that standard.

Similar to Anderson, Gee has tried to set himself apart from the stereotypical notions associated with Black people, particularly African American college men. Gee believes that attending college has "made me understand the stereotypes of a Black man in college." Gee continued to affirm,

Just pretty much saying we're not gonna make it, that's what most people are thinking. So that stereotype, like I said, it makes me wanna do the opposite and make it out of college and be successful in life. So yea, that's been important to me, like it's been a factor. 
Gee believes that him being more knowledgeable about racial stereotypes motivated him to continue striving for success. He Tweets "success at all cost" as motivation every morning,

Yea, every morning, that's the first thing I say to myself, "Success at all cost." That's what I say to myself every day. I put it on Twitter and I say it to myself when I wake up. "Success at all cost," daily Tweet, every day, just because that's what my focus is on. I have somebody to provide for, the success $i s$ at all cost, no matter what... It's me, my son, my family. Provide for everybody. "If I eat, everybody eats", isn't that what they say? That's what I'm trying to do.

Gee believed since attending college, he had been able to identify stereotypes, which assists him in his own development and growth. Because he is able to identify stereotypes, it actually pushes him to succeed, graduate college, be successful in life, and transcend stereotypes ascribed to African American men.

An overall assessment of the major theme College Networks and Relationships is that their college experience has provided them an affirming opportunity demonstrate what they knew they could do, that they will succeed despite any social obstacles they have encountered in their past or have yet to hurdle in the future. They were affirmed by African American affinity groups, which provided them supporting networks to connect their experiences with other African American men and women. They found role models in themselves as well as established relationships with trusted faculty and staff.

\section{Chapter Summary}

This chapter presented four major findings by centering the lived experiences of nine African American college men by using critical race theoretical and methodological 
strategies to lift their voices and perceptions about ethnicity and masculinity. All findings were organized by the major themes to shed light upon the research questions of this study and to reflect what the literature revealed about these topics. Data from the focus groups informed the formulation of open-ended questions and participants illustrated their perceptions of their ethnic and masculine identities. In-depth individual interviews were used as the primary source of data. 


\section{CHAPTER FIVE}

\section{DISCUSSION AND CONCLUSION}

The purpose of this study was to understand how African American college men construct masculine and ethnic notions of their identities, despite disproportionate social obstacles. The selection of a qualitative research design and a critical race theoretical and methodological approach was derived from the purpose of this study to understand how the lived experiences of African American college men inform the construction of masculine and ethnic notions of their identities at a predominately White institution (PWI). Furthermore, this study explored the perceptions and characterizations that these African American college men understood as most salient toward successfully negotiating the intersectionality of ethnicity and masculinity.

This chapter will present a summary and discussion of the inquiry's findings. The total collection of counterstories consisted of approximately 17 hours of in-depth, semistructured and transcribed interviews with nine participants. In addition, I will describe the emergent themes from participant interviews, limitations of the study, recommendations for practice, implications for theory development, recommendations for future research, and conclusions that may be drawn from the study. 


\section{Overview of the Study}

This study was an exploration of the lived experiences of nine African American college men attending Metropolitan University, a predominately White institution in the southeast region of the United States. The study explored (a) African American college men's characterization of their ethnic identity; (b) African American college men's perception of their masculinity; (c) the performance of African American college men's perception of masculinity; (d) the intersection of the masculine and ethnic identities of African American college men; and (e) the impact of attending college on African American men's identities at a predominately White institution.

In-depth, semi-structured interviewing served as the primary data collect source (Seidman, 1998; Patton, 2002). The tenets of critical race theory and methodology were used throughout this study to frame data collection and analysis (Solórzano \& Yosso, 2002). Participants' in-depth interviews formed counterstories of how the nine African American college men made meaning of perceptions of their ethnic and masculine identities. Interpretation of their stories structured the data into the four major themed categories presented in Tables $4,5,6,7, \& 8$. A listing of the major themes and primary sub-themes will follow each research question to further assist in organizing this chapter. 
Table 4

Research Questions and Major Themes

\begin{tabular}{|c|c|}
\hline Research Qu & Major Themes \\
\hline Research Question 1 & Dimensions of Race and Ethnicity \\
\hline Research Question 2 \& 3 & Dimensions of Masculinity and Manhood \\
\hline Research Question 4 & Intersection of Ethnicity and Masculinity \\
\hline Research Question 5 & College Networks and Relationships \\
\hline
\end{tabular}

\section{Research Question 1}

How do African American college men characterize their ethnic identity?

Table 5

Major Theme: Dimensions of Race and Ethnicity

\begin{tabular}{|c|c|c|}
\hline \multicolumn{2}{|c|}{ Dimensions of Race and Ethnicity } \\
\hline $\begin{array}{c}\text { Ethnic Identity as Culture } \\
\text { Community Commitment }\end{array}$ & $\begin{array}{c}\text { Race and Racial Stereotyping } \\
\text { Impact of Others Racial } \\
\text { Perceptions }\end{array}$ & $\begin{array}{l}\text { Intersection of Race and Ethnicity } \\
\text { Culture as the Environment } \\
\text { Code Switching }\end{array}$ \\
\hline
\end{tabular}

\section{Summary of Findings: Dimensions of Race and Ethnicity}

In order for the African American college men involved in this study to authentically characterize their ethnic identity, they also discussed issues related to race and racial stereotyping. For the first time, the majority of participants were confronted with the task to critically examine and discuss the distinction and meaning associated with their ethnic and racial identities. Typically, they would refer to their racial and 
ethnic identities interchangeably, although they comfortably expressed the connection of their ethnic identity with the affirming cultural background of family, while their racial identity was narrowly associated with the color of their skin, racial stereotypes, and society's negative and limited perception of them.

In describing the significance of race, they shared incidents and stories of racial stereotypes. Parents, family, peers, and the African American community served as socializing agents to make them knowledgeable and defend themselves against the racial stereotypes, social and institutional barriers that became commonplace in the lives of African Americans since slavery. All participants shared how they have been misrepresented by racial stereotypes and the majority of participants shared how racial stereotypes continued to impact their lives at varied capacities directly and indirectly. With a deeper understanding of their identities, underlying themes emerged about how their racial and ethnic identities intersected, as participants began to share how these identities overlapped in their physical environment (rural, suburban, or urban communities). Their African American culture and heritage were significant toward the formation of their ethnic identities, but appeared to shift or overlap if they attended predominately White schools and lived in predominately White communities in rural and suburban areas or if participants attended predominately African American schools and lived in predominately African American communities in urban areas.

Experiences of being racially stereotyped and their understanding of society's negative perception of them as African American men influenced participants' perception of their racial identity. These experiences and perceptions of negative racial stereotypes manifest themselves in the lives of these African American college men in the form of 
"code switching." Participants would use code switching as a strategic tool by modifying their language by "talking White," style of dress, behavior, and cultural insight to adapt to and negotiate the sociocultural boundaries between a predominate White society and the cultural characteristics of their own environment to establish relationships.

All nine African American college men differentiated ethnicity and race. All described their ethnic identity as an extension of their culture, heritage, and lived experiences as African American men as opposed to what they understood about the majority of society's pejorative stereotypes and perceptions associated with their racial identity. Participants' understanding of their ethnic identity was framed around the historical context of the impact and significance of slavery and African Americans' fight for civil rights, cultural heritage, and the counterstories presented of participants selfexploration of their ethnicity identity. Most of the participants characterized a commitment to giving back to their communities as a responsible and compassionate expression of who they are as African American men.

\section{Discussion of the Findings: Dimensions of Race and Ethnicity}

After probing participants for deeper meaning during in-depth interviews, I was able learn more about how these African American college men characterized their ethnic identity, which was seemingly buried just beneath the surface of their knowledge of who they are based upon their counterstories and critical incidents. The counterstories and critical incidents involved their families, the African American community, racialized stereotypes and experiences from society, and finally how they ultimately saw themselves. 
Gilroy (1993) supports how the suppressive effects of slavery dramatically fractured how African Americans and others of African ancestry would be challenged in how they come to understand their ethnicity and other cultural formations of who themselves. Gilroy said those of African ancestry would be left "exiled" and "isolated" from deeper meanings. However, these African American college men are not exiled, because they had varying degrees of knowledge about their culture and heritage, such as the significance of identifying themselves as African American and their communityoriented or collectivists perspective of giving back and the passion associated with service for the greater good of the community (Akbar, 1991; Johnson \& Cuyjet, 2010; McAdoo, 2007; Ture and Hamilton, 1967). Even so, I would describe that they were culturally isolated from their African rootedness, as shared in the literature by Gilroy and Akbar, due to slavery's global dislocation of people of African descent. Only two participants connected Africa loosely to their African American male identity. Although, all understood the significance of Africa, but it was more of a historical significance that made its connection through slavery, to civil rights, to their families, and finally to themselves than a connection to African rootedness.

Race and Racial Stereotyping and the Impact of Others Racial Perspectives emerged as significant themes as part of the major category of Dimensions of Race and Ethnicity was supported throughout the literature (Akbar, 1991; Gibbs, 1988; Gordon, 2002; Franklin, 1994; Johnson \& Cuyjet, 2010; Staples, 1987, 1987b; White and Cones, 1990). This is particularly evident in Franklin's description of the paradox African American men encounter when negotiating the perceptions of who they are based on the messages received in their communities (Black male primary group), among their peers 
(Black male peer group), and how they are racially marginalized in society (Mainstream society and Black males), all serving as socializing agents to race, racism, and racial stereotyping contribute to the ethnic formation of their identity.

For these African American college men, the Intersection of Race and Ethnicity emerged as an unexpected emergent theme. This theme emerged after noticing that there was a gap in how they described their culture once these African American college men began to distinguish their racial and ethnic identities during in-depth interviews. Participants frequently related where they lived in their local communities to how they perceived their ethnicity as well as how they associated or experienced racial stereotypes. All participants would then reference the focus group or critique how other group participants' cultural perspectives were similar or varied from their own perceptions of identity based on where others lived, their physical environment. Rural, Suburban, and Urban communities emerged as themes as participants described their cultural and racial and ethnic identities; essentially describing their Culture as the environment as an overall sub-theme. Staples (1978b) argued that it is necessary to examine a blending of "sociocultural forces" that further challenge the plight of African American men (p. 170). Gibbs (1988) identified one of these sociocultural challenges as the urbanization that took place during the 1960 s and 1970 s.

Urbanization was claimed to be a contributing factor in creating and widening the social and employment gap between the poor and middle-class after as mass "exodus" of African Americans from rural areas who sought new job opportunities, then relocated to urban and suburban communities. Among the cited affects were the heightened isolation of the Black poor and the alienation of the Black middle-class from the White 
community. According to Gibbs (1988), the unanticipated effects of urbanization undermined the once thought socioeconomic opportunities for African Americans as the urban population grew beyond what the city could offer as far as employment, creating overpopulated African American inner-city ghettos where it became a matter of survival for African American men and women, which have persisted today. A part of survival was not only socioeconomic, but how to adapt to predominate White social norms, aesthetics, and language styles in the form of the sub-themes associated with Code Switching (i.e., Talking White and Code Switching to Establish Relationships), whereby African Americans had been applying strategies to adapt to a predominate White society after the end of legal slavery (Du Bois, 1903/2003; Gilroy, 1993). As discussed in Chapters One and Two, in predominately White rural and suburban areas, "code switching" may have served as a method to acquire cultural capital in the face of cultural isolation from a predominate White community (Gilroy, 1933). Code switching is somewhat similar to the concept of cultural border crossing that is used both in the context of preparing teacher candidates to engage diverse students in urban areas and in the acclimation of culturally diverse students to engage each other in the United States and abroad (Smiley, 2006; Rose \& Bylander, 2007). Similarly, for African American men in predominately African American urban communities, code switching may have served a strategic tool to mitigate negative racial stereotyping in their lives, while being confronted with social alienation in a predominate White society. Perhaps urbanization explains the difference in how these nine African American men from rural, urban, and suburban areas perceived their identities due to the cultural isolation and racial alienation that took place over 50 years ago (Gibbs, 1988; Gilroy, 1933; Ogbu, 2002). It is this 
researcher's inference that additional research is recommended; however, urbanization may have some impact on the perceptions of the urban African American college men involved in this study, much like the conceptual model for young urban African American male identity postulated by Majors and Billson (1992), authors of Cool Pose: The Dilemmas of Black Manhood in America.

\section{Research Questions 2 and 3}

How do African American college men characterize their perception of their masculinity? and How do African American college men perceive their performance of masculinit(ies)?

Table 6

Major Theme: Dimensions of Masculinity and Manhood

\section{Dimensions of Masculinity and Manhood}

\begin{tabular}{|l|l|l|}
\hline $\begin{array}{c}\text { Duty, Strength, and Masculinity } \\
\text { "Handling you Business" as a } \\
\text { student }\end{array}$ & Faith, Values, and Respect & $\begin{array}{c}\text { Traditional Roles of Manhood } \\
\text { Provider, problem solver, } \\
\text { protector }\end{array}$ \\
$\begin{array}{l}\text { "Handling you Business" as a } \\
\text { father }\end{array}$ & \\
"Handling you Business" like a \\
$\begin{array}{l}\text { father } \\
\text { "Emotionally Strong" }\end{array}$ & \\
\hline
\end{tabular}

\section{Summary of Findings: Dimensions of Masculinity and Manhood}

All African American college men involved in the study characterized their perception of masculinity as a function of their masculine performances. The overall theme of how they characterized their masculinity was Duty, Strength, and Masculinity through a perception of responsibilities whereby most participants described derivatives 
of the phrases "handling" or "taking care of your business." Handling Your Business was used as a metaphor used by most of these African American college men to characterize their perceived masculine performance of identity. All described Handling Your Business as a Student, two described Handling Your Business as a Father, and most described Handling your Business Like a Father. Participants also characterized their masculinity through "strength" or being Emotionally Strong. Being Emotionally Strong provided them the opportunity to fulfill an alternative version of the traditional perceptions of masculinity, while showing emotion and compassion through strength.

The majority of participants characterized their perception of masculinity and manhood through core fundamental lessons of Faith, Values, and Respect. They learned throughout their lives, but it was the early lessons learned from their parents of how to live out their values each day because they represent not only themselves, but also their families and the African American community. The majority of participants also continued to reference their parents, community role models, and family members regarding how they came to characterized their perception of manhood and masculinity. These characterizations were largely Traditional Roles of Manhood that would prepare them for when they would establish their own families. What was interesting to note is that none of the participants declared that they had achieved the level of responsibilities to be called men, even for the two participants who were fathers.

\section{Discussion of the Findings: Dimensions of Masculinity and Manhood}

Na'im Akbar (1991) supports how participants characterized their perception and performances of masculinity and manhood that emerged in the theme, Traditional Roles of Manhood. Unlike what Mutua (2006) would consider a form of Progressive Black 
Masculinities, Akbar affirms the perceptions that all of these African American college men conveyed that although they understood many of the responsibilities of manhood, they are not yet men. Akbar argued that African American males transition to manhood is much more than the biological development of maleness and that having children is not an automatic criterion that transforms African American youth into men.

Akbar further asserts, however, that it is counterintuitive for African American men to try to conform to the ideals of traditional manhood, rather, he encourages African American men to maintain the lessons learned within the African American community as well as incorporating traditional values. Additionally, from a sociohistorical perspective, Newton (2005) posits that African American men began to embrace traditional hegemonic roles of manhood as the Black Power Movement evolved and a Black national manhood advanced with it. White and Cones (1999) and hooks (1981, 2004) also insist that traditional hegemonic values of manhood and masculinity are not completely congruent with the community-oriented, emotionally expressive, and cultural collective ideology as also affirmed by the African American community and the participants in the Faith, Values, and Respect and being Emotionally Strong. Essentially, White and Cones argued that for some African American men, completely assuming traditional roles and performances may create a socially constructed paradox of masculinity and ethnicity.

With further regard to how these nine African American men perceive their performance of masculinity, these findings confirm assertions by Akbar (1991) and White and Cones (1999) that they must confront and seek to reconcile the paradox of manhood and masculine ideologies on their own, as represented in participants' theme of 
Duty, Strength, and Masculinity. Akbar does not refer to this process as "Handling your Business," however, he does cite that, "we require them to tackle real life problems and watch them find solutions. They should have early work responsibilities, management responsibilities, and social responsibilities. These responsibilities force the muscles of growth to develop" (p. 13). Akbar continues and asserts that if these lessons are taught at an early age and the responsibilities are assumed, "he begins to discover the fullness of his potential and can then move to ever-increasing higher horizons" (p. 13).

\section{Research Question 4}

How do the ethnic and masculine identities of African American college men intersect?

Table 7

Major Theme: Intersection of Ethnicity and Masculinity

\begin{tabular}{|l|l|l|}
\hline \multicolumn{2}{|c|}{ Intersection of Ethnicity and Masculinity } \\
\hline \multirow{3}{*}{ Stereotyped Black Man } & Reframing Black Manhood and & Reframing Blackness \\
& Masculinity \\
& Reframing Black Masculinity \\
& Reframing Black Manhood & \\
& & \\
\hline
\end{tabular}

\section{Summary of Findings: Intersection of Ethnicity and Masculinity}

As Stereotyped Black Men, racial stereotypes impacted the overlapping associated with all of the African American college men's identity due to their race as well as their gender, despite the differences in the physical environment where they were raised and the early lessons they learned from parents, family, role models in the African American community or affirming contemporary models of African American men. It was understood by all participants that the media's constructed a negative portal that all 
African American men are seen through and have entered, which subsequently impacted how society see them, but does not reflect how they see themselves.

Within the sub-theme of Reframing Black Manhood and Masculinities, all participants indicated that because they do not 'fit in' with the expectations of society's perceptions of all African American men, they were oftentimes left feeling constrained and frustrated for always having their identity as African American men challenged and having to defend it. In addition, participants were further challenged by some of the negative racial perceptions of Black masculinity, but recognized that their performances of Black masculinity were similar to each other because of their shared cultural values, but also varied based upon individual experiences and their physical environments.

Lastly, for the majority participants, the process of Reframing involved much thought and a critical self-examination about the intricacies of Black masculinity. Primarily, the significance of their race and ethnicity was socially isolating because of their experiences living in a predominately White American society that sees them so stereotypically. Yet, they were still able to share a broader and complex perception of Black masculinity.

\section{Discussion of the Findings: Intersection of Ethnicity and Masculinity}

As eluded to in the discussion of Dimensions of Race and Ethnicity, Franklin (1994) postulated that African American men found themselves in a paradox between European and African ideologies. In the case for the nine African American college male participants, the paradox is based upon their knowledge, perceptions, and experiences as African American men negatively racially stereotyped in a predominately White society social structure; as expressed in the theme Stereotyped Black Man. Their experiences 
appeared different, but the general concept is a function as to how these African American college men perceive their worldview with influences from their parents and the African American community (Black male primary group), peers (Black male peer group), and the racial stereotypes of society (Mainstream society and Black males).

The major difference is that these African American men do not fit within a "type" of African American man; the controlled group that Franklin references that is associated with the community, peers, and society. It is better to describe that these men are influenced or taught lessons by their communities, peers, and society. These influences contribute to establishing their own complex versions of Black masculinity, one that intersects with other parts of their social identities. These men have been provided life lessons, identified many of the stereotypical challenges of African American men, but, for the majority, accept themselves and other peers' versions of being a African American man. They have pride in who they are and understand that their journey to Black manhood is not finished; they described it as an on-going developmental process

\section{Research Question 5}

How does being in college impact African American men's identities?

\section{Table 8}

Major Theme: College and Relationships

\begin{tabular}{|l|l|l|}
\hline \multicolumn{2}{|c|}{ College Networks and Relationships } \\
\hline $\begin{array}{l}\text { African American Networks and } \\
\text { Relationships } \\
\text { Heightened Ethnic Identity }\end{array}$ & $\begin{array}{l}\text { Men and Masculinity Networks } \\
\text { and Relationships }\end{array}$ & Transcending Stereotypes \\
\hline
\end{tabular}




\section{Summary of Findings: College Networks and Relationships}

The College Networks and Relationships theme emerged as a major contributor towards their academic success and how they were able to establish meaningful relationships and networks with students, faculty, and staff through academic and cocurricular programs and African American student-led organizations. The African American Networks and Relationships theme emerged because it aided in their transition from high school into college to engage with a network of other African American students, particularly for the majority of the participants from predominately White high schools and communities.

Men and Masculinity Networks and Relationships emerged after participants began to speak specifically about how their African American college networks aided them in transitioning to college and then noted that student organizations designed for African American men provided an opportunity to build relationships with other African American men. Men and Masculinity Networks and Relationships also allowed them to not only share experiences with other African American men, but provided an opportunity for them to serve in leadership roles with other men. This was particularly significant because all participants were engaged in organized athletic sports with other young males at least during their years in junior high and high school, but they did not mention to their similar shared experience of establishing meaningful relationships and assuming leadership roles prior to college.

Transcending the Stereotypes was representative of an attitude each participant shared when he spoke about how he was able to negotiate his own path to college. The participants spoke about their lessons learned while growing up that were meant to 
prepare them for life as African American men. They spoke of meaningful mantras, songs, scripture, and quotes that personally motivated them to improve themselves and to be their very best, despite the negative stereotypes and messages conveyed by the media. They spoke about success, graduation, and the opportunities that are waiting for them in the future. The spoke about all of these things, but their attitude spoke more about their perceptions of who they are and who they will become. College, along with the relationships and networks they established and continued to build, became a place where their opportunities and identities were affirmed.

\section{Discussion of the Findings: College Networks and Relationships}

The Men and Masculinity Networks and Relationships theme was the most impactful towards all participants' college experience and towards how they came to develop meaningful relationships with other African American male faculty, staff, and students. Tinto $(1987,1993)$ noted that institutional fit is important to the academic success of students. Specifically, if the values, goals, and attitudes of students are not congruent with those of the institution then it is likely that student enrollment and persistence will be negatively impacted (Tinto, 1987). However, in the case of the nine African American college men involved in this study, Tinto's theory of student retention only indirectly accounted for the current success of these participants as African American male students. Furthermore, the participants did not speak directly about how Metropolitan University impacted their identities. Although AAMI, SAAB, Collegiate 100, Louis Stokes Alliances for Minority Participation, Greek-letter organizations, and other African American honors and social organizations are extensions of the University, these nine participants did not credit the institution directly for their transition, 
involvement or academic success in college, or what provided them with the determination to transcend racial stereotypes; they named the affinity group organizations and programs for African Americans, especially those organizations dedicated to African American men. Thus, these groups appeared to be the manifestation of the institution's impact on the day-to-day lives of these men.

\section{Implications of the Study}

The results of this study offer informative insights with implications for theory, future research, and student affairs practice. These insights are derived from the process

of framing the study using critical race theory, the in-depth interviews, and the process of making meaning of participants' lived experiences.

Implications for future research and theory development. The findings from this study revealed how participants understood themselves as African American college men. These findings also contributed to the existing scholarship on ethnic and masculine identity development as well as African American college men at predominately White institutions of higher education. Upon completion of this study, the following are recommendations for future research and theory development:

1. This study highlights the critical importance of exploring the intersection of ethnic and masculine identity development, specifically for African American men. A grounded theory approach is suggested to derive theoretical models that further explore the intersections of race and ethnicity and manhood and masculinity for African American men. Particular elements might include a cross-section of undergraduate African American college men from urban, suburban, and rural communities, with 
poor, middle-class, and upper middle-class socioeconomic statuses. It is also recommended that a purposeful sample of participants be equally represented by academic ranking (freshman, sophomore, junior, senior) to understand if there are differences of how they perceive their identities by each academic classification. This may serve as a method of identifying patterns to establish theory for the identity development of African American college men.

2. Majors and Billson (1992), authors of Cool Pose: The Dilemmas of Black Manhood in America, provided a conceptual model for young urban African American male identity. This study extends the scope beyond the Cool Pose of urban African American men as postulated by Majors and Billson by examining how the intersection of African American college men's identities varied by their physical and cultural environment within rural, suburban, and urban communities. A phenomenological study using the tenets of critical race theory is proposed to examine broader dimensions of African American men's ethnic and masculine identities from rural, suburban, and urban communities.

3. The study may be duplicated and expanded to focus on the intersection of ethnicity and masculinity of the diversity of Latino college men (Dominican, Puerto Rican, Cuban, Mexican American, etc.). The exploration of machismo and the ethnic distinctions of the various ethnic identities that comprise the largest minority population in the United States may provide further insight for American colleges and universities 
serving the diversity of Latino American college men. The intersection of language fluency and their respective backgrounds may also reveal more about their lived experiences as Latino American college men in a predominately monolingual White society.

4. Brod (1987) argued that the study of men, does not fully account for "what is unique to men qua men" (p. 40). Similarly, the exploration of the masculine and ethnic ideologies of White college men must not become over-generalized; therefore, future research on White male collegians' identity is recommended. A critical race theory approach will seek to dismantle White hegemonic and patriarchal ideologies that may deconstruct White male identity development. Furthermore, the study of White college men from rural, suburban, and urban communities may provide college and university educators new insight in how to serve this predominate population of college men.

5. The exploration of the intersections of race and ethnicity and manhood and masculinity for African American college men at Historically Black Colleges and Universities (HBCU) is recommended for future research. The performances of masculinity and ethnic cultural expression of African American college men at predominately Black colleges and universities may manifest themselves differently than African American college men at predominately White institutions. This type of study will not only provide implications for how HBCUs can better serve their male students, but offer further understanding about the intricacies of African American 
college male identity in environments where race is not a major, distinctive characteristic that separates African American males from the rest of the student population as it does at predominantly White institutions.

Implications for practice. The practical implications of this study highlight why the ethnic and masculine identity development of African American men must be understood as an intentional and targeted service among American colleges and universities. Here are practical recommendations for student affairs and academic affairs educators who provide services and those considering providing services and programs for African American college men.

1. Living-learning communities (LLCs) in residential halls provide opportunities for students to purposefully engage with each other, often around curricular and co-curricular community experiences and programming. Establishing a LLC of African American college men, particularly at predominately White institutions, would promote an educational environment, networks, and resources conducive to the success and identity development of African American college men. LLCs often include partnerships between faculty, staff, and students, which are a significant resource for African American college men. The practical implications that the findings of this study support also include creation of residential college models, theme learning communities, and academic course clustering of diverse groups of students interested in sharing and learning more about the rich culture and heritage of African American 
people. Essentially, this community-based model would establish allies for African American students, while also providing culturally affirming networks and relationships for African American college men and women.

2. One of findings of this study addresses the commitment of African American college men to give back to and to involve themselves with their communities. African American college men would be a natural asset to civic engagement and service learning professionals who seek to engage students in community development experiences. A particular focus for civic engagement and service learning professionals is to target areas representative of the African American students from urban, suburban, and rural communities. This strategy may create a broader scope of services for the institution as well as create meaningful experiences for African American college men who desire to positively impact local communities, particularly the African American segments.

3. Similar to the professionals in students affairs units who have oversight of civic engagement and service learning initiatives, academic affairs professionals who seek to promote institutional goals for international service learning initiatives may also target the commitment to service of African American college men. International service learning may provide an opportunity for African American college men to develop a global perspective to service as well as reflect about the significance of who they are and their contributions within a global community. 
4. As college and university educators prepare students to enter the world of work, career services and development professionals must also consider how to reconcile the passion associated with community service and the career exploration or vocations of African American college men. It is incumbent upon these professionals to understand the influence the cultural identity of African American men can have on their specific ambitions, particularly when academic preparation may have a meaningful connection to vocational aspiration and service.

5. Counseling and psychological service professionals will serve as a needed resources for African American college men as they explore the significance of their racial and ethnic, manhood and masculine identities. Specifically, counseling and psychological service professionals must know how to effectively support the mental health maintenance, emotional distress reduction, crisis management, and overall psychological wellness of African American college men transitioning to and matriculating through college. In addition, these findings may assist college mental health professionals by contributing to their cultural knowledge and recommended responsiveness as practitioners to African American college men.

6. The findings presented in this study contribute to the recruitment and retention strategies of college admissions and enrollment management professionals. In the field, admission counselors may use these findings in relating to and understanding the particular intricacies of ethnicity and 
masculinity of prospective African American male college students within urban, suburban, and rural recruitment territories. Additionally, these findings aid undergraduate enrollment management or undergraduate academic service professionals who provide or may consider offering precollege student support initiatives that promote the academic and institutional transition of underrepresented student populations to the college environment. Furthermore, these findings support connecting African American networks and resources to admissions' campus visit recruitment strategies throughout the academic year for prospective African American men and women.

7. It is the responsibility of orientation and new student programs to introduce new students to the institution, the campus environment, and its collective support networks to ensure that students are knowledgeable of campus resources and well equipped to transition into college. Orientation and new student service professionals may establish specific networks or initiatives that directly connect African American networks with African American college men during campus orientation events and continuing initiatives throughout the academic year for the purpose of assisting African American male students to develop important relationships with faculty, staff, and students. Likewise, faculty, staff, and students may develop or enhance an academic orientation that integrates and prepares African American men and women for each academic discipline to further establish 'fit' within academia. 


\section{Limitations of the Study}

Although it was difficult to anticipate all related limitations of this study, it is important to understand that no research design—qualitative, quantitative, or mixed methods - goes without its limitations (Creswell, 2003). First, this study was limited by any potential selection biases of participant nominators of African American college men because each nominator used their subjective judgment when recommending potential participants. However, this particular limitation is defensible, as all potential participants must have met the selection criteria, first. Also, due to underrepresented percentage of enrolled African American collegiate men at Metropolitan University, this purposeful sample of participants is not intended to be generalizable to other populations. This study did not take into consideration or sought to include perspectives of other genders or ethnicities. Participants elected not to submit critical incident reports after in-depth interviews, despite follow up with each participant to ensure they had any further statements to report for this study. The data and subsequent findings from this study may not be considered applicable to all predominately White institutions of higher education. Furthermore, I had to enter this study with the reality that my ethnic and masculine identity as an African American man with similar backgrounds of participants may present researcher bias, however journaling and memos assisted me in avoid bias analysis. To this point, my ethnic and masculine identities also provided access into the lives of these African American college men that might otherwise present limiting factors for other researchers who did not share similar characteristics and experiences. 


\section{Conclusion}

The purpose of this study was to understand how the lived experiences of African American college men inform the construction of masculine and ethnic notions of their identities at a predominate White institution, despite disproportionate racial, hegemonic, and social obstacles. Specifically, this research examined perceptions and critical incidents that nine African American college men understood as most salient toward successfully negotiating the intersection of ethnicity and masculinity. The counterstories of these college men gave voice to the authentic meaning they prescribed to their lived experiences as African American men. The conclusions from this study address: (a) African American college men's' characterization of their ethnic identity; (b) African American college men's perception of their masculinity; (c) the performance of African American college men's perception of masculinity; (d) the intersection of the masculine and ethnic identities of African American college men; and (e) the impact of attending college on African American men's identities at a predominately White institution. The following is presented in four conclusions based on a synthesis of the research questions as they relate to the findings.

\section{The performance of African American college men's perception of masculinity}

The African American college men involved in this study characterized their ethnic identity by the shared commonality of their African American heritage and culture. In effect, they ethnically identified themselves as African American, with little direct connections to Africa besides how they understood and related to the historical significance of slavery and distinctions of their African rootedness. Because race and ethnicity was often used interchangeably to categorize Black and African American 
people, race and racial stereotyping emerged as a persistent social hurdle, but not an insurmountable barrier, in the lives of the nine African American college men. Race was associated with the pervasive negative racial stereotyping ascribed to African American people, but particularly negatively associated to them as African American men.

What is most intriguing was how participants varied the dimensions of their culture with their ethnic and racial identities based upon their local communities and the location of their physical environment. Their physical environments were representative of the rural, suburban, and urban communities where they lived. These demarcated geographic areas also corresponded with the degree of negative racial stereotypes and the critical mass of African Americans who populated each community. For example, urban communities had a greater population of African Americans and were ascribed more negative racial stereotypes. However, it was a consensus among participants that no physical environment, or social class, freed them from the pervasive messages of negative racial stereotypes reserved for all African Americans. As a result, participants acknowledged using code switching as a social coping strategy to counter negative racial stereotyping and to adapt to predominate White social norms.

\section{The characterized perceptions and performances of manhood and masculinity}

Most of the African American college men characterized their perception and performances of masculinity and manhood with patriarchal expectations of masculine ideology; however, their counterstories embraced a community-oriented, emotionally expressive, and cultural collective ideology as affirmed by the cultural values and faith of their African American communities. Their performance of masculinity was thematically represented as Handling Your Business, which involved their overall attitude of being 
responsible, accomplishing tasks, taking care of prescribed responsibilities as a student and their overall characterizations and perceptions associated with serving as African American male role models and the responsibilities representative of fatherhood as African American men. These African American college men assumed the characteristics of masculinity, but understood manhood as a developmental process of responsibilities, which they have not yet achieved.

The intersection of the masculine and ethnic identities of African American college men

The intersections of their ethnic and masculine identities are influenced by the varied messages and experiences of their cultural background within African American families, communities, peers, and the negative racial stereotypes of within a predominately White society. As stated in the discussion of findings, these influences contribute in establishing their own complex versions of Black masculinity that intersects with other parts of their social identities. Because of their social and communal influences and that they perceived manhood as a developmental process, their journey towards Reframing their versions of Black Manhood and Masculinities is also a developmental process.

The impact of college on African American men's identities at a PWI

African American college networks, especially those dedicated to the academic and social success of African American men, established an environment where they could thrive as African American college men. These men were able to develop meaningful relationships with other African American male faculty, staff, and students. These networks and relationships served as socializing agents at the start of their college experience and remain a part of their culturally connected experiences in college. Lastly, 
these African American networks and relationships aided them in further developing an attitude of success and the resolve to continue to reject and transcend negative racial stereotypes. 


\section{REFERENCES}

A brief history of UofL Retrieved from http://louisville.edu/about/history.html

Abreu, J. M., Goodyear, R. K., Campos, A., \& Newcomb, M. D. (2000). Ethnic belonging and traditional masculinity ideology among African Americans, European Americans, and Latinos. Psychology of Men \& Masculinity, 1, 75-86.

Akbar, N. (1991). Visions for Black men. Tallahassee, FL.: Mind Productions \& Associates, Inc.

August, E. R. (1982). “Modern Man,” or Men's Studies in the '80s. College English, 42, 583-595.

Bem, S. (1974). The measurement of psychological androgyny. Journal of Consulting and Clinical Psychology, 42, 165-174.

Blackhurst, A. B. (1995). The relationship between gender and student outcomes in a freshman orientation course. Journal of the Freshmen Year Experience, 7, 63-80.

Braithwaite, L. R. (1981). Interpersonal relations between Black males and Black Females. In L. E. Gary (Ed.), Black Men (pp. 83-97). Beverly Hills, CA: Sage.

Branch-Simpson, G. (1984). A study of the patterns in the development of Black seniors at The Ohio State University. (Doctoral dissertation, The Ohio State University, 1984). Dissertation Abstract International, 45-08A, 2422. 
Brod, H. (1987). A case for men's studies. In M. S. Kimmel (Ed.), Changing men: New directions in research on men and masculinity (pp. 263-277). Beverly Hills, CA: Sage.

Brod, H. \& Kaufman, M. (Eds.). (1994). Theorizing masculinities. Thousand Oaks, CA: Sage.

Cabrera, A., Nora, A., Terenzini, V., Pascarella, E., and Hagedorn, L. (1999). Campus racial climate and the adjustment of students to college: A comparison between White students and African American-American students. Journal of Higher Education, 70, 134-160.

Chickering, A. W. (1969). Education and identity. San Francisco: Jossey-Bass.

Chickering, A. W., \& Reisser, L. (1993). Education and identity (2nd ed.). San Francisco: Jossey-Bass.

Clatterbaugh, K. (1990). Contemporary Perspectives on Masculinity: Men, Women, and Politics in Modern Society. Boulder, CO.: Westview Press.

Collins, P. H. (2006). A telling difference: Dominance, strength, and Black masculinities. Progressive Black masculinities. A. D. Mutua. New York: Routledge.

Cornwall, A. \& Lindisfrane, N. (Eds.). (1994). Dislocating masculinity: Comparative ethnographies. New York: Rutledge. 
Crenshaw, K. W. (1989). Demarginalizing the intersection of race and sex: A Black feminist critique of antidiscrimination doctrine, feminist theory, and antiracist politics. University of Chicago Legal Forum, 139-67.

Crenshaw, K. W. (1991). Mapping the margins: Intersectionality, identity politics, and violence against women of color. Stanford Law Review, 43(6), 1241-1299.

Crenshaw, K., Gotanda, N., Peller, G., \& Thomas, K. (Eds.). (1995). Critical race theory: The key writings that formed the movement. New York: New Press.

Creswell, J. W. (2003). Research design: Qualitative, quantitative, and mixed methods approaches (2nd ed.). Thousand Oak, CA: Sage.

Cross, W. E., Jr. (1971). The Negro to Black conversion experience: Towards a psychology of Black liberation. Black World, 20, (9), pp. 13-27.

Cross, W.E., Jr. (1995). The psychology of Nigrescence: Revisiting the Cross model. In J. G. Ponterotto, J. M. Casas, L. A. Suzuki, \& C. M. Alexander (Eds.), Handbook of multicultural counseling (pp. 93-122). Thousand Oaks, CA: Sage.

Cuyjet, M. J. (1997). African American men on college campuses: Their needs and their perceptions. In M.J. Cuyjet (Ed.), Helping African American men succeed in college. New Directions for Student Services, no. 80, pp. 5-16, San Francisco: Jossey-Bass.

Cuyjet, M. J. (Ed.). (1997). Helping African American men succeed in college. New Directions for Student Services, no. 80. San Francisco: Jossey-Bass. 
Cuyjet, M. J. (Ed.). (2006). African American men in college. San Francisco, CA. JosseyBass.

Davis, T. (1985). Men's Studies: Defining its contents and boundaries. Paper presented at the Tenth National Conference on Men and Masculinity, St. Louis, MO.

Delgado-Bernal, D. (2001). Living and learning pedagogies of the home: the mestiza consciousness of Chicana students, International Journal of Qualitative Studies in Education, 14(5), 623-639.

Delgado-Bernal, D. (2002). Critical race theory, LatCrit theory and critical racedgendered epistemologies: recognizing Students of Color as holders and creators of knowledge, Qualitative Inquiry, 8(1), 105-126.

Delgado, R. (1995). Critical race theory: The cutting edge. Philadelphia: Temple University Press.

Delgado, R. \& Stefancic, J. (2001) Critical race theory: An introduction. New York: New York University Press.

Denzin, N. K. and Y. S. Lincoln (2003). The landscape of qualitative research: theories and issues. Thousand Oaks, CA: Sage.

Di Stefano, C. \& Kimmel, M. S. (1992). Configurations of masculinity. Contemporary Sociology, 21, 162.

Doyle, J. A. (1983). The male experience. Dubuque, IA: W.C. Brown. 
Du Bois, W. E. B. (1903/2003). The Souls of Black Folk. Chicago: A.C. McClurg \& Co.; [Cambridge]: University Press John Wilson and Son, Cambridge, U.S.A.; Modern Library Edition.

Du Bois, W. E. B. (1908). The Negro American family. Paper presented at the Thirteenth Annual Conference for the Study of the Negro Problem, Atlanta University, Tuesday, May 26, 1908, Atlanta, GA.

Durham, R. L., Hays, J., \& Martinez, R. (1994). Socio-cognitive development among Chicano and Anglo-American college students. Journal of College Student Development, 35, 178-182.

Edmunds, H. (1999). The focus group research handbook. Chicago: NTC/Contemporary Publishing Group, Inc.

Eisler, R. M. \& Skidmore, J. R. (1987). Masculine role gender stress: Scale development and component factors in the appraisal of stressful situations. Behavior Modification, 11, 123-136.

Erikson, E. H. (1950). Childhood and society. New York: W. W. Norton \& Company.

Erikson, E. H. (1968). Identity: Youth and crisis. New York: W. W. Norton \& Company.

Erikson, E. H. (1980). Identity and the life cycle. New York: W. W. Norton \& Company.

Evans, N. J., \& D'Augelli, A. R. (1996). Lesbians, gay men, and bisexual people in college. In R. C. Savin-Williams \& K. M. Cohen (Eds.), The lives of lesbians, 
gays, and bisexuals: Children to adults (pp. 201-226). Fort Worth, TX: Harcourt Brace.

Evans, N. J., Forney, D. S., Guido, F., Patton, L. D. \& Renn, K. (2010). Student development in college: Theory, research, and practice (2nd ed.). San Francisco: Jossey-Bass.

Farrel, W. (1974). The liberated man. New York: Random House.

Fasteau, M. (1975). The male machine. New York: McGraw-Hill.

Foubert, J., Nixon, M. L., Sission, V. S., \& Barnes, A. C. (1995). A longitudinal study of Chickering and Reisser's vectors: Exploring gender differences and implications for refining the theory. Journal of College Student Development, 46, 461-471.

Franklin, C.W. (1984). The changing definition of masculinity. New York: Plenum Press.

Franklin, C. W. (1988). Men in society. Chicago, IL: Wadsworth Publishing.

Franklin, C. W. (1994). Men's studies, the men's movement, and the study of Black masculinities: Further demystification of masculinities in America. In R. G. Majors \& J. U. Gordon (Eds.), The American Black male: His present status and his future. Chicago: Nelson-Hall.

Frazier, E. F. (1926). Three scourges of the Negro Family. Opportunity, 4, 210-213, 234.

Frazier, E. F. (1927). Is the Negro a unique sociological unit? Opportunity, 5 (6):165168. 
Frazier, F. E. (1966). The Negro family in the United States. Chicago: University of Chicago Press.

Gary, L. (Ed.). (1981). Black men. Newbury Park, CA: Sage.

Gibbs, J. T. (1988). Young, Black, and male in America: An endangered species. New York: Auburn House.

Gibson, G. (1995). Chickering's model of student development and the academic performance of African American college students on a predominantly White campus, Doctoral Dissertation, North Carolina State University.

Gilmore, D. G. (1990). Manhood in the making: Cultural concepts of masculinity. New Haven, CT: Yale University Press.

Gilroy, P. (1993). The Black Atlantic: Modernity and double consciousness. Cambridge, MA: Harvard University Press.

Given, L. M. (2008). The Sage encyclopedia of qualitative research methods. Los Angeles, CA: Sage.

Glesne, C. (1999). Becoming qualitative researchers: An introduction. New York: Addison Wesley Longman.

Good, G. E., Robertson, J. M. \& O’Neal, J. M. (1995). Male gender role conflict. Journal of Counseling and Development, 43, 2-10.

Gordon, J. U. (Ed.). (2002). The Black male in White America. New York: Nova Science Publishers 
Grier, W. \& Cobbs, P. (1968). Black rage. New York: Basic Books, Inc.

Hammond, W.P. \& Mattis, J.S. (2005). Being a man about it: Manhood meaning among African American men, Psychology of Men \& Masculinity. 6, (2), 114-126

Hardiman, R. (1982). White identity development: A process oriented model for describing the racial consciousness of White Americans. Doctoral Dissertation, University of Massachusetts, Amherst.

Hare, N. (1971). The frustrated masculinity of the Negro male. In R., Staples, (Ed.) The Black family. Belmont, CA: Wadsworth.

Harris, F. (2008). Deconstructing masculinity: A qualitative study of college men's masculine conceptualizations of gender performance. NASPA Journal, 45, 453474.

Helms, J. E. (1995). An update of Helms's White and people of color racial identity models. In J. G. Ponterotto, J. M. Casas, L. A. Suzuki \& C. M. Alexander (Eds.), Handbook of multicultural counseling (pp. 181-198). Thousand Oaks, CA: Sage.

Holstein, J. A. \& Gurbrium, J. F. (1995). The active interview. Sage University Paper Series on Qualitative Research Methods, v. 37. Thousand Oaks, CA: Sage.

hooks, b. (1981) Ain't I a Woman?: Black women and feminism. Boston, MA: South End Press.

hooks, b. (1984). Feminist theory: From margins to center. Boston, MA: South End Press. 
hooks, b. (2004). We real cool: Black men and masculinity. Routledge: New York

Jackson, B.W. (1976). Black identity development. In L. H. Golubchick and B. Persky (Eds.), Urban, Social, and Educational Issues (pp.158-164). Dubuque, Iowa. Kendall/Hunt

Jackson, B. W. (2001). Black identity development: Further analysis and evaluation. In C L. Wijeyesinghe \& B W. Jackson III (Eds.), New perspectives on racial identity development: A theoretical and practical anthology (pp.8-31).New York: New York University Press.

Johnson, J. L., \& Cuyjet, M. J. (2010). Enhancing identity development and sense of community among African American males in higher education. In H. T. Frierson, J. H. Wyche, \& W. Pearson, Jr. (Eds.) Black American males in higher education: Research, programs and academe (pp. 57-78). United Kingdom: Emerald Books.

Kimmel, M. S. (1996). Manhood in America: A cultural history (2nd ed.). New York: Oxford University Press.

Kimmel, M. (2006). Toward a pedagogy of the oppressor. In A. D. Mutua (ed.), Progressive black masculinities (pp. 63-72). New York: Routledge.

Kodama, C. M., McEwen, M. K., Liang, C., \& Lee, S. (2001). A theoretical examination of psychosocial issues for Asian Pacific American students. NASPA Journal, 38, 411-437. 
Kodama, C. M., McEwen, M. K., Liang, C. T. H., \& Lee, S. (2002). An Asian American perspective on psychosocial development theory. In M. K. McEwen, C. M. Kodama, A. N. Alvarez, S. Lee, \& C. T. H. Liang (Eds.), Working with Asian American college students, New Directions for Student Services, No. 97, pp. 4559. San Francisco: Jossey-Bass.

Levant, R. F., Hirsch, L. S., Celentano, E., \& Cozza, T. M. (1992). The male role: An investigation of contemporary norms. Journal of Mental Health Counseling, 14, 325-337.

McAdoo, H. P. (2007). Black families (4 ${ }^{\text {th }}$ ed.). Thousand Oaks, CA: Sage.

Majors, R. G. \& Billson, J. M. (1993). Cool pose: The dilemmas of Black Manhood in America. New York: Touchstone.

Majors, R. G. \& Gordon, J. U. (1994). (Eds.), The American Black Male. Chicago: Nelson-Hall.

Matsuda, M. (1991). Voices of America: accent, antidiscrimination law and a jurisprudence for the last reconstruction. Yale Law Journal, 100, 1329-1407.

Morgan, D.H.J. (1981). Men, masculinity and the process of sociological enquiry. In H. Roberts (ed.), Doing feminist Research. (pp.83-113). Routledge.

Morgan, D. L. (1988). Focus groups as qualitative research. Sage University Paper Series on Qualitative Research Methods, v. 16. Newbury Park, CA: Sage. 
Moynihan, D. P. (1965). The Negro family: The case for national action. Washington, DC: U.S. Government Printing Office

Mutua, A. D. (Ed.). (2006). Progressive black masculinities. New York: Routledge.

Newton, J. (2005). From panthers to promise keepers: rethinking the men's movement. Lanham, MD: Rowman \& Littlefield.

Ogbu, J. (2002) Black-American students and the academic achievement gap: What else you need to know. Journal of Thought, 37(4), 9-33.

Omni, M. \& Winant, H. (1995). Hate-violence. In P. S. Rothenberg, Race, class and gender in the United States: An integrated study ( $3^{\text {rd }}$ Ed.), (p. 13-22). New York: St. Martin's Press.

O’Neal, J. (1981). Patterns of gender-role conflict and strain: Sexism and fear of femininity in men's lives. Personnel and Guidance Journal, 60, 203-210.

Parham, T. A., White, J. L. \& Ajamu, A. (2000). The psychology of Blacks: An African centered perspective (3rd ed.). Upper Saddle River, NJ: Prentice Hall.

Pascarella, E. T., \& Terenzini, P. T. (2005). How college affects students: A third decade of research (Vol. 2). San Francisco: Jossey-Bass.

Patton, M. Q. (2002). Qualitative research and evaluation methods. Thousand Oaks, CA: Sage.

Pleck, E. H., and Pleck, J. H. (1980). The American man. Englewood Cliffs, NJ: PrenticeHall. 
Pleck, J. H. (1981). The myth of masculinity. Cambridge, MA: M.I.T. Press.

Pope, R. L. (1998). The relationship between psychological development and racial identity of Black college students. Journal of College Student Development, 39, $273-282$.

Pope, R. L. (2000). The relationship between psychological development and racial identity of college students of color. Journal of College Student Development, 41, 302-312.

Reed, R. (1988). Education and achievement of young Black males. In J. T. Gibbs (Ed.), Young, Black, and male in America: An endangered species (pp. 37-96). Dover, MA: Auburn House Pub. Co.

Roach, R. (2001). Where are the Black men on campus? Black Issues in Higher Education, 18(6), 1-24.

Rose, S. D., \& Bylander, J. (2007). Border crossings: Engaging students in diversity work and intergroup relations. Innovative Higher Education, 31(5), 251-264. Retrieved from http://search.proquest.com/docview/62039158?accountid=14665

Rothenberg, P. S. (1995). Race, class and gender in the United States: An integrated study ( $3^{\text {rd }}$ Ed.). New York: St. Martin's Press.

Rumberger, R. (1983). Dropping out of high school: The influence of race, sex and family background. American Educational Research Journal, 20, 199-220. 
Seidman, A. (1989). Recruitment begins with retention: Retention begins with recruitment. Colleague, $40-45$

Seidman, I. E. (1998). Interviewing as qualitative research: A guide for researchers in education and the social sciences $\left(2^{\text {nd }} \mathrm{Ed}\right)$. New York: Teachers College Press.

Sheffield, C. (1995). Hate-violence. In P. S. Rothenberg, Race, class and gender in the United States: An integrated study ( $3^{\text {rd }}$ Ed.), (pp. 432-444). New York: St. Martin's Press.

Smiley, A. D. (2006). Urban legend in teacher education. Journal of Urban Learning, Teaching, and Research, 2, 244-253. Retrieved from http://search.proquest.com/docview/964184766?accountid=14665

Solomon, B. (1988). The impact of public policy on the status of young Black males. In J. T. Gibbs (Ed.) Young, Black, and male in America: An endangered species. New York: Auburn House.

Solórzano, D. G., \& Yosso, T., J. (2002). Critical race methodology: Counter-storytelling as an analytical framework for education research. Qualitative Inquiry, 8(1), 2344.

Spender, D. (Ed.). (1981). Men's Studies Modified: The Impact of Feminism on the Academic Discipline. Oxford: Pergamon Press.

Staples, R. (1978a). The Black family: Essays and studies. Journal of Social Issues, 34, 169-183. 
Staples, R. F. (1978b). Masculinity and race: The dual dilemma of Black men. Journal of Social Issues, 34, 169-183.

Staples, R. F. (1982). Black masculinity: The Black male's role in American society. San Francisco: The Black Scholars Press.

Straub, C. (1987). Women's development of autonomy and Chickering's theory. Journal of College Student Personnel, 28, 198-205.

Stroller, R. (1968). Sex and gender: On the development of masculinity and femininity. New York: Science House.

Taub, D. J., \& McEwen, M. K. (1991). Patterns of development of autonomy and interpersonal relationships in Black and White undergraduate women. Journal of College Student Development, 32, 502-508.

Taub, D. J. (1995). Relationship of selected factors to traditional-age undergraduate women's development of autonomy. Journal of College Student Development, 36, $141-151$.

Taub, D. J., \& McEwen, M. K. (1992). The relationship of racial identity attitudes to autonomy and mature interpersonal relationships in Black and White undergraduate women. Journal of College Student Development, 33, 439-446.

Taylor, R. L. (1977). Socialization to the Black male role. In D. Y. Wilkinson \& R. L. Taylor (Eds.), The Black male in America: Perspectives on his status in contemporary society (pp. 1-7). Chicago, IL: Nelson-Hall. 
Taylor, R. J. \& Johnson, W. E. (1997) The Significant other: Family roles and family satisfaction among Black men. In R. J. Taylor, J. S. Jackson, \& L. M. Chatters (Eds.), Family Life in Black America (pp. 250-263). Thousand Oaks: Sage.

Thomas, C. W. (1971). Boys No More: A Black Psychologist's View of Community. Beverly Hills, CA.: Glencoe.

Thompson, E. H. \& Pleck, J. H. (1986). The structure of male norms. American Behavioral Scientist, 29, 531-543.

Thompson, E. H., Pleck, J. H., \& Ferrera, D. L. (1992). Men and masculinities: Scales for masculinity ideology and masculinity-related constructs. Sex Roles, 27, 573-607.

Tinto, V. (1975). Dropouts from higher education: A theoretical synthesis of recent research. Review of Education Research, 45, 89-125.

Tinto, V. (1987), Leaving college: Rethinking the causes and cures for student attrition. Chicago: University of Chicago Press.

Tinto, V. (1993). Leaving college: Rethinking the causes and cures of student attrition (2nd ed.). Chicago: University of Chicago Press.

Tinto, V. \& Wallace D. L. (1986). Retention: An academic admission concern. College and University, 61, 290-293.

Tolson, A. (1977). The limits of masculinity. London: Tavistock. 
Torres, V. (2003). Influences on ethnic identity development of Latino college students in the first two years of college. Journal of College Student Development, 40 (3), 285.

Ture, K. \& Hamilton, C. V. (1967/1992). Black power: The politics of liberation. New York: Vintage Books.

Upcraft, M. L. \& Schuh, J. H. (1996). Assessment in student affairs: A guide for practitioners. San Francisco, CA: Jossey-Bass.

Vogt, W.P. (1998). Dictionary of statistics and methodology: A non-technical guide for the social sciences $\left(2^{\text {nd }}\right.$ ed.). Thousand Oaks, CA: Sage.

White, J. L. \& Cones, J. H. (1999). Black men emerging: Facing the past and seizing a future in America. New York: W. H. Freeman and Company.

Wright, D. J. (1987). Minority students: Developmental beginnings. In D. J. Wright (Ed.), Responding to the needs of today's minority students. New Directions for Student Services, No. 38, pp. 5-22. San Francisco: Jossey-Bass.

Yin, H. (2013, February 25). U.S. Census will no longer use the term 'Negro' [U.S. Census is predicted to stop using Negro in census checkbox "Black, African Am., or Negro.’]. Retrieved from http://www.huffingtonpost.com/2013/02/25/uscensus-surveys-will-no-longer-use-negro_n_2759306.html 
Yosso, T. J. (2006a). Whose culture has capital? A critical race theory discussion of community cultural wealth. In C. K. Rousseau \& A. D. Dixson (Eds.), Critical race theory in Education (pp. 167-189). New York: Routledge.

Yosso, T. J. (2006b). Critical race counterstories along the Chicana/o educational pipeline. NewYork: Routledge. 


\section{APPENDIX A}

\section{Participant Nominator Email}

Date:

Dear [nominator name],

I am writing to request your assistance to nominate African American undergraduate men at your institution to serve as participants for my dissertation research. The purpose of this study is to explore and advance how African American college men construct authentic masculine and ethnic perceptions of their identities. Specifically, this study seeks to understand as well as give voice to participants' perspectives and experiences with racialized gender structures, while challenging traditional knowledge that shape African American college men's lives.

As a participant nominator, I request that you recommend African American college men to participate in a group and/or individual interviews that meet the following criteria:

- Identify as Black of African American

- Identify as male

- Enrolled as a current degree-seeking undergraduate student (Freshman, Sophomore, Junior, and Senior).

- Willingness to discuss issues of race and racism

- Willingness to discuss issues of manhood and masculinity

For this study, I am seeking diverse student perspectives and experiences. Perhaps you have engaged in conversation with these men about issues of race, ethnicity, or masculinity. You may have knowledge that they discuss these issues with their peers, in the classroom, during co-curricular activities, or through college affinity groups (e.g., resident assistants, men's peer groups, fraternities, military, academic honor societies, athletics, student government, or peer advisors). Other than the criterion listed above, I am not requesting a particular "type" of student, but a student who is willing to share candidly their perspectives and experiences as African American, men, and college students. Their participation will be for approximately 4-6 weeks.

Please email me the names and contact information (if possible, email addresses) of at least three or more African American men who may serve as potential candidates for this important study. You may send me their names by August 6, 2012. Unless you would like to remain anonymous, I will inform students who personally nominated them for this study.

Please feel free to contact me should you have questions or require clarification. You may contact me directly 706-XXX-XXXX or by email at jonathanjohnson@me.com. 
You may also contact my faculty advisor, Dr. Michael J. Cuyjet, at 502-xxx-xxxx or by email at cuyjet@,louisville.edu for further questions about this study.

Respectfully,

Jonathan L. Johnson

Dr. Michael J. Cuyjet

Doctoral Candidate

Professor

Educational \& Counseling Psychology

Educational \& Counseling Psychology 


\section{APPENDIX B \\ Nominated Participant Email}

Date:

Dear [nominated name],

Greetings! My name is Jonathan (JJ) Johnson. I am a doctoral student at the University of Louisville conducting research on the ethnic and masculine identities of African American college men. [participant nominator's name] gave me your name because he/she believes your insight and participation may greatly contribute to my study. It is my hope that you will consider the potential of making an important contribution to this study of African American college men.

First, I request that you confirm your preliminary interests by simply responding "Yes" and sending me a phone number to speak with you for less than 5 minutes. Or, simply reply, "No thanks, I am not interested." If your are interested, during our brief conversation, I would like to further introduce myself, answer your questions, share information about this study, as well as learn about your availability should more information from you is potentially needed later this fall semester.

Please know that our conversation will be confidential and you will choose a pseudonym or "code name" to use for the purpose of this study. It is also important to know that your participation is voluntary and you have the choice not to participate or may withdraw from the study at any time. Based on your response to this email, I will contact you to schedule a convenient time to talk.

Please do not hesitate to contact me should you have questions or require clarification about anything regarding this study. Your time and insight is valuable to me. You may call or text me directly using my mobile phone at $706-\mathrm{XXX}-\mathrm{XXXX}$ or by email at jonathanjohnson@me.com. You may also contact my faculty advisor, Dr. Michael J. Cuyjet, at 502-xxx-xxxx or by email at cuyjet@,louisville.edu for further questions about this study.

Respectfully,

Jonathan L. Johnson

Doctoral Candidate

Educational \& Counseling Psychology
Dr. Michael J. Cuyjet

Professor

Educational \& Counseling Psychology 


\section{APPENDIX C}

\section{Preamble/Script for Prescreening Survey}

Date [date of phone screening]

Good afternoon (morning or evening) [Participant's name]:

My name is Jonathan Johnson. I am a doctoral candidate in the Department of Educational and Counseling Psychology at the University of Louisville. You are being invited to participate in a phone survey by answering questions during this phone conversation about your college status as well as your readiness to discuss topics about race and manhood. There are no known risks for your participation in this phone survey. The information collected may not benefit you directly. The information learned in this study may be helpful to others. The information you provide will enhance what college educators know about the ethnic and masculine identities of African American college men and their ability to assist Black males to successfully matriculate college. The phone survey will take approximately five minutes to complete.

Individuals from the Department of Educational and Counseling Psychology, the Institutional Review Board (IRB), the Human Subjects Protection Program Office (HSPPO), and other regulatory agencies may inspect these records. In all other respects, however, the data will be held in confidence to the extent permitted by law. Should the data be published, your identity will not be disclosed.

Taking part in this phone survey is voluntary. By answering questions during this phone conversation you agree to take part in this phone survey. You do not have to answer any questions that make you uncomfortable. You may choose not to take part at all. If you decide to take part of this phone survey you may stop taking part at any time. If you decide not to be in this phone survey or if you stop taking part at any time, you will not lose any benefits for which you may qualify.

If you have any questions, concerns, or complaints about the research study, please contact: Dr. Michael J. Cuyjet, at 502-xxx-xxxx.

If you have any questions about your rights as a research subject, you may call the Human Subjects Protection Program Office at (502) 852-5188. You can discuss any questions about your rights as a research subject, in private, with a member of the Institutional Review Board (IRB). You may also call this number if you have other questions about the research, and you cannot reach the research staff, or want to talk to someone else. The IRB is an independent committee made up of people from the University community, staff of the institutions, as well as people from the community not connected with these institutions. The IRB has reviewed this research study.

If you have concerns or complaints about the research or research staff and you do not wish to give your name, you may call 1-877-852-1167. This is a 24 hour hot line answered by people who do not work at the University of Louisville.

Do I have your consent to proceed with this brief phone survey?

[Conduct prescreening survey] 


\section{APPENDIX D \\ Prescreening Interest Questions}

Name:

Local or Campus Address:

Email Address:

Telephone Number:

Please describe your college involvement (fraternity, athlete, resident assistant, student groups, etc.) List all that apply.

What is your college Major/Minor/Certifications:

What is your academic classification (year in school)?

What are your plans after graduating college (career, graduate school, volunteer, military, etc.)?

Date of birth:

Willingness to discuss issues of race and racism:

Willingness to discuss issues of manhood and masculinity:

Are you available this Fall if I have additional questions? 


\section{APPENDIX E}

\section{Invitation Letter}

Date:

Dear [participant name],

You are invited to actively participate in this study. Know that your participation is voluntary. Because your participation is voluntary, you have the choice not to participate and may withdraw from the study at any time. It is also important to know that your choice to participate or not to participate will be held confidentially and will not affect your status at the University.

The purpose of this study is to explore and advance how African American college men construct authentic masculine and perceptions notions of their identities. Specifically, this study seeks to understand and give voice to participants' perspectives and experiences with racialized gender structures, while challenging traditional knowledge claims that shape African American college men's lives.

If you chose to participate, you will be asked to participate in a focus group with approximately ten to twelve other African American men for 60-90 minutes. Second, you would be asked to engage in a series of 1 to 2 in-depth individual interviews for approximately 90-120 minutes each. Given your consent, both the focus group and individual interviews will be audio recorded and transcribed verbatim. You have the right to not answer any question at anytime during all interviewing sessions. Your total participation in this study will span approximately 4 to 6 weeks.

The focus group discussion and series of individual interviews are designed for you to self-explore the personal intricacies of being Black and male in college. The knowledge gained from this study may enhance what college educators know about the ethnic and masculine identities of African American college men.

Your participation in this study is completely voluntary. There is no cost to participate, however, your time in participating in the dialogue and interviews are desired and valuable. Your decision to participate will not affect your future relationship with the University or any related affiliations. If you decide to participate, you may withdraw from the study at any time without affecting your status as a student. Also, because issues or race and racism will be discussed at times during the study, it might evoke memories or an emotional response from you. Again, please know that you can chose not to answer any questions that you do not feel comfortable answering.

Should you have any questions about the study, please feel free to ask me. I will be glad to answer them at any time during and after the study. You may contact me directly at 706-XXX-XXXX or by email at jonathanjohnson@me.com. You may also contact my 
faculty advisor, Dr. Michael J. Cuyjet, by phone at 502-xxx-xxxx or by email at cuyjet@louisville.edu for further questions about this study.

Respectfully,

Jonathan L. Johnson

Doctoral Candidate

Educational \& Counseling Psychology
Dr. Michael J. Cuyjet

Professor

Educational \& Counseling Psychology 


\section{APPENDIX F \\ Not Selected for Study Email}

Date:

Dear [nominated name],

Hello! I would like to thank you again for indicating your interest in my study of African American college men and for talking with me on the telephone about yourself. This study is in the final stages and I was fortunate to have the interest and participation of a number of African American men like you and I would like to thank you for your contribution.

Should you have questions, feel free to contact me directly at 706-XXX-XXXX or by email at jonathanjohnson@me.com. You may also contact my faculty advisor, Dr. Michael J. Cuyjet, at 502-xxx-xxxx or by email at cuyjet@louisville.edu for further questions about this study.

Respectfully,

Jonathan L. Johnson

Doctoral Candidate

Educational \& Counseling Psychology
Dr. Michael J. Cuyjet

Professor

Educational \& Counseling Psychology 


\section{APPENDIX G}

\section{Informed Consent}

\section{Title of study:}

The Social Construction of Ethnicity and Masculinity of African American College Men

IRB assigned number: \#12.0325

Investigator(s) name \& address:

Jonathan L. Johnson

614 Campus Place Apt. 4

Dalton, GA 30720

Site(s) where study is to be conducted: University of Louisville

Phone number for subjects to call for questions: 706-XXX-XXXX

\section{Introduction and Background Information}

You are invited to participate in a research study. The study is being conducted by Jonathan L. Johnson, a doctoral candidate in the Department of Educational and Counseling Psychology. The study is sponsored the University of Louisville, Department of. The study will take place at the University of Louisville, Belknap campus.

Approximately 10-12 subjects will be invited to participate.

\section{Purpose}

The purpose of this study is explore and advance how African American college men construct authentic perceptions of their masculine and ethnic identities.

\section{Procedures}

In this study, you will be asked to participate in a focus group with approximately 10-12 other African American men for 60-90 minutes. Second, you would be asked to engage in at least one in-depth individual interview for approximately 90-120 minutes. Given your consent, both the focus group and individual interviews will be audio recorded and transcribed verbatim. You have the right not to answer any question or to make any statement that makes you feel uncomfortable at anytime during all interviewing sessions. Your total participation in this study will span approximately 4 weeks.

\section{Potential Risks}

While there are possible unforeseen risks associated with participating in focus groups and individual interviews, there are no foreseeable risks in participation in this study other than possible discomfort in answering personal questions.

\section{Benefits}

The possible benefits of this study include your personal exploration of being Black and male in college. The knowledge gained from this study may enhance what college educators know about the ethnic and masculine identities of African American college men and their ability to assist Black males to matriculate successfully. 


\section{Confidentiality}

Total privacy cannot be guaranteed. Your privacy will be protected to the extent permitted by law. If the results from this study are published, your name will not be made public. While unlikely, the following may look at the study records: The University of Louisville Institutional Review Board, Human Subjects Protection Program Office ; Office for Human Research Protections (OHRP); or members of the primary researcher's dissertation committee.

The information collected will be protected and secured in a secured area.

\section{Conflict of Interest}

There is no conflict of interest and as the primary investigator, I am not being compensated in any way to conduct this study.

\section{Voluntary Participation}

Taking part in this study is voluntary. You may choose not to take part at all. If you decide to be in this study you may stop taking part at any time. If you decide not to be in this study or if you stop taking part at any time, you will not lose any benefits for which you may qualify.

\section{Research Subject's Rights, Questions, Concerns, and Complaints}

If you have any concerns or complaints about the study or the study staff, you have three options.

You may contact the principal investigator, Dr. Michael J. Cuyjet, at 502-xxxXXXx.

If you have any questions about your rights as a study subject, questions, concerns or complaints, you may call the Human Subjects Protection Program Office (HSPPO) (502) 852-5188. You may discuss any questions about your rights as a subject, in secret, with a member of the Institutional Review Board (IRB) or the HSPPO staff. The IRB is an independent committee composed of members of the University community, staff of the institutions, as well as lay members of the community not connected with these institutions. The IRB has reviewed this study.

If you want to speak to a person outside the University, you may call 1-877-8521167. You will be given the chance to talk about any questions, concerns or complaints in secret. This is a 24 hour hot line answered by people who do not work at the University of Louisville.

This paper tells you what will happen during the study if you choose to take part. Your signature means that this study has been discussed with you, that your questions have 
been answered, and that you will take part in the study. This informed consent document is not a contract. You are not giving up any legal rights by signing this informed consent document. You will be given a signed copy of this paper to keep for your records.

Signature of Subject/Legal Representative

Signature of Person Explaining the Consent Form (if other than the Investigator)

Signature of Investigator
Date Signed

Date Signed

Date Signed 


\section{APPENDIX H}

\section{Demographic Questionnaire}

Code Name or Pseudonym:

\section{Part 1: GENERAL INFORMATION}

1. Gender:

2. Race/Ethnic distinction:

$\square$ Black/African American

Black/Asian American

Black/Hispanic-Latino/a American

Black/White American

$\square$ Black/American Indian

Other:

3. What is your date of birth?

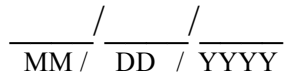

4. Marital status:

$\square$ Married

$\square$ Divorced

Separated

Widowed

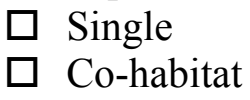

5. How many children do you have?

$$
\text { children }
$$

6. Mark all sources of support you are using to finance your education.

$\square$ Full-time work

Loans

$\square$ Part-time work

$\square$ Scholarships or Grants

$\square$ Employer support

$\square$ Aid from relatives

$\square$ Veteran's benefits

Other (please explain)

$\square$ Savings

\section{PART II: EDUCATION INFORMATION}

7. What type of high school diploma have you completed?
$\square$ GED (general equivalency diploma)
High school diploma

8. When did you first enroll at the University?

$$
\text { Year Semester }
$$

9. What is your approximate grade-point average (GPA)?

$$
\text { GPA }
$$

10. How many credit hours have you completed at the University?

Credits hours 


\section{PART III: FAMILY BACKGROUND}

11. Mother's level of education:

$\square$ No high school diploma

$\square$ GED (general equivalency diploma)

$\square$ High school diploma

$\square$ Baccalaureate degree (B.A., B.S.)

$\square$ Master's degree (M.A., M.S., M.Ed., M.B.A.)

12. Mother's Race/Ethnic identity:

$\square$ Black/African American

$\square$ Black/Hispanic-Latino/a American

Black/White American $\square$ Doctorate (Ph.D., Ed.D.)

$\square$ Professional degree (M.D., D.D.S., J.D.)

Other (please specify)

13. Father's level of education:

$\square$ No high school diploma

$\square$ GED (general equivalency diploma)

$\square$ High school diploma

Baccalaureate degree (B.A., B.S.)

$\square$ Master's degree (M.A., M.S., M.Ed., M.B.A.)

14. Father's Race/Ethnic identity:

$\square$ Black/African American

$\square$ Black/Hispanic-Latino/a American

$\square$ Black/White American $\square$ Black/Asian American

$\square$ Black/American Indian

$\square$ Other: 


\section{APPENDIX I}

\section{Group Interview Guide}

Code Names or Pseudonyms of Participants:

Time:

Date:

Interview Location:

\section{Introduction}

I will introduce myself and explain my role as the facilitator, the purpose of the group, and review the topics we will discuss as it relates to this study. The group will discuss issues of racial and masculine identity as college students.

\section{Purpose of the study}

The purpose of this study is explore and advance how African American college men construct authentic perceptions of their masculine and ethnic identities.

\section{Personal purpose of the group}

I will ask each group participant to introduce himself by stating his name and what he hopes to get out (or personal purpose) of the group's discussion about African American college men.

After introductions, I will summarize the group's collective purpose as well as establish basic group norms of respect, listening to and sharing opinions, and further explain confidentiality.

\section{Materials}

Easel pad, paper/construction paper, pencils, pens, and color markers

\section{Potential group questions}

1. How would you describe your racial and/or ethnicity?" Use words, drawings, and other expressions to illustrate what you feel and/or think. (5-7 minutes for participants to complete)

- How did you come to this meaning?

- How does society make meaning of race and ethnicity?

- How does society's meaning fit or not fit your understanding as African American men? Other African American men?

- What was most significant to you during this activity?

2. What is your definition of manhood and masculinity?

- How did you come to this definition?

- What is society's definition of manhood and masculinity? 
- How does society's definition fit or not fit your understanding as African American men? Other African American men?

3. What have you learned about your race and/or ethnicity and your manhood since coming to college?

- Has your race and/or ethnicity been an important factor since attending college?

- Has your masculinity or manhood been an important factor since attending college?

- Describe if the college has been helpful to affirm and validate your identities (race, ethnicity, masculinity)?

- Describe if you established any relationships with students, faculty, staff, clubs, or organizations that you found affirming to who you are?

- Describe personal expectations and/or experiences that lead you to complete tasks to graduate college successfully?

4. What does it feel like to have a conversation about your race/ethnicity and masculinity/manhood with someone who shares similar characteristics?

- Different characteristics than your own?

- What things about yourself make it both easier and difficult for you to have this conversation?

\section{Concluding and wrap-up questions}

- What topics during our conversation seem to assist you the most?

- Describe what understanding about your identities you did not have before joining the group?

- How would you apply what you heard during this activity to what your experiences have been while in college? Your life experiences beyond campus?

- What questions or comments would you like the group to respond to, for further processing?

- What questions and/or topics would you like to suggest for further discussion during your individual interview? 


\begin{abstract}
APPENDIX J
Individual Interview Guide
\end{abstract}

Code Name or Pseudonym:

Time:

Interview Location:

Date:

\title{
GENERAL
}

- How would you describe yourself in the most general terms?

○ Background

- Characteristics or qualities are most important to you?

○ How would others describe you?

\section{RACE AND ETHNIC IDENTITY}

- How do you describe your racial identity?

- Is race a major feature of your identity? Why or why not?

- How would others describe you?

- How do you describe your ethnic/cultural identity?

○ Is ethnicity a major feature of your identity? Why or why not?

○ How would others describe you?

- Do these race and ethnic descriptions vary by the circumstance or situation?

$\circ$ How and when?

- Describe an experience or time you had a heightened sense of yourself as a Black person or African American?

\section{MASCULINE IDENTITY}

- How do you describe yourself in terms of your masculine identity?

○ Is masculinity a major feature of your identity? Why or why not?

○ How would others describe you?

- How do you describe manhood?

○ Is your description of manhood a major feature of your identity? Why or why not?

○ How would others describe you?

- Do these descriptions of manhood and masculinity vary by the circumstance or situation? 
○ How and when?

- Describe an experience or time you had a heightened sense of yourself as a man?

\section{RACE/ETHNICITY AND MASCULINITY}

- Are your sense of being Black and your sense of being a man interconnected? If so, how?

\section{COLLEGE IDENTITY}

- Has your race/ethnicity been an important factor since attending college? If so, how?

- Has your masculinity/manhood been an important factor since attending college? If so, how?

- Describe how college has affirmed or not affirmed your racial and ethnic identities?

- Describe how college has affirmed or not affirmed your sense of manhood and masculine identities?

- Describe if you have established any relationships with students, faculty, staff, clubs, or organizations that you found affirming to your racial and ethnic identities?

- Classroom

- Campus event

○ Campus involvement

O Within the city

- Peers similar to you

○ Peers not similar to you

- Describe if you have established any relationships with students, faculty, staff, clubs, or organizations that you found affirming to your sense of manhood and masculine identities?

- Classroom

○ Campus event

○ Campus involvement

$\circ$ Within the city

- Peers similar to you

- Peers not similar to you 


\section{Demographic Profiles}

\begin{tabular}{|c|c|c|c|c|c|c|c|c|c|}
\hline 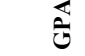 & $\stackrel{\circ}{\dot{m}}$ & $\hat{m}$ & $\bar{m}$ & $\ddot{n}$ & $\stackrel{m}{m}$ & $\hat{i}$ & $\stackrel{n}{m}$ & $\stackrel{m}{n}$ & 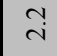 \\
\hline 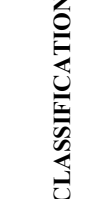 & 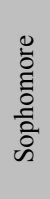 & 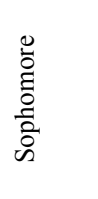 & 苂 & 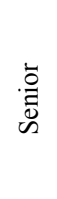 & 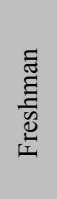 & 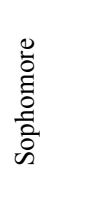 & $\begin{array}{l}\stackrel{\breve{\Xi}}{\leftrightarrows} \\
\stackrel{\bar{\nu}}{2}\end{array}$ & 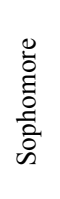 & 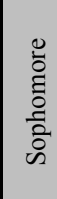 \\
\hline 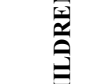 & 0 & 0 & 0 & - & 0 & 0 & 0 & 0 & $N$ \\
\hline 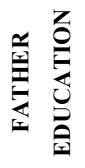 & 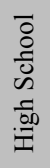 & 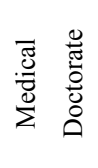 & 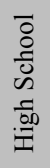 & $\begin{array}{l}\overrightarrow{0} \\
\overline{0} \\
\tilde{y} \\
\bar{D} \\
\overline{0} \\
\overrightarrow{01}\end{array}$ & 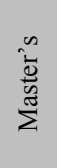 & 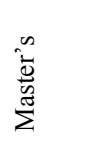 & 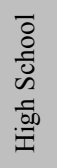 & $\begin{array}{l}\overrightarrow{0} \\
\overline{0} \\
\tilde{c} \\
\overrightarrow{0} \\
\overrightarrow{0.0} \\
\overrightarrow{1}\end{array}$ & 풩 \\
\hline 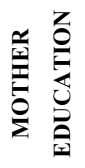 & $\begin{array}{l}\overline{0} \\
\overline{0} \\
\tilde{0} \\
\overline{0} \\
\overline{00} \\
\overrightarrow{0}\end{array}$ & 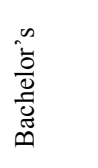 & 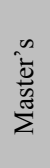 & $\begin{array}{l}\overrightarrow{0} \\
\stackrel{0}{0} \\
\ddot{n} \\
\overrightarrow{.00} \\
\overrightarrow{0}\end{array}$ & 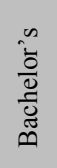 & 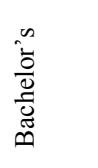 & 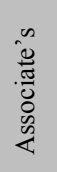 & 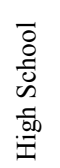 & $\begin{array}{l}\overline{8} \\
\overline{0} \\
\tilde{D} \\
\overrightarrow{0} \\
\overrightarrow{00} \\
\vec{\exists}\end{array}$ \\
\hline 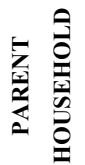 & 䓂 & $\begin{array}{l}\tilde{E} \\
\stackrel{0}{0}\end{array}$ & 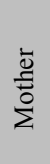 & 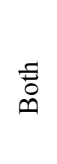 & $\begin{array}{l}\overline{\bar{c}} \\
\overline{\bar{z}} \\
\end{array}$ & 莒 & 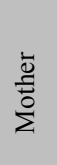 & 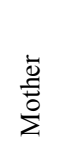 & $\begin{array}{l}\overline{0} \\
\overline{\bar{z}} \\
\bar{c}\end{array}$ \\
\hline 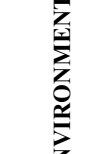 & 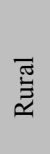 & 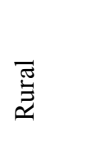 & 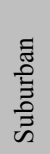 & 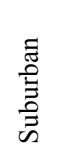 & 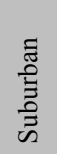 & 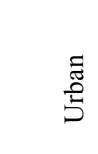 & $\begin{array}{l}\text { : } \\
\text { D్ } \\
5\end{array}$ & 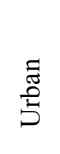 & $\begin{array}{l}\text { D్ } \\
\text { D్ }\end{array}$ \\
\hline 㦼 & 9 & $\stackrel{\sim}{\sim}$ & तิ & $\vec{\sim}$ & $\stackrel{\infty}{-}$ & 2 & $\vec{\sim}$ & 2 & $\bar{\lambda}$ \\
\hline 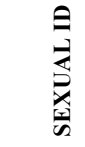 & 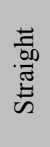 & 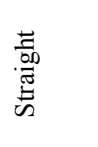 & 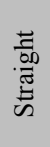 & 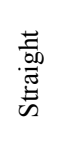 & 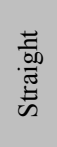 & 鹿 & 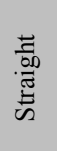 & 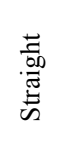 & 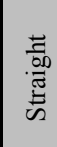 \\
\hline 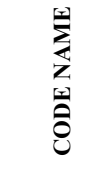 & \begin{tabular}{l}
$z$ \\
0 \\
0 \\
\multirow{1}{1}{} \\
Z
\end{tabular} & 兄 & $\overrightarrow{\vec{a}}$ & 壵 & 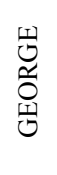 & 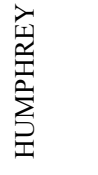 & 空 & 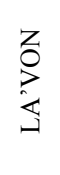 & 踉 \\
\hline
\end{tabular}




\section{Code List}

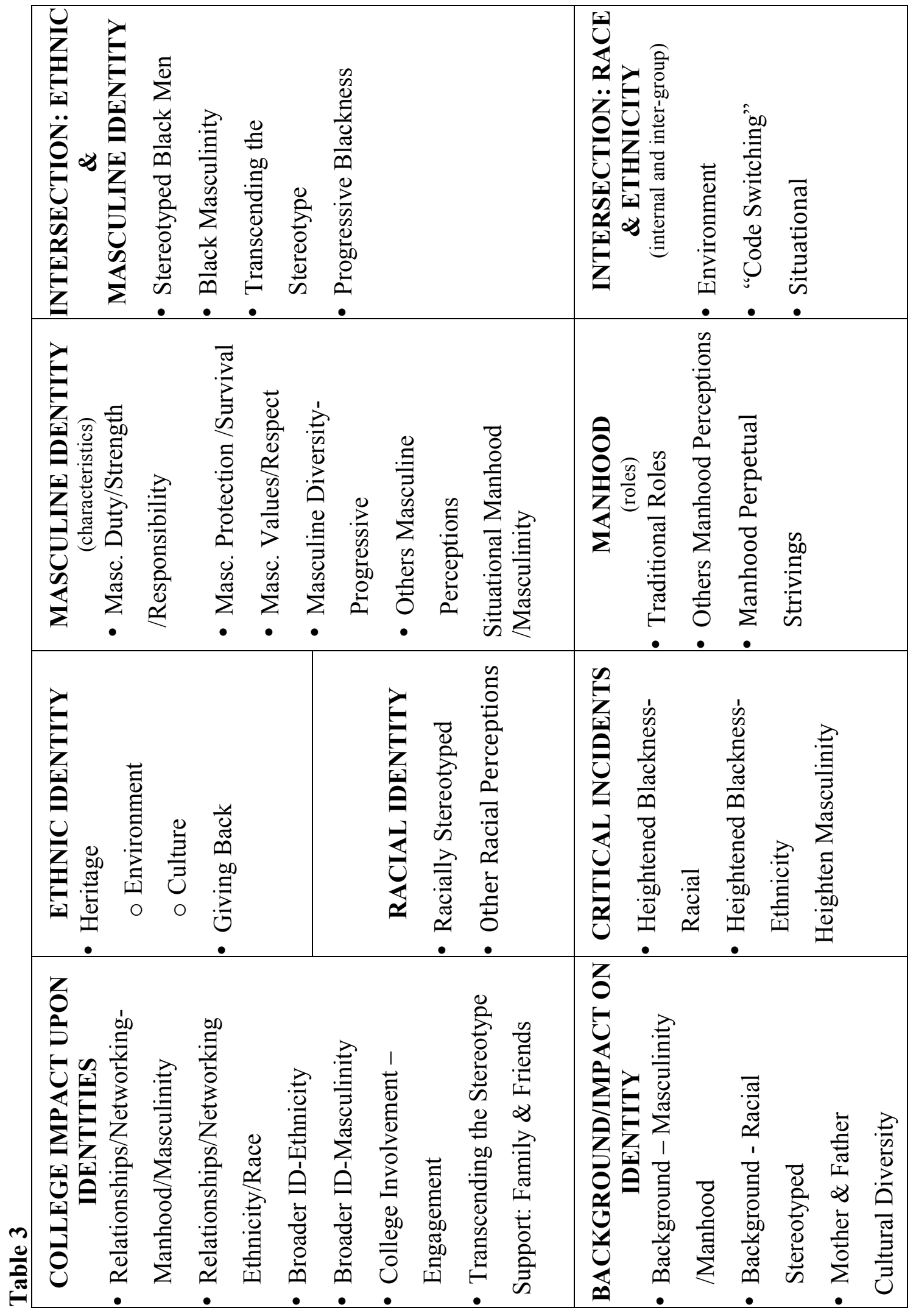




\section{CURRICULUM VITAE}

Jonathan Lee Johnson

\section{EDUCATION:}

University of Louisville, Louisville, Kentucky

Doctor of Philosophy, Counseling and Student Personnel Services, 2013

Concentration: College Student Personnel

Graduate Certificate: Pan-African Studies

Dissertation: The Social Construction of Ethnicity and Masculinity of African American College Men

University of Kentucky, Lexington, Kentucky

Master of Science, Higher Education and Administration, 2004

Specification: College Student Personnel

Thesis: Sojourners Abroad: Black Women of the African Diaspora

Explore Their Heritage and Racial/Ethnic Identity in Ghana, West Africa

University of Kentucky, Accra, Ghana

Research Consultant/Facilitator, 2004

Berea College, Berea, Kentucky

Bachelor of Science, Technology and Industrial Arts, 1999

Emphasis: Management

Berea College, Morelia, Mexico

Study Abroad, 1999

\section{EXPERIENCE:}

DALTON STATE COLLEG

Enrollment: 5,000-4-year, public, University System of Georgia

Director, Office of Residential Life

Dalton, Georgia

- Provide overall leadership, supervision, and management of 3 full-time professionals and 13 part-time paraprofessionals

- Develop and manage an operating budget of over $\$ 1.2$ million

- Design strategic planning, program development and assessment, student development and learning outcomes

- Administration of contracts, all levels of student conduct, publications and webpage, housing assignments, marketing development and implementation, residential education, and facilities management 
- Partner with Enrollment Management, Career and Counseling Services, Student Life, Financial Aid, and Athletics to recruit, retain, and provide an environment conducive to academic and student success

Accomplishments

- Created the Office's first Mission, Vision, and Diversity statements, which were guided by the institutional mission

- Partnered with the First Year Experience program to establish a FYE course for Residential Education

- Established a restorative justice-based student conduct process for the Office of Residential Life

- Implemented a Quality of Life Survey to assess the needs and satisfaction of the residential community

- Created, hired, and trained new professional and student staff for new job positions

- Partnered with the Office of Business in negotiating and establishing a new housing assignment software contract

- Created an Emergency Procedure Booklet for the Offices of Residential Life, Public Safety, Counseling Services, and Student Life to provide a safe and secure living environment for our residential community

- Established the first Residence Hall Association (RHA) for students to become advocates for the residential population, liaisons to student government, and engaged leaders

- Streamlined and consolidated departmental services to enhance operational effectiveness and efficiency

- Implemented new and alternative services to increase revenue by $8 \%$ during institutional budgetary crisis

- Introduced and revised departmental policies and procedures to enhance the quality of life and sustainability of services for residents and prospective residents

- Enhance the web presence of Office of Residential Life with the update of the website, the addition of Facebook, Twitter, and the use of QR codes

- Partnered with New Student Orientation to promote on-campus housing and recruit students to live in the Campus Housing apartments

- Organized various academic disciplines, staff, and groups — on campus and in the community - to provide a seamless move-in experience for residential students and their families

UNIVERSITY OF LOUISVILLE

Enrollment: 23,000 -4-year, large public, urban, major research university

Associate Director for Facilities \& Operations, Housing and Residence Life 07/01/07$01 / 02 / 12$

- Managed an operating budget of over $\$ 3.1$ million for the renovation, facilities management, maintenance, utility, and security services of all residential facilities

- Served on the Student Conduct board for the Dean of Students Office

- Authorize and oversight of all services completed by Physical Plant, housekeeping, and outside contractors for halls 
- Serve as the principal contact with Physical Plant staff and outsourced contractors, vendors and renovation projects

- Monitor monthly billing statements from Physical Plant, housekeeping, and security, adjusting practices as needed

- Partnered with contract supervisors for necessary training for staff

- Ensure all residence hall facilities are in compliance of state and federal ADA, fire and life safety codes

- Coordinate and maintain updated Building Emergency Action Plan and distribute appropriately

- Served as contract administrator for all contracted services and equipment for Housing and Residence Life (i.e., security, housekeeping, renovations, website services for off-campus housing, purchasing and other services)

- Serve as principal contact person with university Inventory Control

- Member of the Housing and Residence Life leadership team, while supporting the university and division mission

Accomplishments

- Inclusion, Safety and Security

- Created a Residence Life Coordinator specialization position that promotes safety and security education

- Developed an anti-bias strategy for the University of Louisville that lead to the University's collaborative creation of the Bias Incident Response Team (jointly with the LGBTQ, Cultural, and PEACC Centers)

- Established a health, safety and security committee of resident assistants and desk operation assistants that fosters a safe and healthy residential environment

- Partnered with Campus Police in establishing publications and programs that educates residence about safe tips, current incidents, and proactive safety strategies, while cultivating a healthy relationship between students and campus police officers over "Coffee and Doughnuts"

- Facilities Management and Maintenance

- Revised work order reporting process to improve communication and customer service between residents, housing staff, and Physical Plant

- Created a process of communication and 1-on-1 feedback between maintenance technicians, housekeeping, and residence hall directors

- Budget Management

- Improved budgetary procedures that eliminated over projection and improved financial reconciliation, which aided Housing and Residence Life during the University's budgetary challenges and fiscal consolidation

- Coordinated a Budgeting Task Force of residential representatives to assess and propose efficient programming practices and fiscal accountability

- Sustainability Initiatives

- Partnered with the Vice President of Business to fund over $\$ 25,000$ of residential recycling equipment

- Granted $\$ 10,000$ by Arts \& Sciences faculty to fund and renovate a "Green" learning residential space 
- Partnered with Louisville Department of Public Works to provide solid waste and recycling services

- Advised the Resident Student Association to promote Recyclemania and foster sustainable practices

UNIVERSITY OF LOUISVILLE Louisville, Kentucky Graduate Assistant for Recruitment \& Orientation, The Graduate School 7/01/05$6 / 31 / 07$

- Organized university-wide efforts for the recruitment, orientation, and campus engagement of all graduate students, especially efforts to recruit and retain master's and doctoral degree seeking students of underrepresented populations

- Coordinated the planning and implementation of major recruitment events (locally and nationally)

- Responsible for the planning and implementation of activities programs for graduate students and teaching assistants

Accomplishments

- Increased Graduate Visitation Day participants by more than $400 \%, 2005$ \& 2006 fall-term

- Conducted assessments of all graduate recruitment, orientation services, and activities, while providing evaluative recommendations for improvements

- Published research article for the National Association of Graduate Admissions Professionals' journal, Perspectives

UNIVERSITY OF LOUISVILLE

Doctoral Internship Experience, Office of the VPSA
Louisville, Kentucky Spring \& Summer 2007

- Supervised the VPSA's office first NASPA's Undergraduate Fellows Program Intern

- Integrated academic coursework and knowledge of various student development theories, techniques and interventions in practical settings, which demonstrated the "big picture" of student engagement practices

\section{Accomplishment}

- Developed an anti-bias policy for the University of Louisville that lead to the collaborative creation of the Bias Incident Response Team (BIRT) with offices under the Vice Provost of Diversity and International Affairs

KENTUCKY STATE UNIVERSITY

Frankfort, Kentucky

Enrollment: 2,800-4-year, small public, Historically Black College and University

Doctoral Internship Experience, Division of Student Affairs

- Served as a generalist in the Division of Student Affairs at Kentucky State University, which includes, but not limited to, activities and/or assignments in the Offices of Student Life and Holistic Development, Residence Life, Career Planning and Placement, Student Health Service, and University Police

- Developed comprehensive knowledge of the organizational, leadership functions and skills of the Vice President and the Assistant to the Vice President, specifically at a Historically Black College and University 
BEREA COLLEGE

Berea, Kentucky

Enrollment: 1,600 -4-year, selective, highly residential, Liberal Arts college

Interim Director, Black Cultural Center

$7 / 01 / 04-6 / 31 / 05$

- Provided special support services and activities that contribute to the recruitment, enrollment, retention and matriculation of Black and African American students, including: managing the Center's peer counseling and mentoring programs; available to offer counsel, advise and referral for Black and African American students; and work closely with the Black Student Union and various student groups to identify and serve as an advocate for the needs of Black and African American students

- Directed hiring, training, development, labor supervision and evaluation of the Center's professional and student staff

- Sponsored, provided leadership and collaborated with other campus departments of the responsibility for developing programs relative to racial diversity, interracial understanding among all students and the distinct contributions and experiences of African Americans (e.g., Dr. Carter G. Woodson celebration, Kwanzaa, African Awareness Week, MLK celebration, Black History Month, and undergraduate recruitment by sponsoring the Center's the Unity Banquet with the Office of Admissions)

- Researched, planned and implemented cultural programs and educational opportunities that reflect the interests, activities and topical subjects of Black and African American culture

- Managed an operating budget of $\$ 35,000$ for the Center

Accomplishments

- Created, administered and implemented all facets of the R.A.D.A.A.R. (Resident Assistants Dedicated to African American Retention) Liaisons (RLs) Program, which was created to:

- Develop strategies for recruitment, early intervention, retention and student success;

- Assess and enhance the residential experience of all Black and African American students;

○ Encourage and support service-learning and outreach opportunities on campus and the local community; and

- Promote Berea College's commitment of interracial education

- Built multidimensional coalitions of spirituality, culture, ethnicity and race, particularly, between African American, African, European American and international students by working with the Residence Life Office, International Center, Campus Christian Center, Campus Life Office, the local community and student organizations to assist in the development of structures and cultural programs that enhanced cultural engagement

BEREA COLLEGE (Ghana, West Africa)

Berea, Kentucky

Research Consultant/Facilitator

1/4/2004-2/4/04

- Co-facilitated class lectures and dialogues during pre-departure, overseas and reentry abroad

- Assisted in the coordination of class excursions in Ghana 
- Assessed and evaluated the cultural responsiveness and identity development of 18 college student women

- Ensured students adhered to all safety protocols and policies of the course and Berea College

\section{BEREA COLLEGE}

\section{Residence Life Coordinator, Residential Life Collegium} Collegium Responsibilities

- Member of an 8-person team (the "Collegium") which coordinates, plans and implements the student affairs' activities for a campus community of 1,600 students, including housing, orientation, leadership, programming, facilities management and crisis intervention

- Collaborated with other campus departments in the recruitment, early intervention program, integrated learning communities, policy review and other program initiatives that promote the overall experience for Berea College students

- Coordinated the planning of staff selection, staff training and labor meetings of residence hall staff

- Shared responsibilities for emergency on-call 24-hour pager rotation

Residence Life Coordinator Responsibilities

- Directed and managed two residential housing facilities of upper-class women and first-year men

- Selected, supervised, trained and evaluated 16 residence hall staff members (2-Hall Coordinators, 2- Hall Monitors, 2-Chaplains and 10-Resident Assistants) and 15 student janitors

- Organized and facilitated weekly staff meetings centered on a shared leadership model that promotes student development through training and team building activities

- Counseled and advised residents in personal, spiritual, academic, social and career concerns

- Enforced residence hall policies and procedures, oversee student judicial process and advise in formulating creative educational sanctions

- Advised the residence halls' House Councils in the areas of leadership, programming and community development

- Promoted community standard values and a sense of pride in the residence hall among all residents

Facilities Management Liaison Responsibilities

- Monitored a budget of $\$ 350,000$ for Berea College's residential facilities

- Assisted in the conceptualizing, planning and budgeting of all Residence Halls' renovations and system upgrades

- Promote collaboration between the departments of the Office of Admissions, Student Life Division, Career Services, Collegium, Facilities Management and outside contractors

- Designed and coordinated training for (17) Residence Hall Monitors and (70) Custodians Accomplishments 
- Created and coordinated recruitment and retention programs for college men

- Improved all procedures and manuals related to all residence hall operational tasks including payroll, all residence halls' budgets of $\$ 3,100$, and annual check-in/checkout procedures for residence halls

\section{TEACHING \& INSTRUCTION}

- FYES 1000: First Year Experience Seminar, Dalton State College, Fall 2012

- ECPY 604: College Student Subcultures, Graduate Course Lecturer, University of Louisville, Fall 2008

- GEN 101: Arts and Sciences Orientation, University of Louisville, Fall 2005, 2006

- GST 101: Strategies for Academic Success, Berea College, Fall 2004, Spring 2005

\section{ADVISORY EXPERIENCE}

- Advisor, Residence Hall Association, Dalton State College, 2012-Present

- Advisor, Men of PEACC, University of Louisville, 2009-2012

- Advisor, Green Team, Housing and Residence Life, University of Louisville, 2007-2012

- Advisory Board, National Pan-Hellenic Council, 2007-2012

- Advisor, Black Student Union, Berea College, 2004-2005

- Advisor, Ebony Explorations Book Club (EEBC), 2002-2005

- Advisor, Residence Hall House Council, Berea College, 2001-2005

- Advised, Student Judicial Board, Berea, College, 2001-2004

\section{LEADERSHIP AND PROFESSIONAL ASSOCIATIONS}

- Association of College Personnel Administrators (ACPA), 2002-Present Standing Committee for Men 2006-Present

- Chair, Research and Scholarship, 2010-2011

- Chair, Convention Programs and Services, 2009-2010

- Chair, Racial/Ethnic Issues, 2008-2009

- Association of College and University Housing Officers-International (ACUHO-

I), 2007-Present

- Association for Student Conduct Administration (ASCA), 2011-2012

Donald D. Gehring Academy for Student Conduct Administration 2011

- Mid-Level Managers' Institute, Track Moderator

- Local Arrangements Committee

- Association for the Study of Higher Education (ASHE), 2007-2012

- College Personnel Association of Kentucky (CPAK), 2001-2012

○ Treasurer/Secretary 2008-2009

- Treasurer/Secretary-Elect 2007-2008

- Technology Coordinator 2003-2004

- Kentucky Association of Blacks in Higher Education (KABHE), 2004-2012

Hospitality Committee \& Entertainment Committee 2004-2005

- National Association of Student Personnel Administrators (NASPA), 2001-Present 
Sustainability Knowledge Community 2009-Present

○ Region III KC Representative 2010-Present

Men and Masculinities Knowledge Community 2008-Present

- Southeastern Association of Housing Officers (SEAHO), 2007-Present

- Southern Association of College Student Affairs (SACSA), 2003-Present

Research Committee 2005-Present

- SACSA Research Tip Writer, 2005-Present

- Dissertation of the Year and Grant Reviewer, 2005-Present

Multicultural Awareness Committee 2003-2012

- Chair, Research and Scholarship, 2008-2010

- Co-Chair, Multicultural Drive-In, 2006-2007

\section{HONORS AND AWARDS}

- College of Education and Human Development Scholarship, University of Louisville, Spring 2013

- Research Incentive Grant, Southern Association for College Student Affairs (SACSA), Fall 2012

- Mid-Level Manager's Institute, ASCA, Donald D. Gehring Academy, University of Louisville, Summer 2011

- Emergency Management Institute, FEMA, ICS-100 for Higher Education, University of Louisville, Summer 2011

- Mid Manager Institute (MMI) Participant, NASPA/SACSA, St. Leo University, Summer 2010

- Strengths Educator, StrengthQuest Seminar, The Gallup Organization, Summer 2009

- Green Initiative of the Year, National Residence Hall Honorary, 2008

- Golden Key International Honour Society, Graduate Chapter Charter Member, 2006

- Paul Newman Scholarship, University of Kentucky, 2003-2004

- New Professionals Institute (NPI) Participant, NASPA/SACSA, University of Georgia, Summer 2003

- Commonwealth Incentive Award, University of Kentucky, 2002, 2003, 2004

- Vice President, Black Graduate and Professional Student Association (BGPSA), University of Kentucky, 2003-2004

- Staff Member of the Year, Image Awards, Berea College, 2003 \& 2004

- Berea College Labor Award, 1998 \& 1999

- Homecoming King, Berea College, 1998

- President, Black Student Union, Berea College, 1997-1999

- President, Martin Luther King Committee, Berea College, 1996-1997

- Historian, Black Music Ensemble, Berea College, 1996-1997

\section{Dalton State College}

\section{COMMUNITY AND CAMPUS INVOLVEMENT}

- Incident Review Committee, 2012-Present

- Strategic Planning Committee, 2012-Present

- Chair, Enhancing Student Climate and Engagement 
- Intercollegiate Department of Athletic Search Committee, 2012-Present

- Environmental Management Systems, 2012-Present

\section{University of Louisville}

- Safety and Security Task Force, Office of the Provost for Business, 2010-2012

- University Sustainability Council, Office of the University Provost, 2010-2012

- Hearing Board for Student Conduct, Dean of Students Office, 2009-2012

- African American Male Retention Initiative, Vice Provost for Diversity and International Affairs Office, 2009-2012

- Bias Incident and Response Team, Office of the Vice Provost for Diversity and International Affairs, 2009-2012

- Green Committee, Housing and Residence Life, Co-Chair, 2008-2012

- Sustainable Operations Committee, Office of the Provost for Business, 2007-2012

- National Pan-Hellenic Council Advisory Board, 2007-2012

- Professional Development Committee, Division of the Vice President of Student Affairs, 2007-2010

- Chair, Careers in Student Affairs 2006-2008

- ECPY/GAPSA Representative, Graduate Student Council, 2005-2007

- Chair, Graduate Orientation Committee

- Volunteer, Student African American Brotherhood (SAAB)

- Volunteer, The Brotherhood

\section{Berea College}

- Liaison, Berea College Judicial Board for Student Conduct

- The Strategic Planning Committee for Berea College

- Off Campus Appeals Committee (Chair 2001)

- Residence Hall Staff Training Team

- Chair, Residence Life Collegium Hiring Team

- Creator/founder of Ebony Explorations Book Club (EEBC)

- Book club created for the interpersonal and identity development of African American men

- Black Studies Advisory Board

- Participant, Black Music Ensemble

- Chair, Martin Luther King, Jr. Planning Committee

- Student Life Team

- Chair, Student Life Division Committee on Facilities Management

\section{Local Community}

- Elementary and Middle-grades speaker, Career Day

- Bates Memorial Baptist Church

- Non-Profit Board Member, Steward's Staff

- Non-Profit Board Member, Men's Work

- Volunteer, Habitat for Humanity

- Volunteer, Hunger Hurts Food Drive 
- Alpha Phi Alpha Fraternity, Incorporated, Alpha Lambda Chapter, Louisville, Kentucky

\section{PRESENTATIONS}

"Institutional Based Strengths," Faculty Deans and Administrative Directors Retreat, Dalton State College, June 6, 2012

"Discovery Our Strengths," Young Alumni Advisory Council Annual Meeting, Berea College, November 9, 2012

"Creating and Sustaining Bias Incident Response Teams: From Inception to Execution," Co-Presenting with Michael D. Anthony, StudentAffairs.com Webinar, April 19, 2012

"From Inception to Execution: Responding to Bias Incidents on Campus," Co-Presenting with Michael D. Anthony, Association of College Personnel Administrators, March 26, 2012

"NASPA Knowledge Communities-Gateway to the Association," Panelist, other panelist was Chris Holland, Southern Association for College Student Affairs, November 8,2010

"How Black Men and Black Women Experience College Differently," Co-Presented with Michael J. Cuyjet, Association of College Personnel Administrators, March 23, 2010

"A Housing Revolution: Pioneering the Way to Strategic Partnerships," Co-Presented with Bradley R. Shaw, David Braden, David Chadwick, Michelle Massey, and Teresa Crum, Association of College Personnel Administrators, March 22, 2010

"How Black Men and Black Women Experience College Differently," Co-Presented with Michael J. Cuyjet, NASPA, March 9, 2010

"The Green Team: Strategic Sustainable Initiatives for Student Affairs," Co-presented with Lauren Wilson Rust, Southern Association for College Student Affairs, November 9, 2009

"Creating a Green Team: Sustainable Initiatives in Housing and Residence Life," Copresented with Lauren Wilson Rust, Kentucky Association of Housing Officers Conference, October 13, 2009

"Standing Committee for Men 25th Anniversary Panel on Multiple Identities," Moderator/Panelist, panelist were Elisa Abes, Marcia Baxter Magolda, Tracy Davis, and Rachel Wagner, Association of College Personnel Administrators, March 31, 2009

"Responding to Incidents of Bias within Campus Communities," Co-Presenting with Michael D. Anthony, Association of College Personnel Administrators, March 30, 2009

"The Challenge for Excellence: Strategic Partnerships in Minority Graduate Recruitment," Co-Presented with Fashaad Crawford and Kate McAnulty, Association of College Personnel Administrators, March 31, 2008

"Blacker than You - African American Men: Racial and Social Constructs of Identity Development," National Council for Black Studies, March 22, 2008

"Strategic Partnerships in Minority Graduate Recruitment," Co-Presented with Fashaad Crawford and Kate McAnulty, National Association of Graduate Admissions Professionals, April 27, 2007 
"From Conception to Commencement: Pursuing the Doctorate as African Americans," Co-Presented with Erica Holloman, Kentucky Association of Blacks in Higher Education Conference, April 16, 2007

"Strategic Partnerships in Minority Graduate Recruitment," Co-Presented with Fashaad Crawford and Kate McAnulty, College Personnel Association of Kentucky Conference, March 2, 2007

"Diversifying the Graduate Student Body," Co-Presented with Fashaad Crawford and

Kate McAnulty, Kentucky Association of Blacks in Higher Education

Conference, April 16, 2007

"Cultural Competencies of Student Affairs Professionals: A Critical Examination and

Discussion," Pre-Conference Workshop, Co-Presented with Michael Snowden,

Ph.D. and Melissa Shivers, Southern Association of College Student Affairs

Conference, November 3, 2006

"To PhD or Not to PhD: Consideration of Doctoral Study in Student Affairs," Co-

Presented with Evelyn Woods and Jenn Schum, College Personnel Association of

Kentucky Conference, March 2, 2006

"Trinity Multicultural Network," Best Practices in Student Affairs-Poster Sessions,

College Personnel Association of Kentucky Conference, March 1, 2006

"Say What!?: Breaking Down the Walls of Communication," Housing and Residence

Life Spring Training, Co-Presented with DJ Todd and Mikiba Wigfall, University

of Louisville, January 6, 2006

"A Different World: Understanding types of Institutions: Public, Private, HBCU, Community, Vocational and Technical," NIA Conference, University of Louisville, October 15, 2005

"Embracing Excellence: Redefining Self-Concepts of Black Identity," Kentucky Association of Blacks in Higher Education Annual Conference, April 14, 2005

"Culturally Responsive Supervision: Using the Right Tools for the Job," Inside

Supervision, Labor Department, Berea College, March 4, 2005

"Life After Berea: Vocation, Faith and Work," Workshop Co-Presented with Ashley

Cochrane, Betty Hibler and Loretta Reynolds, Berea College, October 16, 2004

"Diversity: Acknowledgement of Culture, Value, Perspective and Awareness," Residence

Life Staff Training, Berea College, August 24, 2004

"Careers in Student Affairs," Residence Hall Staff Labor Gathering, Berea College, March 17, 2004

"Get up, Stand Up and Do Something!," Chapel Service, Berea College, February 24,2004

"Look to the Mission in ALL the Things You Do," Baptist Student Union, Berea College, September 14, 2003

\section{PUBLICATIONS}

Johnson, J. L., \& Cuyjet, M. J. (2012). "The Relationship between African American Males' Collegiate Peer Support Groups and Their Racial Identity Development" In Jas M. Sullivan and Asharf Email (Eds.) African American Racial Identity: An Interdisciplinary Exploration of the Racial and Cultural Dimensions of the Black Experience. Lexington Books 
Johnson, J. L., (2010). A “Critical” Methodology in Qualitative Research, SACSA Research Tip of the Month, Southern Association of College Student Affairs, October 2010

Johnson, J. L. (2010). New Black Man [Review of the book New Black Man.] ACPA Standing Committee for Men Briefs, Spring 2010, 12-13

Johnson, J. L., \& Cuyjet, M. J. (2009). Enhancing identity development and sense of community among African American males in higher education. In H. T. Frierson, J. H. Wyche, \& W. Pearson, Jr. (Eds.) Black American males in higher education: Research, programs and academe (pp. 57-78). United Kingdom: Emerald Books.

Johnson, J. L., (2009). Multicultural Awareness in Research and Assessment, SACSA Research Tip of the Month, Southern Association of College Student Affairs, October 2009

Johnson, J. L., (2008). Truncation, Wildcard and Operator Expressions, SACSA Research Tip of the Month, Southern Association of College Student Affairs, November 2008

Johnson, J. L, McAnulty, K., \& Crawford, F., (2008). Strategic Partnerships in Minority Graduate student Recruitment: Graduate Visitation Day at the University of Louisville, Perspectives, National Association of Graduate Admissions Professionals, 20, 2, Winter 2008

Johnson, J. L., (2007). Strategic Considerations for Qualitative Dissertations, SACSA Research Tip of the Month, Southern Association of College Student Affairs, June 2007

Johnson, J. L., (2006). Build Your Own Reference Library, SACSA Research Tip of the Month, Southern Association of College Student Affairs, May 2006

Johnson, J. L., (2004). African or American: An Exploration of Identity. The Onyx, Black Cultural Center, Berea College, $6,3 \& 12$ 